\title{
COMBUSTION BYPRODUCTS RECYCLING CONSORTIUM (CBRC)
}

Final Comprehensive Technical Report

For the period

9/24/98 - 8/31/08

Paul F. Ziemkiewicz, Director, National Center

Tamara F. Vandivort, Consortium Manager

Debra Pflughoeft-Hassett, Western Regional Director

Y. Paul Chugh, Midwestern Regional Director

James Hower, Eastern Regional Director

October 31, 2008

DOE Award No.: DE-FC26-98FT40028

Combustion Byproducts Recycling Consortium

A Program of the National Mine Land Reclamation Center

West Virginia University

PO Box 6064

Morgantown, WV 26506-6064 


\section{Acknowledgments}

The authors would like to acknowledge the following for their unique roles in making the Combustion Byproducts Recycling Consortium a successful program with far-reaching impacts into the future.

The U.S. Department of Energy - National Energy Technology Laboratory for its support of the program through funding, oversight, and direction. Special thanks go to the three CORs who led the program: Scott Renninger, Lynn Brickett, and William Aljoe.

Members of the National Steering Committee for their guidance and hard work. Members reviewed over 300 proposals, attended many meetings, and made significant contributions in time and sometimes financial support to project researchers. Special mention goes to Dave Goss, Director, American Coal Ash Association; Jackie Bird, Ohio Coal Development Office, Paul Ehret, Kentucky Department of Natural Resources, Howard Humphrey, American Coal Ash Association; Jim Roewer, Utility Solid Waste Activities Group; Kimery Vories, Office of Surface Mining; Dave Meadows, U.S. Army Corps of Engineers-Huntington, WV District; Dan Wheeler, Interstate Mining Compact Commission; Cheri Miller, Tennessee Valley Authority; Bonnie Robinson, USEPA Office of Solid Waste; Jimmy Knowles, The SEFA Group; Richard Halverson, Headwaters Resources; Robert Dolence, Pennsylvania Department of Environmental Protection; Greg Conrad, Interstate Mining Compact Commission; Taylor Eighmy, University of New Hampshire Recycled Materials Resource Center; Fred Fox, Office of Surface Mining; Dennis Ruddy, USEPA Office of Solid Waste; Samuel Tyson, American Coal Ash Association; Wayne Bahr, Illinois Department of Commerce and Community Affairs; Michael Murphy, Illinois Department of Commerce and Community Affairs; Andrew Stewart, PPE Inc.; Tom Robl, University of Kentucky; Jacob Gonzales, TXU; and Andy Wittner, USEPA.

Expert Reviewers for taking the time and effort to review proposals and submit evaluations to the National Center and Steering Committee members. Special mention goes to Kenneth Raymond, Robert Amme, Harry Payne, Joel Beeghly, Dennis Dobbs, Ted Frady, Randy Pollek, Orville Werner, Mark Bryant, David Supon, Mac Crosby, Michael Thomas, Stephen Smith, Niles Parker, Bruce Ramme, Larry Harper, Kevin Dennis, Duane Steen, Earl Bush, Joel Pattishall, and Leslie Vincent.

Utility Industry for their support in terms of time, in-kind, and cash contributions to many of the project researchers.

American Coal Ash Association for support and promotion of the program. 


\section{Disclaimer}

This report was prepared as an account of work sponsored by an agency of the United States Government. Neither the United States Government nor any agency thereof, nor any of their employees, makes any warranty, express or implied, or assumes any legal liability or responsibility for the accuracy, completeness, or usefulness of any information, apparatus, product, or process disclosed, or represents that its use would not infringe privately owned rights. Reference herein to any specific commercial product, process, or service by trade name, trademark, manufacturer, or otherwise does not necessarily constitute or imply its endorsement, recommendation, or favoring by the United States Government or any agency thereof. The views and opinions of authors expressed herein do not necessarily state or reflect those of the United States Government or any agency thereof. 


\begin{abstract}
The Combustion Byproducts Recycling Consortium (CBRC) program was developed as a focused program to remove and/or minimize the barriers for effective management of over 123 million tons of coal combustion byproducts (CCBs) annually generated in the USA. At the time of launching the CBRC in 1998, about $25 \%$ of CCBs were beneficially utilized while the remaining was disposed in on-site or off-site landfills. During the ten (10) year tenure of CBRC (1998-2008), after a critical review, 52 projects were funded nationwide. By region, the East, Midwest, and West had 21, 18, and 13 projects funded, respectively. Almost all projects were cooperative projects involving industry, government, and academia.

The CBRC projects, to a large extent, successfully addressed the problems of large-scale utilization of CCBs. A few projects, such as the two Eastern Region projects that addressed the use of fly ash in foundry applications, might be thought of as a somewhat smaller application in comparison to construction and agricultural uses, but as a novel niche use, they set the stage to draw interest that fly ash substitution for Portland cement might not attract. With consideration of the large increase in flue gas desulfurization (FGD) gypsum in response to EPA regulations, agricultural uses of FGD gypsum hold promise for large-scale uses of a product currently directed to the (currently stagnant) home construction market.
\end{abstract}

Outstanding achievements of the program are given below.

- The CBRC successfully enhanced professional expertise in the area of CCBs throughout the nation. The enhanced capacity continues to provide technology and information transfer expertise to industry and regulatory agencies.

- Several technologies were developed that can be used immediately. These include: 1) Use of CCBs for road base and sub-base applications; 2) full-depth, in situ stabilization of gravel roads or highway/pavement construction recycled materials; and 3) fired bricks containing up to $30 \%-40 \% \mathrm{~F}-\mathrm{fly}$ ash. Some developed technologies have similar potential in the longer term.

- Laboratory studies have been completed that indicate that much higher amounts of fly ash could be added in cement-concrete applications under some circumstances. This could significantly increase use of fly ash in cement-concrete applications.

- A study of the long-term environmental effects of structural fills in a surface mine in Indiana was completed. This study has provided much sought after data for permitting large-volume management options in both beneficial as well as non-beneficial use settings.

- The impact of CBRC on CCBs utilization trends is difficult to quantify. However it is fair to say that the CBRC program had a significant positive impact on increased utilization of CCBs in every region of the USA. Today, the overall utilization of CCBs is over $43 \%$.

- CBRC-developed knowledge base led to a large number of other projects completed with support from other sources of funding. 
- CBRC research has also had a large impact on CCBs management across the globe. Information transfer activities and visitors from leading coal producing countries such as South Africa, Australia, England, India, China, Poland, Czech Republic and Japan are truly noteworthy.

- Overall, the CBRC has been a truly successful, cooperative research program. It has brought together researchers, industry, government, and regulators to deal with a major problem facing the USA and other coal producing countries in the world. 


\section{Executive Summary}

The Combustion Byproducts Recycling Consortium (CBRC) program was developed as a highly focused program to remove and/or minimize the barriers for effective management of over 123 million tons of coal combustion byproducts (CCBs) annually generated in the USA. At the time of launching CBRC in 1998 , about $25 \%$ of the CCBs were beneficially utilized while the remaining were disposed in on-site or off-site landfills. Ten years later, $43 \%$ of CCBs were beneficially utilized.

Due to the national scope of the CBRC program and the varying priorities between regions, three regional geographic areas were identified as East, Midwest, and West. Regional centers were located at the University of Kentucky, Southern Illinois University, and the University of North Dakota. The program's National center was headquartered at West Virginia University.

During the ten year tenure of CBRC (1998-2008), 52 peer-reviewed projects were funded nationwide. Of those 52 projects, 21, 18, and 13 were funded in the East, Midwest, and West, respectively. About $65 \%$ of the Midwestern projects emphasized development and demonstration of new technologies to enhance medium and large-volume management of CCBs. The other $35 \%$ of Midwestern projects focused on understanding and/or dealing with environmental issues. Almost all projects were cooperative projects involving industry, government, and academia to: 1) develop professional capacity near-term as well as long-term; 2) keep research highly focused to enhance beneficial utilization of CCBs; and 3) provide rapid transfer of technologies and information to the marketplace to have near-term positive impacts. CBRC met these goals within the constraints imposed by limited funding of the program. More specific CBRC achievements are given below:

- The CBRC has developed professional expertise in the area of CCBs throughout the nation. The 52 funded projects were distributed through 21 states. Within each region, local area power plants and regulatory agencies worked with professionals leading the projects and enhanced their expertise even further. Most projects have also led to graduation of one or more M.S. or Ph.D-level students. The enhanced capacity continues to provide technology and information transfer expertise to industry and regulatory agencies.

- Several technologies were developed and demonstrated that are either commercial or have such proven potential. These include: 1) Use of CCBs for road base and sub-base applications; 2) full-depth, in situ stabilization of gravel roads or highway or pavement construction recycled materials; and 3) fired bricks containing up to $30 \%-40 \%$ F-fly ash. In addition, some technologies were developed that were not commercialized during this period but have such potential. These include development of CCBs-based transmission poles and construction materials using sulfate-rich scrubber sludge.

- About $25 \%$ of cement is currently allowed to be replaced by fly ash. Laboratory studies have been completed that indicate that much higher amounts of fly ash could be added in 
cement-concrete applications under some circumstances. Additional studies are needed in this area to extend these results to field evaluations.

- Management of CCBs in mine settings remains a viable alternative. A study of the longterm environmental effects of structural fills in a surface mine was completed. This study has provided much-needed data for permitting large-volume management in both beneficial as well as non-beneficial use settings.

- Of the CBRC projects funded, some of the projects with the most potential for encouraging large-volume utilization of CCBs are the projects dealing with the agricultural use of flue gas desulfurization (FGD) gypsum.

- With power plants adding and enhancing FGD systems in response to the 2005 EPA Clean Air Interstate Rule and the saturation of the traditional wallboard market, there is a need to utilize the growing amounts of FGD gypsum entering the market. Agricultural uses are a good outlet, providing a sustainable market for gypsum.

- Educational efforts to reach farmers were an important component in the projects since, without the buy-in from the customers, FGD gypsum runs the risk of being stigmatized as a poor, and possibly toxic, substitute for natural gypsum. The CBRC projects demonstrated that the latter perception has no basis in fact.

- The use of fly ash in large fills, as in an airport runway extension project, and as a substitute for Portland cement, was also promoted among the projects.

- Evolving air quality standards impact the nature of the fly ash produced, whether it is an increase in fly ash carbon due to the 1990's conversion to low-NOx combustion or an increase in ammonia on fly ash due to the installation of selective catalytic reduction systems. In both cases, traditional markets could be jeopardized, taking fly ash off of the market at a time when DOE is striving to increase overall utilization of CCBs. The CBRC projects addressed these problems.

- The use of CCBs in mine fills as a means of reducing acid mine drainage is another example of a large-scale use of material. While mine utilization is likely less of a longterm use than, for example, the agricultural use of FGD gypsum, it has the potential to solve environmental problems left by previous generations of coal mining.

- In addition to the direct outcomes of CBRC funded projects outlined above, several other projects were completed with support from other sources of funding. Some examples of such projects included: 1) Development and use of flowable fills containing CCBs; 2) high-strength cattle feedlot construction materials; 3) large-volume fly ash-based highway barriers; 4) demonstration of underground placement of CCBs-based paste backfills for higher extraction and subsidence control; 5) development of frictional materials for automotive brake applications; and 6) novel value-added materials concepts from Integration Gasification Combined Cycle (IGCC) byproducts.

- It is difficult to quantify the impact of the CBRC on CCBs utilization trends. However, it is fair to say the CBRC program had a significant positive impact on increased utilization of CCBs in every region in the USA. Today, the overall utilization of CCBs in the USA is over $43 \%$. 
- $\quad$ CBRC has led to a large number of healthy cooperative relationships among researchers, industry, and government agencies that will continue to have long-term positive impacts on the CCBs management topics.

- CBRC research has also had a large impact on CCBs management across the globe. Information transfer activities and visitors from leading coal producing countries such as South Africa, Australia, England, India, China, Poland, Czech Republic and Japan are truly noteworthy.

- Overall, CBRC has been a truly successful cooperative research program. It has brought together researchers, industry, government, and regulators to deal with management issues related to production of CCBs with varying characteristics.

- The coal combustion industry is constantly changing. The increased amount of fluidizedbed combustion products, the potential for the entry of gasification products in the market, and the variety of products from the co-combustion of coal/biomass/tires/etc., all indicate that more research is needed to keep pace with the evolving market. In this context, it is unfortunate that the $\mathrm{CBRC}$ will no longer be a venue for the exploration of emerging technologies.

This report provides a summary of accomplishments. Final reports for each project are included in the appendices and are available on the CBRC website along with more detailed information on the program. 


\section{Table of Contents}

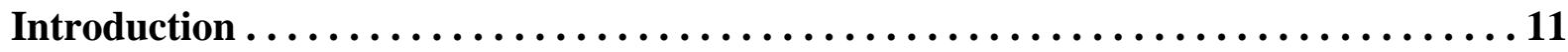

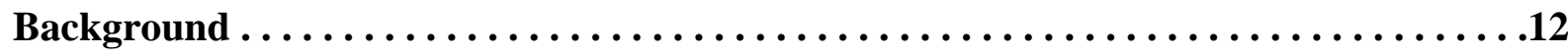

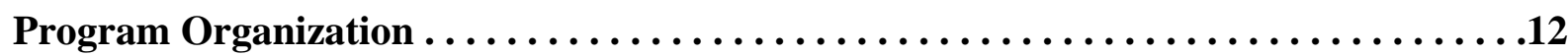

Advantages of the CBRC Consortium Structure $\ldots \ldots \ldots \ldots \ldots \ldots \ldots \ldots \ldots \ldots \ldots$

Regional Divisions and Research Priorities . . . . . . . . . . . . . . . . . . . . 17

Regional Research Area Priorities . . . . . . . . . . . . . . . . . . . . 19

National Research Priorities ..............................

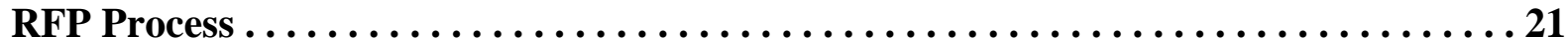

Proposed Solicitation $\ldots \ldots \ldots \ldots \ldots \ldots \ldots \ldots \ldots \ldots \ldots \ldots \ldots \ldots \ldots \ldots \ldots \ldots \ldots \ldots \ldots \ldots, 22$

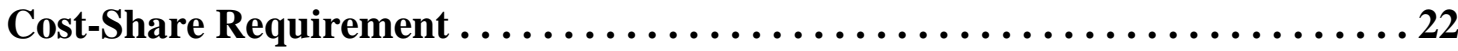

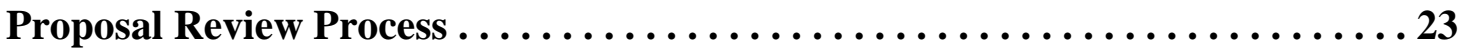

Award Implementation ................................. 24

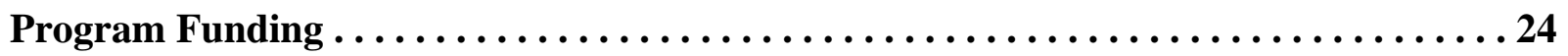

Research Projects ....................................... 26

Distribution of Projects . . . . . . . . . . . . . . . . . . . . . . . . . . 26

Eastern Region .................................... 29

Midwestern Region.................................... 45

Western Region. ......................................60

Successes................................................. 71

Outcomes...........................................75

Outputs..................................... 76

Lessons Learned. ...........................................77

Program Outreach, Promotion, and Technology Transfer ................79

Conclusions............................................. 87

Future Implications $\ldots \ldots \ldots \ldots \ldots \ldots \ldots \ldots \ldots \ldots \ldots \ldots \ldots \ldots \ldots . .68$

References........................................... 89 


\section{Appendices}

Appendix A: Roles \& Responsibilities

Appendix B: Request for Pre-proposals 2005

Appendix C: Invitation to Submit Full Proposals 2005

Appendix D: Notice from USDOE-NETL Regarding Reduction in USDOE's Power Plants Program Budget

Appendix E: Project Final Reports

Appendix F: Ashlines 


\section{Introduction}

About half of America's electrical power comes from coal. According to the American Coal Foundation, U.S. coal deposits contain more energy than all of the world's oil reserves. With increasing concern about the cost and security of foreign energy supplies, coal will continue to play a key role in supplying the Nation's electrical needs. In generating this power, U.S. utilities produce and capture more than 123 million tons of coal combustion byproducts (CCBs) each year. That amounts to about half the volume of ash ejected by the eruption of Mt. St. Helens in 1980. It is expensive to place such a volume of material in landfills, and there is also the environmental cost of dedicating land to $\mathrm{CCB}$ disposal. As a result, the industry seeks to find beneficial uses for its ash and minimize its need for landfill space.

The mission of the Combustion Byproducts Recycling Consortium (CBRC) was to support and promote the commercially-viable and environmentally-sound recycling of CCBs. These materials are left behind after coal is burned to generate electricity. Once viewed as waste, the CBRC recognized the value of CCBs as a resource and provided seed money for researchers to develop and field test innovative and productive uses for these materials.

CCBs are used in new pavements, recycling asphalt pavements, and stabilizing gravel roads. They perform well when used in Portland cement for roadway construction. CCBs make concrete stronger, more durable, and less permeable. Using CCBs in concrete preserves natural resources typically mined for cement production. CCBs can also be used in place of natural materials in manufacturing building products such as wallboard, blocks, bricks, countertops, and decorative tiles. These products are environmentally-safe and structurally sound. Substituting CCBs in place of natural materials is cost-effective and preserves natural resources. CCBs are an environmentally-safe and economical way to reclaim mine lands as well. Used for fill in surface mine pits and in grout for underground mine voids, they serve to reduce acid mine drainage. Use of these materials has been proven safe without harming groundwater supplies. This large-scale use of CCBs also serves to remediate poor mine soils and allow for revegetation with grasses or trees. CCBs have also been safely and successfully used to amend agricultural soils to improve crop production from tomatoes and corn to alfalfa. They have also been used to create impermeable liners to contain swine manure on large commercial pig farms.

The projects funded through the CBRC program addressed these particular uses. Since its inception in 1998, the CBRC funded 52 research projects nationwide with a total value exceeding $\$ 10$ million from federal, state, and private sources of support. The CBRC also assisted industry and regulatory agencies identify beneficial applications for CCBs thereby increasing understanding, use of CCBs in beneficial applications, and building partnerships among stakeholders. 
This report will guide the reader through the ten year tenure of the CBRC program. The organization of the program, its participants, the research conducted, successes, lessons learned, and future implications are described.

\section{Background}

The CBRC began in 1998 with a five-year cooperative agreement initiated between the U.S. Department of Energy-National Energy Technology Laboratory (USDOE-NETL) and West Virginia University (WVU) to set up a program called the Emission Control By-Products Consortium (ECBC). The overall objective of the program was to develop and demonstrate technologies for coal-burning utilities and their suppliers to solve problems related to the production and handling of byproducts from coal combustion processes. The intent was for developed technologies to serve as byproduct management technologies capable of increasing the overall utilization of CCBs by $10 \%$ overall.

In 1998 , about $25 \%$ of CCBs were beneficially utilized while the remaining were disposed in landfills either on- or off-site of utilities. Ten years into the program, over $43 \%$ of CCBs are beneficially used (ACAA 2007).

The initial phase of the five-year program was a start-up seed money phase in which program organization and planning were the primary objectives. An organizational structure was developed in which the National Center would be headquartered at the National Mine Land Reclamation Center at West Virginia University. Part of this organizational structure included a program steering committee capable of providing guidance on $\mathrm{CCB}$ research priorities and policy objectives. In addition, due to the national scope of the program and the varying priorities between regions, three regional geographic areas were identified and a regional director selected for each of the three regions. These participants worked together to further define program goals and objectives as well as regional research priorities. The first Request for Proposals was developed for release in 1999.

\section{Program Organization}

The CBRC was comprised of four major elements: the U.S. Department of Energy - National Energy Technology Laboratory (USDOE-NETL), the National Steering Committee (NSC), regional advisors/reviewers for each of the three regions, and program management. Each element is described below:

U.S. Department of Energy - National Energy Technology Laboratory: The Department of Energy - National Energy Technology Laboratory (USDOE-NETL) as the sponsoring agency provided funding for the CBRC. USDOE-NETL also provided program oversight.

National Steering Committee: The National Steering Committee (NSC) served as the key 
element of the CBRC. Decisions on how the CBRC conducted business were made by consensus of the NSC. Critical roles and responsibilities of the NSC included:

- advising National Center on strategic direction

- approving overall CBRC structure and timetables

- selecting from its membership chairpersons for the regional reviewers/advisors

- authorizing requests for pre-proposals and full proposals (RFP's)

- evaluating both pre-proposals and full proposals

- making project funding decisions

- reviewing program performance annually

The National Steering Committee members were initially solicited by the National Director with input from USDOE-NETL. Membership included representatives from stakeholder groups including the following organizations and agencies:

- American Coal Ash Association

- Interstate Coal Compact Commission

- U.S. Office of Surface Mining

- Utility Solid Waste Activities Group

- USEPA Office of Solid Waste

- U.S. Army Corps of Engineers

- Tennessee Valley Authority

- Ohio Coal Development Office

- Utilities

- Headwaters Resources

- The SEFA (South Eastern Fly Ash Group) Group

- Synmat (Synthetic Materials)

A Chair of the National Steering Committee was elected from amongst its membership. The Chair would oversee and facilitate the NSC meetings and communicate directly between the Committee members and the National Center Director. Regional Chairs were also elected from amongst the membership to work with their respective Regional Director and reviewers to develop research priorities for their respective regions. Terms were for 2 years and staggered as much as possible to keep turnover in positions from occurring simultaneously.

Regional Advisors/Reviewers: The types of coals burned by electric utilities and the technologies employed for emission control greatly affect the characteristics of the byproducts that are produced. The NSC recognized that these characteristics often vary from region to region. Regional prioritization of research needs is also dictated by the cost of transportation and the state-to-state differences in regulations governing byproduct disposal and utilization. For these reasons, regional advisors/reviewers were solicited for the eastern, midwestern, and western regions of the United States. 
The regional advisors/reviewers chairperson had the primary responsibility for selecting the reviewers/advisors for that region. The roles and responsibilities of the reviewers/advisors were as follows:

- identify regional research priorities for use in the RFP

- review, score, and rank proposals received in accordance with research priorities

- review technical progress on projects that were funded

- report important results to the National Steering Committee

Program Management: The National Mine Land Reclamation Center (NMLRC) at West Virginia University served as the National Center for the CBRC. The roles and responsibilities under the direction of the NMLRC included the following:

- soliciting members to serve on the National Steering Committee (NSC)

- scheduling, organizing, and facilitating NSC meetings

- providing draft pre-proposals and RFP's to the NSC for review

- developing final pre-proposals and RFP's for release

- developing pre-proposal and RFP dissemination strategies

- developing a scoring/ranking system for use by reviewers

- compiling the results of reviews for the National Steering Committee

- awarding and administering research subcontracts

- assuring that contractors met all performance, reporting, and budget requirements

- facilitating communications between the NSC, USDOE-NETL, research contractors, and external agencies

- technology archive and transfer

- disseminating research results via seminars, newsletters, internet, etc.

There were also three Regional Centers: The Eastern, Midwestern, and Western Regional Centers. The Eastern Regional Center was initially located at West Virginia University; then at the University of Kentucky. The Midwestern Center was located at Southern Illinois University at Carbondale, and the Western Center at the University of North Dakota. A director at each regional center served as technical advisor over the progress of the CBRC projects for their particular region, facilitated communications with the National Center Consortium Manager, Regional Chair, and regional advisors/reviewers. Specific responsibilities included:

- advising technical aspects of the projects

- reporting regional center activities to the National Center

- providing technical information to regulatory agencies and industry

- technology archive and transfer

- facilitating communications with their respective region 
A Roles and Responsibilities document was developed at the National Center to aid CBRC participants in understanding their responsibilities. A copy of this document can be found in Appendix A.

Figure 1 depicts the organizational structure of the Combustion Byproducts Recycling Consortium program participants. 
Sponsoring Agency

U.S. Department of Energy -

National Energy Technology Laboratory

Funding; Program Oversight

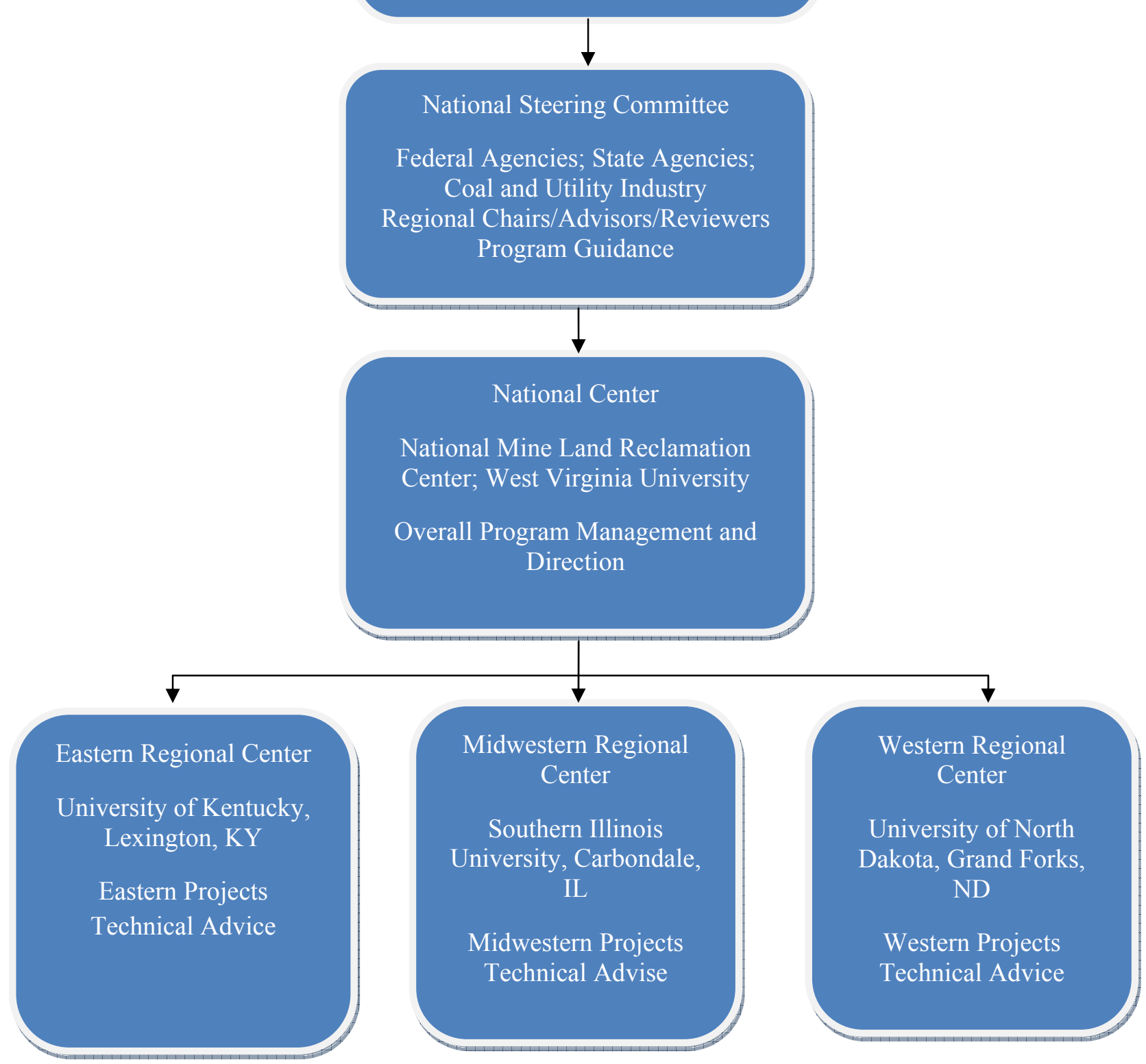

Figure 1. Organizational Structure of the Combustion Byproducts Recycling Consortium 


\section{Advantages of the CBRC Consortium Structure}

Advantages of this program structure included:

! The public would be better served if research priorities were based on the common needs of both industry and government and issues critical to the region were addressed.

! Contracting procedures would be streamlined by having only one federal contact between USDOE-NETL and the CBRC managers. The CBRC managers would be responsible for assuring that the technical and budget-reporting requirements associated with the performance of individual research contracts were as efficient and effective as possible.

! The structure of the regional advisors/reviewers ensured that proposals met regional technical needs and that the research did not duplicate on-going work.

! Steering committee members and regional advisors/reviewers were exposed to innovative research ideas that would not have been revealed via their own efforts. Even if the National Steering Committee as a whole decided not to fund a particular proposal, the individual participants had the opportunity to work with the proposing organization using other funding sources.

\section{Regional Divisions and Research Priorities}

The fifty United States and its territories made up three specific CBRC regions. Each region identified priorities that, if met, would result in an increase in the utilization of CCBs within that region. In addition, regional priorities served to identify the issues and research needs related to the geographic sectors of the country. Although many priorities were shared between regions, proposed projects were evaluated separately by region in order to help each region meet its own priorities. Figure 2 depicts which states fall within these three $\mathrm{CBRC}$ regions.

Initially only regional priorities for the east, midwest, and west were included in the RFPs. Later, at USDOE-NETL's request, a list of National priorities was also included. These national priorities were included based on the national perspective identified by USDOE-NETL for issues and research needs on a national scale. Following Figure 2 is a listing of both regional and national priorities used in the 2005 RFP. 


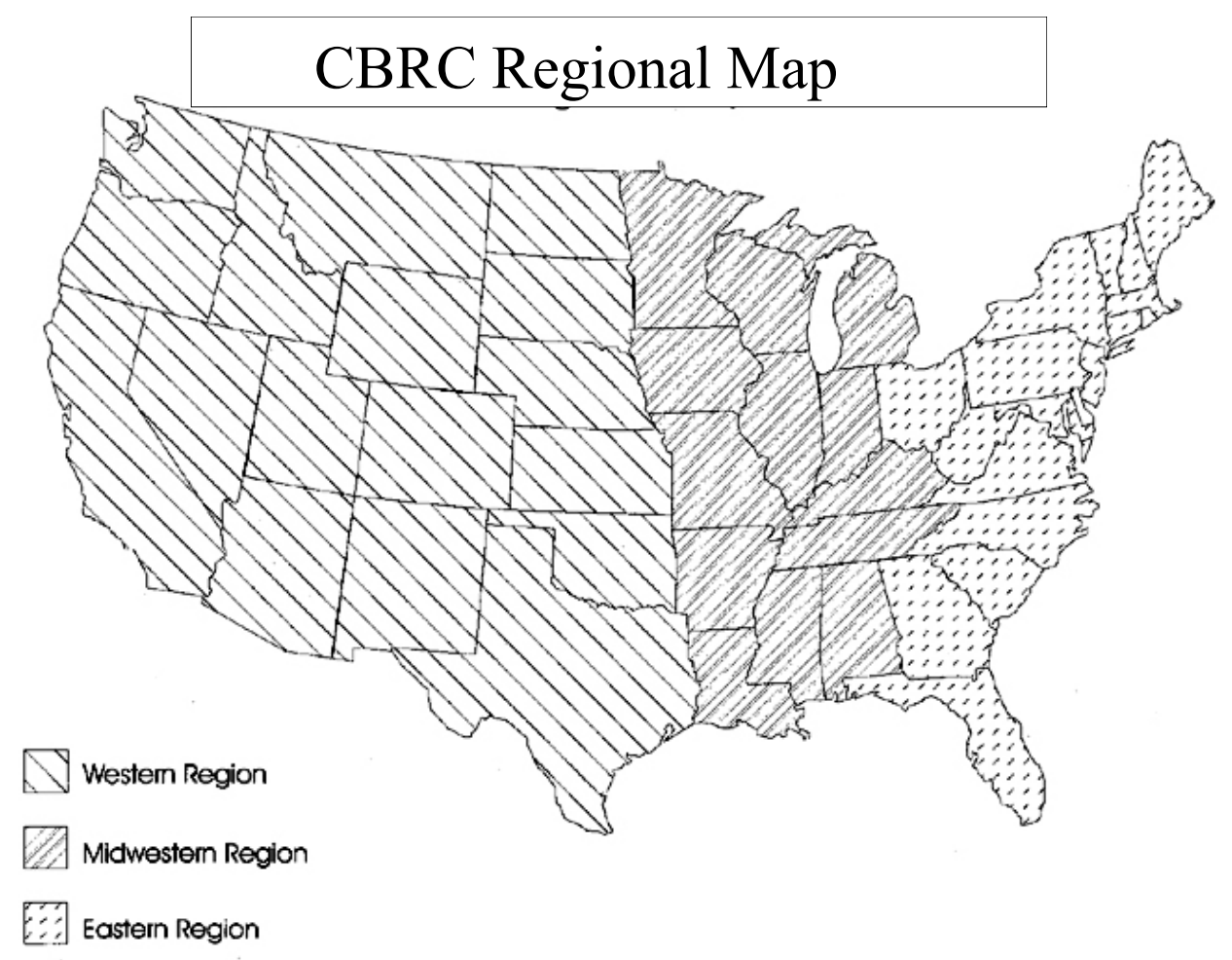

Figure 2. Map depicting the three geographic regions of the CBRC program. 


\section{Regional Research Area Priorities}

\section{Eastern Region Research Priorities}

The eastern region has traditionally relied on coals produced in the eastern U.S. and produced class F fly ashes. Imports of sub-bituminous Indonesian coals and bituminous South American coals are contributing to changing ash characteristics. Ashes from blended coals and from coal feeds with no eastern bituminous component are becoming more common. Along with the midwestern region, the eastern states have had a longer history of producing FGD materials. For utilities that have ponded or landfilled FGD and fly ash products, the volumes of material, combined with land-use restrictions, may lead to increased incentive to utilize previouslydisposed materials.

E1 High volume utilization of CCBs, including ponded/stored fly ash and FGD material; offspec fly ash; and ash with inconsistent quality.

E2 Impact of changing air pollution control technologies on potential uses of $\mathrm{CCBs}$ and methods to keep them in use.

E3 FGD gypsum in wallboard and other manufactured products with limited negative environmental impact.

E4 Ashes from co-combustion of different coal ranks (Eastern bituminous with other coals [PRB or non-U.S. sub-bituminous, western U.S. bituminous, South American bituminous, etc.]) or different ash chemistries (high $\mathrm{Fe}$ and/or high $\mathrm{S}$ with high $\mathrm{Ca}$ ), or ashes from co-combustion of coal and non-coal fuels (tires, pet coke, biomass).

E5 Material handling and transportation issues associated with high volume uses of ash and scrubber gypsum (i.e., reclaiming material from ponds, rail and barge loadout/unloading, dewatering/drying material, spreaders for agricultural use, etc.).

\section{Midwestern Region Research Priorities}

The Midwestern region utilizes coals from Eastern states, Illinois coal basin, as well as from Powder River basin. Therefore, it produces both $\mathrm{C}$-ash and $\mathrm{F}$-ash. In addition, some power plants are blending biomass and pet coke with coals. Thus, this region uses high sulfur, lowsulfur, and blended coals. Along with the eastern region, the Midwestern states have had a longer history of producing FGD materials.

M1 Large-volume beneficial use applications of new and ponded conventional CCBs (fly ash, bottom ash, boiler slag) and FGD byproducts (wet scrubber byproducts, fluidized-bed combustion byproducts) in:

\$ mining, reclamation, acid mine drainage, and mine-fill applications

$\$$ cement-concrete, construction, building products, soil amendment, soil stabilization, highways, liners, soil cover, etc. 
\$ agricultural applications, with strong consideration of mercury impacts

M2 Impacts of changing air quality standards on CCBs and FGD byproducts quality, with particular emphasis on mercury, and their impacts on large-volume beneficial use applications and products development.

M3 Removing regulatory and socio-political barriers at the national, state and local levels to beneficially utilize CCBs.

M4 Synergistic management of CCBs in product development and large-volume applications.

M5 Characterization studies, with focus on large-volume beneficial use, on CCBs generated from various coal blends, blends of coal and alternate fuels such as biomass and pet coke, and gasification byproducts.

\section{Western Region Research Priorities}

The Western Region needs to address continuing technical and environmental issues that can negatively impact the potential to maximize the use of CCBs in the western U.S. Western Region industry representatives indicate that CCB projects should focus on utilization of fly ash, FGD material, and bottom ash in order of importance. Changes in quality and performance of CCBs from emerging emission control technologies are also a challenge to the use of CCBs in the Western Region.

W1 Development and demonstration of high-volume CCB utilization in geotechnical, mining, and agricultural applications potentially including assessments of impacts to surface water and groundwater quality.

W2 Product development investigations on currently-produced CCBs, CCBs from coal-fuel blends and CCBs resulting from changing emission control technologies.

W3 Development, testing, and proof-of-concept evaluations for CCB-containing products with potential to move high volumes of CCBs $(100,000$ tons or more) to market.

W4 Advance and maintain the use of CCBs in concrete by demonstrating and testing CCB use in high-performance concrete and investigating the impact of CCB variability from single, multiple, and blended sources on concrete, including high-performance applications.

\section{National Research Priorities}

The priorities listed below are national in scope and were meant to complement, not supersede the listed regional priorities. The National Priorities were all of equal importance to CBRC; i.e., the order in which they appear did not reflect their relative level of importance.

N1 Project involving the acquisition and dissemination of information on the environmental 
performance of CCBs in large-scale utilization applications to assist in the development of sound, consistent environmental standards for their reuse.

N2 Project that utilizes fly ash, bottom ash, or wet FGD byproducts at mine sites in an innovative manner that clearly constitutes a beneficial use.

N3 Project that develops new large-volume utilization markets and/or significantly expands existing but under-used large-volume markets for fly ash and/or bottom ash from pulverized coal boilers (does not include utilization at mine sites).

N4 Project that develops new large-volume utilization markets and/or significantly expands existing but under-used large-volume markets for wet FGD byproducts (does not include utilization as a feedstock for wallboard manufacture or utilization at mine sites).

N5 Project that analyzes and clarifies the quantities, costs, benefits, and other market factors that govern decisions by individual CCB producers and users regarding CCB reuse in specific end-use markets.

\section{RFP Process}

The development of Requests for Proposals (RFP's) was a team effort between the USDOENETL National Center, Regional Centers, and National Steering Committee members. When these participants were satisfied with the wording, the National Center would release the RFP. Initially full proposals were requested. In later years, pre-proposals were requested and full proposals were invited from those selected in the pre-proposal review process. The Request for Pre-proposals released in 2005 can be found in Appendix B. The invitation to submit full proposals to those whose pre-proposals were selected can be found in Appendix C. Table 1 depicts the history of the RFPs released, the number of pre- and full proposals received, and number of projects funded.

Table 1. CBRC Request for Proposals (RFP) History

\begin{tabular}{|l|l|l|l|l|}
\hline Release Year & $\begin{array}{c}\text { Pre- or Full } \\
\text { proposal Initially } \\
\text { Requested }\end{array}$ & $\begin{array}{c}\text { Number of Pre- } \\
\text { proposals } \\
\text { Received }\end{array}$ & $\begin{array}{c}\text { Number of Full } \\
\text { Proposals } \\
\text { Received }\end{array}$ & $\begin{array}{c}\text { Number of } \\
\text { Projects Funded }\end{array}$ \\
\hline 1999 & Full & N/A & 34 & 18 \\
\hline 2000 & Full & N/A & 69 & 13 \\
\hline 2001 & Pre & 52 & $17^{*}$ & $9^{* *}$ \\
\hline 2002 & Pre & 59 & $17^{*}$ & $6^{* * *}$ \\
\hline 2005 & Pre & 52 & $19^{*}$ & 10 \\
\hline
\end{tabular}

*Invited from pre-proposal selection to submit full proposals.

$* *$ Six were new projects and three were continuation projects.

$* * *$ Five were new projects and one was a continuation project.

Requests for proposals were limited to the United States and its territories. 


\section{Proposal Solicitation}

Proposals were solicited in a number of ways. Early on, hard copy mailings were sent. Over the first 1-2 years as more contacts were made, an email list serve of over 600 was generated and announcements were distributed via email upon release of the RFP. Announcements were placed on the CBRC web site, in the American Coal Ash Association journal, at exhibits such as World of Coal Ash (WOCA), and in the CBRC quarterly newsletter, Ashlines.

\section{Cost-Share Requirement}

In each RFP, a minimum $25 \%$ cost-share, or matching, requirement was included. This match could be in cash or in-kind services. Private or state funds could be used to supply this match; however, no Federal funds were allowed. Letters of commitment were required prior to awarding federal dollars to the sub-recipients. In many cases, applicants committed to more than the $25 \%$ requirement in matching cost-share. In fact, in many cases, the actual match expended on the project exceeded the committed match to the project. Table 2 reflects the $25 \%$ minimum requirement, the amount committed, and the actual amount expended for each CBRC project.

Table 2. Cost-Share (CS) for Each CBRC Project

\begin{tabular}{|c|c|c|c|c|c|}
\hline Project No. & PI & Organization & $\begin{array}{c}\text { Min. } 25 \% \text { CS } \\
\text { Requirement } \\
\text { (\$) }\end{array}$ & $\begin{array}{c}\text { CS } \\
\text { Commitment } \\
(\$)\end{array}$ & $\begin{array}{c}\text { Actual CS } \\
\text { Expended } \\
(\$)\end{array}$ \\
\hline 99-EC-E04 & LaCount & Waynesburg College & $64,616.63$ & $189,793.50$ & $189,793.50$ \\
\hline 99-EC-E06 & Brendel & GAI Consultants, Inc. & $38,613.75$ & $69,486.00$ & $69,201.07$ \\
\hline 99-EC-E08 & Dick & Ohio State University & $24,322.50$ & $48,650.00$ & $88,182.63$ \\
\hline 99-EC-E11 & Stofella & University of Florida & $28,995.10$ & $41,102.00$ & $44,647.00$ \\
\hline 99-EC-E13 & Das & University of Georgia & $19,851.00$ & $19,851.00$ & $20,263.81$ \\
\hline 99-EC-E15 & Haefner & US Geological Survey & $30,639.50$ & $30,560.00$ & $88,899.63$ \\
\hline 99-EC-E16 & Levy & Lehigh University & $34,862.75$ & $56,263.00$ & $56,774.00$ \\
\hline 99-EC-E17 & Broschart & WV Dept. of Env. Prot. & $13,181.75$ & $27,656.00$ & $81,861.93$ \\
\hline 99-EC-E24 & Wolfe & Ohio State University & $237,456.77$ & $924,544.00$ & $966,180.35$ \\
\hline 99-EC-M01 & Malhotra & Southern Illinois Univ. & $105,731.27$ & $339,166.00$ & $353,720.71$ \\
\hline 99-EC-M04 & Paul & Southern Illinois Univ. & $29,560.25$ & $51,446.00$ & $57,688.16$ \\
\hline 99-EC-M05 & Edil & University of Wisconsin & $33,983.50$ & $34,624.00$ & $36,651.00$ \\
\hline 99-EC-M06 & Naik & University of Wisconsin & $26,547.50$ & $40,000.00$ & $42,339.00$ \\
\hline 99-EC-M07 & Chugh & Southern Illinois Univ. & $103,318.50$ & $299,394.00$ & $307,400.28$ \\
\hline 99-EC-W01 & Adams & CGRS, Inc. & $10,625.25$ & $23,739.00$ & $25,591.65$ \\
\hline 99-EC-W02 & Hunt & AeRock, Inc. & $16,229.00$ & $22,864.00$ & $44,417.23$ \\
\hline 99-EC-W04 & Canty & CC Environmental & $31,112.50$ & $38,560.00$ & $49,307.12$ \\
\hline 99-EC-W05 & Murarka & Ish, Inc. & $16,250.00$ & $20,000.00$ & $21,329.36$ \\
\hline 00-CBRC-E15 & Petzrick & MD Dept. of Nat. Res. & $40,388.00$ & $111,552.00$ & $111,552.00$ \\
\hline 00-CBRC-E24 & Scheetz & Pennsylvania State Univ. & $14,553.75$ & $17,548.00$ & $17,548.00$ \\
\hline 00-CBRC-E37 & McDonald & West Virginia Univ. & $23,961.09$ & $39,004.65$ & $40,298.06$ \\
\hline 00-CBRC-E41 & Glogowski & GAI Consultants, Inc. & $80,525.00$ & $231,600.00$ & $4,318,881.46$ \\
\hline 00-CBRC-E42 & Sobczak & Energy Industries of Ohio & $20,975.00$ & $41,800.00$ & $46,357.00$ \\
\hline 00-CBRC-M04 & Misra & University of Missouri & $44,216.00$ & $100,301.00$ & $101,988.90$ \\
\hline 00-CBRC-M05 & Crouch & Tennessee Technical Univ. & $13,488.24$ & $15,965.00$ & $16,203.05$ \\
\hline 00-CBRC-M09 & Murarka & Ish., Inc. & $120,885.75$ & $300,500.00$ & $590,559.33$ \\
\hline 00-CBRC-M11 & Rusch & Louisiana State University & $31,771.37$ & $45,411.00$ & $46,054.52$ \\
\hline
\end{tabular}




\begin{tabular}{|c|c|c|c|c|c|}
\hline Project No. & PI & Organization & $\begin{array}{c}\text { Min. 25\% CS } \\
\text { Requirement } \\
\text { (\$) }\end{array}$ & $\begin{array}{c}\text { CS } \\
\text { Commitment } \\
(\$)\end{array}$ & $\begin{array}{c}\text { Actual CS } \\
\text { Expended } \\
(\$)\end{array}$ \\
\hline 00-CBRC-M14 & $\mathrm{Wu}$ & Wayne State University & $24,025.25$ & $29,180.00$ & $32,168.34$ \\
\hline 00-CBRC-W02 & Adams & CGRS, Inc. & $15,391.25$ & $15,804.00$ & $44,417.23$ \\
\hline 00-CBRC-W04 & Butz & ADA Technologies, Inc. & $29,708.50$ & $31,015.00$ & $31,872.92$ \\
\hline 00-CBRC-W10 & Carlson & Sunflower Electric Power & $27,787.50$ & $61,575.00$ & $104,000.00$ \\
\hline 01-CBRC-E09 & $\begin{array}{l}\text { Maroto- } \\
\text { Valer }\end{array}$ & Pennsylvania State Univ. & $23,666.98$ & $25,494.00$ & $27,099.00$ \\
\hline 01-CBRC-E10 & Butalia & Ohio State University & $133,485.75$ & $463,943.00$ & $463,943.03$ \\
\hline 01-CBRC-M12 & Meischen & Tennessee Valley Authority & $21,995.26$ & $22,000.00$ & $23,512.53$ \\
\hline 01-CBRC-M21 & Paul & Southern Illinois University & $34,603.00$ & $68,412.00$ & $6,242.16$ \\
\hline 01-CBRC-M23 & Hassett & University of North Dakota & $26,403.25$ & $35,613.00$ & $38,033.16$ \\
\hline 01-CBRC-W01 & Buckley & University of North Dakota & $17,180.25$ & $17,183.00$ & $12,863.02$ \\
\hline 02-CBRC-E10 & Purgert & Energy Industries of Ohio & $35,428.75$ & $80,000.00$ & $91,601.00$ \\
\hline 02-CBRC-E06 & Herd & West Virginia University & $12,150.57$ & $10,889.00$ & $10,977.53$ \\
\hline 02-CBRC-M12 & Chou & $\begin{array}{l}\text { Illinois State Geologic } \\
\text { Survey }\end{array}$ & $35,430.25$ & $81,721.00$ & $82,908.00$ \\
\hline 02-CBRC-W09 & O’Neill & New Mexico State Univ. & $29,752.00$ & $49,344.00$ & $94,915.08$ \\
\hline 02-CBRC-W12 & Dockter & University of North Dakota & $13,929.00$ & $15,716.00$ & $15,113.56$ \\
\hline 05-CBRC-E08 & Dick & Ohio State University & $39,775.61$ & $54,102.45$ & $63,149.18$ \\
\hline 05-CBRC-E18 & Pier & Tennessee Valley Authority & $5,514.97$ & $4,412.37$ & $28,815.00$ \\
\hline 05-CBRC-E19 & Buggeln & University of Tennessee & $12,636.27$ & $10,109.16$ & $13,868.00$ \\
\hline 05-CBRC-M09 & Misra & University of Missouri & $5,879.15$ & $4,6851.31$ & $19,056.74$ \\
\hline 05-CBRC-M16 & Edil & University of Wisconsin & $15,276.81$ & $12,221.25$ & $17,003.52$ \\
\hline 05-CBRC-M20 & Obla & $\begin{array}{l}\text { National Ready Mixed } \\
\text { Concrete Assoc. }\end{array}$ & $37,429.51$ & $35,744.05$ & $64,656.76$ \\
\hline 05-CBRC-M23 & Chou & $\begin{array}{l}\text { Illinois State Geologic } \\
\text { Survey }\end{array}$ & $11,953.13$ & $9,562.50$ & $50,903.00$ \\
\hline 05-CBRC-W03 & Canty & CC Environmental, LLC & $3,740.00$ & $3,358.86$ & $1,269.64$ \\
\hline 05-CBRC-W04 & Dockter & University of North Dakota & $11,718.75$ & $9,375.00$ & $21,465.62$ \\
\hline 05-CBRC-W08 & Stephens & Montana State University & $23,855.43$ & $23,878.00$ & $22,679.00$ \\
\hline Totals & & & $1,905,378.88$ & $4,356,718.00$ & $9,216.223 .77$ \\
\hline
\end{tabular}

\section{Proposal Review Process}

Evaluation criteria and a process for review of pre- and full proposals were developed between the main partners: USDOE-NETL, National Center, Regional Centers, and National Steering Committee members. The National and Regional Centers were not given "votes" in proposal selection; but rather, the Directors were responsible for understanding the proposals and explaining the proposal details to the voting reviewers. Voting reviewers consisted of National Steering Committee members and selected experts in the field. Confidentiality agreements were required of all reviewers prior to their being allowed to obtain proposals. Once the reviewers evaluated the proposals, they completed evaluation forms and sent them to the National Center where they were compiled and scores tallied. The National Steering Committee would then meet to discuss the proposals and make their recommendations for funding. The Regional Directors would clarify any questions related to any of the submitted proposals for their region and the National Director provided input on all proposals under discussion. The USDOE-NETL COR had final approval in moving any proposal forward for funding. 


\section{Award Implementation}

In 1998 a five-year cooperative agreement was established between the USDOE-NETL and West Virginia University (WVU) for the CBRC program. In 2003, this cooperative agreement was extended for an additional five years.

Initially, when the award reached WVU, subcontracts were issued to the regional centers and the regional centers, in turn, issued subcontracts to the sub-recipient researchers. In 1998, the Eastern Center was at WVU as was the National Center. This meant that Eastern region researchers received their subcontracts directly from WVU whereas the Midwestern and Western Regional researchers received their subcontracts from Southern Illinois University and the University of North Dakota, respectively, after SIU and UND received their subcontracts from WVU. The result was that Eastern region researchers had their subcontracts sooner than Midwestern and Western Region researchers and could start their projects sooner. After discussion on this issue, the National Steering Committee agreed that it would be more efficient and keep all projects on a similar timeframe if all subcontracts were issued directly from WVU to the sub-recipient researchers. Henceforth, WVU issued subcontracts directly to the subrecipient researchers in all regions as well as to regional center directors.

The University of Kentucky replaced WVU as the Eastern Regional Center and all three Regional Center Directors were relieved of the administrative tasks associated with sub-recipient subcontracting to their researchers. Thus, regional directors could serve specifically in the role of technical guidance and oversight for their regional projects. This left most administrative functions with the National Center and proved to be the more efficient means for subcontract implementation and management.

\section{Program Funding}

The CBRC received Federal funding from the USDOE-NETL from 1998 - 2007. Matching cost-share support in the form of cash and in-kind services was received from State and private sources including the American Coal Ash Association and utility industries.

In April, 2007, the National Center received a notice from the USDOE-NETL that funding for DOE's Office of Fossil Energy's Innovations for Existing Plants (IEP) Program had been zeroed out of the President's Fiscal Year 2008 budget. (See Appendix D) As a result of these funding cuts, the USDOE-NETL was unable to provide the final $\$ 1,119,826$ it had planned to support the CBRC program and the remaining 10 active projects. All of the 10 active project researchers were asked to revise their statements of work and budgets to bring their projects to a logical conclusion.

Table 3 reflects program funding between 1998-2007. Table 4 reflects the 2008 modification which resulted from the cut in funding to the USDOE-NETL's IEP Program. 
Table 3. CBRC Program Funding 1998-2007

\begin{tabular}{|l|r|r|}
\hline \multicolumn{1}{|c|}{ Source } & Amount Provided & Percentage of Total Value \\
\hline USDOE-NETL & $\$ 5,973.861$ & $56 \%$ \\
\hline Industry/Other & $\$ 4,775,313$ & $44 \%$ \\
\hline Total Value & $\$ 10,749,176$ & $100 \%$ \\
\hline
\end{tabular}

Table 4. 2008 Modification to CBRC Program Funds

\begin{tabular}{|c|c|c|}
\hline Source & Dollar Value & $\begin{array}{c}\text { Percentage of Total } \\
\text { Value }\end{array}$ \\
\hline \multicolumn{3}{|l|}{ USDOE-NETL } \\
\hline Original Budgeted Amount & $\$ 5,973,861$ & $56 \%$ \\
\hline Decreased by & $\$ 1,119,826$ & \\
\hline Adjusted Budgeted Amount & $\$ 4,854,035$ & $52 \%$ \\
\hline \multicolumn{3}{|l|}{ Matching Cost-Share } \\
\hline Original Commitment & $\$ 4,775,315$ & $44 \%$ \\
\hline Decreased by & $\$ 249,209$ & \\
\hline Adjusted to & $\$ 4,526,106$ & $48 \%$ \\
\hline
\end{tabular}




\section{Research Projects}

\section{Distribution of Projects}

Projects were funded in 21 states over the 10 year tenure of the CBRC program. Distribution is reflected in Table 5.

Table 5. Distribution of CBRC Projects by State

\begin{tabular}{|l|l|l|l|}
\hline \multicolumn{1}{|c|}{ State } & \multicolumn{1}{c|}{ No. of Projects } & \multicolumn{1}{c|}{ State } & No. of Projects \\
\hline Alabama & 1 & Missouri & 2 \\
\hline California & 1 & Montana & 1 \\
\hline Colorado & 4 & New Mexico & 1 \\
\hline Florida & 1 & North Dakota & 4 \\
\hline Georgia & 1 & Ohio & 6 \\
\hline Illinois & 6 & Oklahoma & 2 \\
\hline Indiana & Pennsylvania & 6 \\
\hline Kansas & 1 & Tennessee & 3 \\
\hline Louisiana & 1 & West Virginia & 4 \\
\hline Maryland & 2 & Wisconsin & 3 \\
\hline Michigan & 1 & & \\
\hline
\end{tabular}

These 52 projects were distributed throughout the three regions. Table 6 shows the number of projects and the percentage of Federal versus matching cost-share dollars applied per region.

Table 6. Distribution of Projects by Region

\begin{tabular}{|l|r|r|r|r|}
\hline \multicolumn{1}{|c|}{ Region } & $\begin{array}{c}\text { No. Projects } \\
\text { Funded }\end{array}$ & \% Federal \$ & \% Cost Share \$ & \% Total \$ \\
\hline Eastern & 21 & $38 \%$ & $55 \%$ & $48 \%$ \\
\hline Midwestern & 18 & $42 \%$ & $37 \%$ & $39 \%$ \\
\hline Western & 13 & $20 \%$ & $8 \%$ & $13 \%$ \\
\hline Total & 52 & $100 \%$ & $100 \%$ & $100 \%$ \\
\hline
\end{tabular}

Table 7 lists each of the 52 funded CBRC projects by region.

Table 7. CBRC Projects by Region

\begin{tabular}{|l|l|l|l|}
\hline \multicolumn{1}{|c|}{ Project No. } & $\begin{array}{c}\text { Principal } \\
\text { Investigator }\end{array}$ & \multicolumn{1}{|c|}{ Organization } & \multicolumn{1}{|c|}{ Project Title } \\
\hline Eastern Region & LaCount & Waynesburg College & $\begin{array}{l}\text { Economical Treatment of High Carbon Fly Ash to } \\
\text { Produce a Low Foam Index Product(s) with } \\
\text { Carbon Content Retained }\end{array}$ \\
\hline 99-EC-E04 & Brendel & GAI Consultants, Inc. & $\begin{array}{l}\text { Effects of Ammonia Adsorption on Fly Ash Due to } \\
\text { Installation of SCR Technology }\end{array}$ \\
\hline 99-EC-E06 & Dick & Ohio State University & $\begin{array}{l}\text { Flue Gas Desulfurization By-Products Provide } \\
\text { Sulfur and Trace Mineral Nutrition for Alfalfa and } \\
\text { Soybeans }\end{array}$ \\
\hline 99-EC-E08 & Stofella & University of Florida & Utilization of Fly Ash/Urban Yard Waste Compost \\
\hline 99-EC-E11 & &
\end{tabular}




\begin{tabular}{|c|c|c|c|}
\hline Project No. & $\begin{array}{c}\text { Principal } \\
\text { Investigator }\end{array}$ & Organization & Project Title \\
\hline & & & as Soil Amendments to Improve Soil Fertility \\
\hline 99-EC-E13 & Das & University of Georgia & $\begin{array}{l}\text { Odor and HAP Control in Waste Treatment } \\
\text { Processes Using Coal Combustion Ash }\end{array}$ \\
\hline 99-EC-E15 & Haefner & US Geological Survey & $\begin{array}{l}\text { Water-Quality Monitoring at an Abandoned Mine } \\
\text { Site Reclaimed with Pressurized Fluidized Bed } \\
\text { Combustion Byproducts }\end{array}$ \\
\hline 99-EC-E16 & Levy & Lehigh University & $\begin{array}{l}\text { Ammonia Removal from Fly Ash in a Bubbling } \\
\text { Fluidized Bed }\end{array}$ \\
\hline 99-EC-E17 & Broschart & $\begin{array}{l}\text { WV Department of } \\
\text { Environmental Protection }\end{array}$ & $\begin{array}{l}\text { Hydrogeologic Evaluation of Strata Above the } \\
\text { North Lobe of the Omega Mine }\end{array}$ \\
\hline 99-EC-E24 & Wolfe & Ohio State University & $\begin{array}{l}\text { Use of Clean Coal Technology Products in the } \\
\text { Construction of Low Permeability Liners }\end{array}$ \\
\hline 00-CBRC-E15 & Petzrick & $\begin{array}{l}\text { Maryland Department of } \\
\text { Natural Resources }\end{array}$ & Siege of Acre \\
\hline 00-CBRC-E24 & Scheetz & $\begin{array}{l}\text { Pennsylvania State } \\
\text { University }\end{array}$ & $\begin{array}{l}\text { Laboratory and Field Demonstration of the Control } \\
\text { of Ettringite Swelling }\end{array}$ \\
\hline 00-CBRC-E37 & McDonald & West Virginia University & $\begin{array}{l}\text { Effects of Large-Scale CCB Applications on } \\
\text { Groundwater: Case Studies }\end{array}$ \\
\hline 00-CBRC-E41 & Glogowski & GAI Consultants, Inc. & Environmental Effects of Large-Volume FGD Fill \\
\hline 00-CBRC-E42 & Sobczak & Energy Industries of Ohio & $\begin{array}{l}\text { The Use of Fly Ash as an Aggregate for Foundry } \\
\text { Sand Mold and Core Production }\end{array}$ \\
\hline 01-CBRC-E09 & Maroto-Valer & $\begin{array}{l}\text { Pennsylvania State } \\
\text { University }\end{array}$ & $\begin{array}{l}\text { Development of Fly Ash Derived Sorbents to } \\
\text { Capture CO2 from Flue Gas of Power Plants }\end{array}$ \\
\hline 01-CBRC-E10 & Butalia & Ohio State University & $\begin{array}{l}\text { Full-Scale Testing of Coal Combustion Product } \\
\text { Pavement Sections Subjected to Repeated Wheel } \\
\text { Loads }\end{array}$ \\
\hline 02-CBRC-E06 & Herd & West Virginia University & $\begin{array}{l}\text { Prediction of the Effects of Placing CCBs in } \\
\text { Contact with Mine Spoil }\end{array}$ \\
\hline 02-CBRC-E10 & Purgert & Energy Industries of Ohio & $\begin{array}{l}\text { Commercialization of Production Foundry Molds } \\
\text { Made from CCBs for High Volume Automotive } \\
\text { Applications }\end{array}$ \\
\hline 05-CBRC-E08 & Dick & Ohio State University & $\begin{array}{l}\text { National Network of Research and Demonstration } \\
\text { Sites for Agricultural and Other Land Application } \\
\text { Uses of FGD Products }\end{array}$ \\
\hline 05-CBRC-E18 & Pier & $\begin{array}{l}\text { Tennessee Valley } \\
\text { Authority }\end{array}$ & $\begin{array}{l}\text { Field Testing of Arsenic and Mercury } \\
\text { Bioavailability Model from Land-Applied Coal } \\
\text { Combustion Byproducts }\end{array}$ \\
\hline 05-CBRC-E19 & Buggeln & University of Tennessee & $\begin{array}{l}\text { Community-based Social Marketing: The Tool to } \\
\text { Get Target Audiences to Use Coal Combustion } \\
\text { Byproducts }\end{array}$ \\
\hline \multicolumn{4}{|l|}{ Midwestern } \\
\hline 99-EC-M01 & Malhotra & $\begin{array}{l}\text { Southern Illinois } \\
\text { University }\end{array}$ & $\begin{array}{l}\text { Development of Structural Materials from Sulfate- } \\
\text { Rich Wet Scrubber Sludge }\end{array}$ \\
\hline 99-EC-M04 & Paul & $\begin{array}{l}\text { Southern Illinois } \\
\text { University }\end{array}$ & $\begin{array}{l}\text { Boron Transport from Coal Combustion Product } \\
\text { Utilization and Disposal Sites }\end{array}$ \\
\hline 99-EC-M05 & Edil & University of Wisconsin & Soil Stabilization and Drying by Use of Fly Ash \\
\hline 99-EC-M06 & Naik & University of Wisconsin & $\begin{array}{l}\text { Development and Demonstration of High-Carbon } \\
\text { CCPs and FGD Byproducts in Permeable Roadway } \\
\text { Base Construction }\end{array}$ \\
\hline 99-EC-M07 & Chugh & $\begin{array}{l}\text { Southern Illinois } \\
\text { University }\end{array}$ & $\begin{array}{l}\text { Industry-Government-University Cooperative } \\
\text { Research Program for Development of Coal } \\
\text { Combustion Products-Based Transmission Poles }\end{array}$ \\
\hline
\end{tabular}




\begin{tabular}{|c|c|c|c|}
\hline Project No. & $\begin{array}{c}\text { Principal } \\
\text { Investigator }\end{array}$ & Organization & Project Title \\
\hline & & & for Electric Utility Industry \\
\hline 00-CBRC-M04 & Misra & University of Missouri & Crushed Aggregates from Class C Fly Ash \\
\hline 00-CBRC-M05 & Crouch & $\begin{array}{l}\text { Tennessee Technical } \\
\text { Univ. }\end{array}$ & $\begin{array}{l}\text { Long Term Excavatability of Flowable Fill } \\
\text { Containing Coal Combustion Byproducts }\end{array}$ \\
\hline 00-CBRC-M09 & Murarka & Ish., Inc. & $\begin{array}{l}\text { Environmental Performance Evaluation of Filling } \\
\text { and Reclaiming a Surface Coal Mine with Coal } \\
\text { Combustion Byproducts }\end{array}$ \\
\hline 00-CBRC-M11 & Rusch & $\begin{array}{l}\text { Louisiana State } \\
\text { University }\end{array}$ & $\begin{array}{l}\text { Development of CCB Fill Materials for Use as } \\
\text { Mechanically Stabilized Marine Structures }\end{array}$ \\
\hline 00-CBRC-M14 & $\mathrm{Wu}$ & Wayne State University & $\begin{array}{l}\text { High Performance Masonry Units from 100\% Fly } \\
\text { Ash: Synergistic Approach }\end{array}$ \\
\hline 01-CBRC-M12 & Meischen & $\begin{array}{l}\text { Tennessee Valley } \\
\text { Authority }\end{array}$ & $\begin{array}{l}\text { The Effect of Mercury Controls on Wallboard } \\
\text { Manufacture }\end{array}$ \\
\hline 01-CBRC-M21 & Paul & $\begin{array}{l}\text { Southern Illinois } \\
\text { University }\end{array}$ & $\begin{array}{l}\text { The Impact of Adsorption on the Mobility of } \\
\text { Arsenic and Selenium Leached from Coal } \\
\text { Combustion Products }\end{array}$ \\
\hline 01-CBRC-M23 & Hassett & $\begin{array}{l}\text { University of North } \\
\text { Dakota }\end{array}$ & $\begin{array}{l}\text { Quantifying CCBs for Agricultural Land } \\
\text { Application }\end{array}$ \\
\hline 02-CBRC-M12 & Chou & $\begin{array}{l}\text { Illinois State Geologic } \\
\text { Survey }\end{array}$ & $\begin{array}{l}\text { Manufacturing Fired Bricks with Class F Fly Ash } \\
\text { from Illinois Basin Coals }\end{array}$ \\
\hline 05-CBRC-M09 & Misra & University of Missouri & $\begin{array}{l}\text { Cold In-Place Recyling of Asphalt Pavements } \\
\text { Using Self-Cementing Fly Ash: Analysis of } \\
\text { Pavement Performance and Structure Number }\end{array}$ \\
\hline 05-CBRC-M16 & Edil & University of Wisconsin & In Situ Stabilization of Gravel Roads with CCPs \\
\hline 05-CBRC-M20 & Obla & $\begin{array}{l}\text { National Ready Mixed } \\
\text { Concrete Association }\end{array}$ & $\begin{array}{l}\text { New Technology Based Approach to Advance } \\
\text { Higher Volume Fly Ash Concrete with Acceptable } \\
\text { Performance }\end{array}$ \\
\hline 05-CBRC-M23 & Chou & $\begin{array}{l}\text { Illinois State Geologic } \\
\text { Survey }\end{array}$ & $\begin{array}{l}\text { Manufacturing Building Products with Fly Ash and } \\
\text { Advanced Coal Combustion Byproducts }\end{array}$ \\
\hline \multicolumn{4}{|l|}{ Western } \\
\hline 99-EC-W01 & Adams & CGRS, Inc. & Varra Coal Ash Burial Project - Phase I \\
\hline 99-EC-W02 & Hunt & AeRock, Inc. & Fiber-Fly-Ash Based Wall-Panel Development \\
\hline 99-EC-W04 & Canty & CC Environmental, LLC & $\begin{array}{l}\text { The Use of Coal Combustion ByProducts for In } \\
\text { Situ Treatment of Acid Mine Drainage }\end{array}$ \\
\hline 99-EC-W05 & Murarka & Ish, Inc. & $\begin{array}{l}\text { Promote Increased Use of Coal Combustion } \\
\text { Products to State Regulators and Government } \\
\text { Agencies }\end{array}$ \\
\hline 00-CBRC-W02 & Adams & CGRS, Inc. & Varra Coal Ash Burial Project - Phase II \\
\hline 00-CBRC-W04 & Butz & ADA Technologies, Inc. & $\begin{array}{l}\text { Pilot Testing of Fly Ash-Derived Sorbents for } \\
\text { Mercury Control in Coal-Fired Flue Gas }\end{array}$ \\
\hline 00-CBRC-W10 & Carlson & Sunflower Electric Power & $\begin{array}{l}\text { Evaluation of Fly Ash Admixtures for Final Cover } \\
\text { and Composite Line Applications }\end{array}$ \\
\hline 01-CBRC-W01 & Buckley & $\begin{array}{l}\text { University of North } \\
\text { Dakota }\end{array}$ & Development of a Database of CCB Publications \\
\hline 02-CBRC-W09 & O’Neill & New Mexico State Univ. & $\begin{array}{l}\text { Power Plant Combustion Byproducts for Improved } \\
\text { Crop Productivity of Agricultural Soils }\end{array}$ \\
\hline 02-CBRC-W12 & Dockter & $\begin{array}{l}\text { University of North } \\
\text { Dakota }\end{array}$ & $\begin{array}{l}\text { Engineering and Environmental Specifications of } \\
\text { State Agencies for Utilization and Disposal of Coal } \\
\text { Combustion Products }\end{array}$ \\
\hline 05-CBRC-W03 & Canty & CC Environmental, LLC & $\begin{array}{l}\text { Evaluation of Coal Combustion Byproducts for In } \\
\text { Situ Treatment of Acid Mine Drainage }\end{array}$ \\
\hline 05-CBRC-W04 & Dockter & Univ. of North Dakota & Using Class C Fly Ash to Mitigate Alkali-Silica \\
\hline
\end{tabular}




\begin{tabular}{|c|l|l|l|}
\hline Project No. & $\begin{array}{c}\text { Principal } \\
\text { Investigator }\end{array}$ & \multicolumn{1}{|c|}{ Organization } & \multicolumn{1}{c|}{ Project Title } \\
\hline & & & Reactions in Concrete \\
\hline 05-CBRC-W08 & Stephens & Montana State University & $\begin{array}{l}\text { Evaluation of the Durability and Commercial } \\
\text { Potential of 100\% Fly Ash Concrete }\end{array}$ \\
\hline
\end{tabular}

The types of projects funded covered a wide variety of uses and applications. These included:

- Agricultural soil remediation

- Mine void filling

- Soil amendments

- Transportation materials

- Lagoon liners
- Building products

- Marine structures

- Automotive molds

- CCB publications database

- Social marketing

The following are project synopses by Region. Regional Directors' assessments are included. Final technical project reports for each project can be found in Appendix E.

\section{Eastern Region \\ Director: James Hower, University of Kentucky}

\section{$\underline{\text { Agricultural Use and Amendments }}$}

\section{5-CBRC-E08: National Network of Research and Demonstration Sites for Agricultural and Other Land Application Uses of FGD Products Principal Investigator: Warren Dick, Ohio State University}

The long-term goal was to develop new strategies for the beneficial use of FGD products in agriculture. The main objective was to evaluate the effectiveness of a novel strategy to create a national network to test and demonstrate the benefits of FGD products in agriculture. To achieve this objective, three sub-objectives were developed.

1. Develop a workshop to bring together interested parties to pool current knowledge and to create a national research and development network related to large-volume beneficial uses of FGD products in agriculture and other land application uses.

2. Determine the appropriate rates and technologies of FGD products use in agriculture.

3. Evaluate the soil chemical and environmental effects of FGD products when applied to different soil types for improving crop productivity.

A workshop was held in St. Louis, MO in September 2006. Sixty-five people from regulatory, utility, marketing, research, and farming sectors attended. Experiments were designed for a minimum of two years of crop production and data collection. Environmental effects of gypsum application were monitored. The first site was established in 2007 in North Dakota. Results from year one indicated higher wheat yields when high rates of both commercial agricultural gypsum and FGD gypsum were applied. However, the increases in yield were not statistically significant. Gypsum applications showed no strong effects on the chemistry of the wheat grain or on grain quality. Additional sites are being established in five other states. Data obtained from 
these network sites will be made available to network participants to help promote sound agricultural and environmental use of FGD gypsum in the United States (Dick 2008).

\section{5-CBRC-E18: Field Testing of Arsenic and Mercury Bioavailability Model from Land- Applied CCBs \\ Principal Investigator: Paul Pier, Tennessee Valley Authority}

The overall objective of this project was to provide a model to predict the uptake of arsenic (As) and mercury $(\mathrm{Hg})$ by plants in response to $\mathrm{CCB}$ application rates to soil, based on $\mathrm{CCB} /$ soil characteristics. This will provide a measure of contaminant bioavailability for plants and concomitant risk assessment for soils that are being considered for CCB application thus eliminating the need to grow plants to maturity at each site to obtain risk assessment data. Greenhouse studies were conducted. The first study consisted of sorghum sudan grass, sunflower, and brake fern, an arsenic accumulator, grown in a potted soil amended with fly ash. The second study consisted of corn, soybean, and brake fern grown in soil amended with FGD gypsum. Data was used to develop a multiple-variable regression model for predicting As and Hg plant uptake. This predictive model can be used when considering amending soil with fly ash or FGD gypsum (Pier, 2008).

\section{5-CBRC-E19: Community-based Social Marketing: The Tool to Get Target Audiences to Use CCBs Principal Investigator: Richard Buggeln, University of Tennessee}

The overarching goal of this project was to demonstrate the utility of Community-Based Social Marketing (CBSM), a method for implementing sustainable agricultural use of combustion byproducts by farmers, and in so doing to develop a model that can be expanded and applied to other CCBs. To achieve this goal, the project had the following objectives: 1) Use CBSM to create a commitment to use a combustion byproduct, flue-gas desulfurization gypsum (FGD gypsum), among agricultural communities in Tennessee; and 2) make the CBSM tool understandable and accessible to members of the Combustion Byproducts Recycling Consortium (CBRC) in order to facilitate its transferability to other combustion byproduct generators/markets.

Farmer enlistment was good and the project remained on target. The Director of the University of Tennessee Center for Industrial Services has made funds available to see the project through to its completion scheduled for June 2009. The Tennessee Valley Authority has also agreed to continue its support and Temple-Inland is considering making a commitment to the project (Buggeln, 2007).

99-EC-E08: FGD Byproducts Provide Sulfur and Trace Mineral Nutrition for Alfalfa and Soybeans

Principal Investigator: Warren Dick, Ohio State University

This project integrated the roles and impacts of FGD on plant sulfur nutrition and the environment in order to make more detailed recommendations concerning the use of FGD byproducts. Study results indicated that FGD byproduct and N-Viro Soil provide sulfur (S) to 
improve growth of alfalfa and soybean and that they work as effectively as gypsum. They also provide other essential trace elements that enhance their value as a soil amendment. Environmental problems associated with the use of FGD byproduct and N-Viro Soil were not observed when application rates as high as $67 \mathrm{~kg} \mathrm{~S} \mathrm{ha}^{-1}$ were tested. Therefore, application of these materials can be safely applied to agricultural soils and provide economic benefit to farmers (Dick, 2002).

\section{9-EC-E11: Utilization of Fly Ash/Urban Yard Waste Compost as Soil Amendments to Improve Soil Fertility Principal Investigator: Pete Stofella, University of Florida}

Project objectives were: 1) To evaluate soil water holding capacities in soils amended with fly ash/urban yard waste compost and determine capabilities of fly ash to neutralize soil $\mathrm{pH}$ in acidic and calcareous soils; 2) to compare vegetable crop growth and yields of plants grown on soils amended with fly ash, yard waste and mixtures of fly ash/yard waste; and 3) to determine leachability and plant availability of metals in fly ash. Project results showed that appropriate applications of fly ash mixed with biosolids and/or yard waste compost should not lead to any significant detrimental impacts to soil, groundwater, or food crop (tomatoes; Stofella, 2002).

Director's Assessment: The three 2005 (05) projects, with the addition of the Dick and Stofella projects from 1999, can be summarized together because of overlapping objectives. The work by Pier, and by the 1999 FGD project, taken in the broader context, provide some of the background necessary for the marketing aspects of the Dick and Buggeln studies. The latter efforts were attempts, regional in the case of Buggeln and national in Dick's efforts, to introduce farmers to the concepts of using flue gas desulfurization gypsum as an agricultural amendment. There are perceptions that must be overcome, and the potential for the uptake of hazardous elements is certainly one of the more serious issues. Pier addressed that issue and demonstrated that for most crops, this is not a serious problem. Stofella's work on the combination of urban yard waste and fly ash as a soil amendment is somewhat different from the other projects, but does share the agricultural application.

In light of the budget constraints in the final years of the CBRC program, Dick's national network was able to advance further than the other projects. He did gather support of utilities and government agencies and was able to hold workshops to promote the concepts. Since FGD gypsum promises to be an abundant byproduct due to utilities having to implement additional $\mathrm{SO}_{2}$ controls under the Environmental Protection Agency's Clean Air Interstate Rule, and the traditional wallboard markets are close to saturation, the efficient use of this byproduct is vital if DOE targets for CCB utilization are going to be approached or exceeded. With environmental and competing-use pressures on the U.S. and global agricultural production, any progress in enhancing crop yield without negative environmental impacts should be welcome.

\section{Automotive Foundry Molds}

02-CBRC-E10: Commercialization of Production Foundry Molds Made from CCBs for High Volume Automotive Applications Principal Investigator: Robert Purgert, Energy Industries of Ohio 
A potential widespread application for CCBs has been established as a replacement for foundry sand in mold/core production in the metal casting process with a secondary benefit of replacing high silica sand suspected of causing silicosis in foundry workers. An earlier CBRC effort provided a proof of concept for using CCBs as a foundry sand and also outlined the need to optimize ash material and binder systems needed for ultimate testing in an actual production environment. In this study, it was determined that certain fly ash materials can replace sand currently used for making cores when the following are addressed: 1) Permissible maximum levels of calcium and unburned carbon in the ash (low levels of both calcium and unburned carbon have been determined to be very suitable); 2) small particle size fly ash can be used with current core production processes if the "venting" is altered or ash and sand mixtures are appropriate to avoid expensive changes to either the process or to equipment; and 3) that the binder system meets the processing requirements insuring ease of removal after casting (Purgert 2005).

\section{0-CBRC-E42: The Use of Fly Ash as an Aggregate for Foundry Sand Mold and Core Production Principal Investigator: J. Sobczak, Energy Industries of Ohio}

With the exception of die casting, the foundry industry in the U.S. uses sand molds and cores in nearly every casting process. About 100 million tons of sand are used each year in these operations. About 8-10 million cubic yards of the sand used is disposed of in landfills every year at a cost of \$100-\$250 million. This project characterized and manipulated fly and bottom ash materials and evaluated their use as replacements for foundry sand in mold and core production. It was determined that fly ash could serve as a replacement for the sand used in foundry molds and was justified as follows: 1) using fly ash eliminates a portion of material desposed of in landfills; 2) using fly ash rather than extremely fine sands could reduce or eliminate the crystalline silica exposure associated with fine sand; 3) ash has a much lower bulk density than sands which would result in lighter molds making them easier for foundry workers to handle and may reduce associated injuries; and 4) the low density of ash should provide a higher insulating value than sand making it possible to pour thinner sections without encountering freeze-off during the pouring process, especially in light metal castings (Sobczak, 2002).

Director's Assessment: While this might be considered to be a niche application, it serves as a good example of a creative application of CCBs. In this case, the CCBs can serve as a substitute for the sand usually used in foundry molds. The investigators determined that not all fly ashes can be successfully used. The shift towards production of class $\mathrm{C}$ fly ash at one plant yielded fly ash that was less suitable than the class F fly ash originally tested. Overall, though, the results were promising.

\section{$\underline{\text { Transportation }}$}

01-CBRC-E10: Full-Scale Testing of CCP Pavement Sections Subjected to Repeated Wheel Loads

Principal Investigator: Tarunjit Butalia, Ohio State University 
The objective of this project was to demonstrate the performance of CCB modified pavement in order for highway planners to have the data necessary to be able to make informed decisions concerning the use of CCBs in highway construction. This project evaluated the use of CCBs in terms of pavement response and performance under accelerated loading. A laboratory test program was conducted on small scale samples to investigate chemical, physical, and engineering properties of CCB materials. This was followed by six full-scale pavement sections constructed using standard construction equipment. These full-scale sections were designed according to Ohio Department of Transportation specifications.

The laboratory program indicated both fly ash and bottom ash are suitable for use in place of natural ingredients for constructing pavement materials. The full-scale pavement sections with CCBs resulted in similar or even better performance and response to load applications than control sections. Leaching test results showed no significant differences in leaching of trace elements from CCBs than control concrete mixes. No leachate concentrations exceeded the National Primary Drinking Water standards or the Ohio EPA's non-toxic criteria. Surface water runoff and groundwater samples showed concentrations of trace elements generally did not exceed either National or Ohio standards (Butalia, 2006).

Director's Assessment: The CBRC funding component in this project was small compared to other government and industry contributions. In general, this is an outstanding example of largescale utilization.

\section{$\underline{\mathrm{CO}}_{2}$ Capture}

\section{1-CBRC-E09: Development of Fly Ash Derived Sorbents to Capture $\mathrm{CO}_{2}$ From Flue Gas of Power Plants \\ Principal Investigator: Mercedes Maroto-Valer, Pennsylvania State University}

This project focused on developing fly ash derived sorbents to capture $\mathrm{CO}_{2}$ from coal burning power plant flue gas emissions. The fly ash derived sorbents that were developed represent a cost-effective alternative to existing methods that tend to be expensive and hinder the viability of $\mathrm{CO}_{2}$ sorption processes due to cost constraints.

Ten fly ash samples were collected from different combustors with different feedstocks, including bituminous coal, PRB coal and biomass. These samples presented a wide range of LOI value from $0.66-84.0 \%$, and different burn-off profiles. The samples also spanned a wide range of total specific surface area and pore volume. These variations reflected the difference in the feedstock, types of combustors, collection hopper, and the beneficiation technologies the different fly ashes underwent.

The fly ash samples were activated by steam. Nitrogen adsorption isotherms were used to characterize the resultant activated samples. The cost-saving one-step activation process applied was successfully used to increase the surface area and pore volume of all the fly ash samples. The activated samples presented very different surface areas and pore volumes due to the range in physical and chemical properties of their precursors. Furthermore, one activated fly ash sample was loaded with amine-containing chemicals (MEA, DEA, AMP, and MDEA). The 
impregnation significantly decreased the surface area and pore volume of the parent activated fly ash sample.

One sample and its de-ashed counterpart before and after impregnation of chemical PEI were used for the $\mathrm{CO}_{2}$ adsorption at different temperatures. The sample exhibited a $\mathrm{CO}_{2}$ adsorption capacity of $17.5 \mathrm{mg} / \mathrm{g}$ at 30 degrees $\mathrm{C}$, and decreased to $10.25 \mathrm{mg} / \mathrm{g}$ at 75 degrees $\mathrm{C}$, while those for de-ashed counterpart were $43.5 \mathrm{mg} / \mathrm{g}$ and $22.0 \mathrm{mg} / \mathrm{g}$ at 30 degrees $\mathrm{C}$ and 75 degrees $\mathrm{C}$, respectively. After loading PEI, the $\mathrm{CO}_{2}$ adsorption capacity increased to $93.6 \mathrm{mg} / \mathrm{g}$ at 75 degrees $C$ for the de-ashed sample and $62.1 \mathrm{mg} / \mathrm{g}$ at 75 degrees $\mathrm{C}$ for the raw fly ash sample.

The activated fly ash and its chemical loaded counterparts were tested for $\mathrm{CO}_{2}$ capture capacity. The activated carbon exhibited a $\mathrm{CO}_{2}$ adsorption capacity of $40.3 \mathrm{mg} / \mathrm{g}$ at 30 degrees $\mathrm{C}$ that decreased to $18.5 \mathrm{mg} / \mathrm{g}$ at 70 degrees $\mathrm{C}$ and $7.7 \mathrm{mg} / \mathrm{g}$ at 120 degrees $\mathrm{C}$. The $\mathrm{CO}_{2}$ adsorption capacity profiles changed significantly after impregnation. For the MEA loaded sample the capacity increased to $68.6 \mathrm{mg} / \mathrm{g}$ at 30 degrees $\mathrm{C}$. The loading of MDEA and DEA initially decreased the $\mathrm{CO}_{2}$ adsorption capacity at 30 degrees $\mathrm{C}$ compared to the parent sample but increased to 40.6 and $37.1 \mathrm{mg} / \mathrm{g}$, respectively, when the temperature increased to 70 degrees $\mathrm{C}$. The loading of AMP decreased the $\mathrm{CO}_{2}$ adsorption capacity compared to the parent sample under all the studied temperatures.

The $\mathrm{CO}_{2}$ adsorption capacities of selected activated fly ash carbons were compared to commercial activated carbons. The $\mathrm{CO}_{2}$ adsorption capacity of fly ash derived activated carbon and its chemical loaded counterpart presented $\mathrm{CO}_{2}$ capture capacities close to $7 \mathrm{wt} \%$, which are comparable to, and even better than, the published values of 3-4\% (Maroto-Valer, 2004).

Director's Assessment: This project examined the potential for the use of steam-activated and steam-activated/amine-impregnated fly ash carbons for the capture of flue gas $\mathrm{CO}_{2}$. The investigators found that certain of the prepared carbons could be employed to capture flue gas $\mathrm{CO}_{2}$ at much the same efficiency as more expensive commercial activated carbons. The application of this technology is uncertain because methods for the capture of flue gas $\mathrm{CO}_{2}$ are still in development. Note: There is a discrepancy both within the text and between the text and tables concerning the nature of sample FAS-9.

\section{Mine Placement of CCBs}

\section{9-EC-E15: Water-Quality Monitoring at an Abandoned Mine Site Reclaimed with Pressurized Fluidized Bed Combustion Byproducts Principal Investigator: Ralph J. Haefner, U.S. Geological Survey}

An abandoned coal mine in eastern Ohio was reclaimed with 125 tons per acre of pressurized fluidized bed combustion (PFBC) byproduct. Water quality at the site (known as the Fleming site) was monitored for 7 years after reclamation; samples included water from soil-suction lysimeters (interstitial water), wells, and spring sites established downgradient of the application area. Data was collected at the Fleming site during the period September 1994 through June 2001. Additionally, geochemical modeling was performed to evaluate the potential fate of elements derived from the PFBC byproduct. Chemical analyses of samples of interstitial waters 
within the PFBC byproduct application area indicated elevated levels of $\mathrm{pH}$ and specific conductance and elevated concentrations of boron, calcium, chloride, fluoride, magnesium, potassium, strontium, and sulfate compared to water samples collected in a control area where traditional reclamation methods were used. Magnesium-to-calcium ( $\mathrm{Mg}: \mathrm{Ca})$ mole ratios and sulfur-isotope ratios were used to trace the PFBC byproduct leachate and showed that little, if any, leachate reached groundwater. Concentrations of most constituents in interstitial waters in the application area decreased during the seven sampling rounds and approached background concentrations observed in the control area; however, median $\mathrm{pH}$ in the application area remained above 6 , indicating that some acid-neutralizing capacity was still present. Although notable changes in water quality were observed in interstitial waters during the study period, quality of groundwater and spring water remained poor. Water from the Fleming site was not potable, given exceedances of primary and secondary Maximum Contaminant Levels (MCLs) for inorganic constituents in drinking water set by the U.S. Environmental Protection Agency. Only fluoride and sulfate, which were found in higher concentrations in application-area interstitial waters than in control area interstitial waters, could be related to the PFBC byproduct. Concentrations of arsenic, lead, and selenium typically were below the detection limits (generally 1 or $2 \mathrm{~g} / \mathrm{L}$ ). Elements detected at elevated concentrations in PFBC byproduct application area interstitial waters were not evident in downgradient groundwater or spring water. Dilution of leachate by groundwater was confirmed with a mixing model generated by the computer code NETPATH. Additionally, thermodynamic modeling of the chemical composition of water samples by use of the computer code PHREEQC indicated favorable conditions for precipitation of secondary minerals in the unsaturated zone and in aquifer materials. Because of low application rates of the PFBC byproduct and precipitation and sorption of elements in the unsaturated zone, it is improbable that concentrations of any toxic elements of concern (arsenic, lead, or selenium) will exceed drinking water standards at this site or other sites where similar volumes of PFBC byproducts are used (Haefner, 2002).

\section{9-EC-E17: Hydrogeologic Evaluation of Strata Above the North Lobe of the Omega Mine Principal Investigator: Dave Broschart, West Virginia Department of Environmental Protection}

The Omega Mine was a post-1977 deep mind bond forfeiture site. The WV Department of Environmental Protection Abandoned Mine Lands (AML) section took over administration of the design and construction contract. This was due to the AML section's expertise with subsurface grouting projects and the State's disproportionate financial interest in the project. GAI Consultants, Inc. (GAI) was selected as the project designer.

The objectives of the project were to develop a suitable mix of coal combustion byproducts available from two of the project sponsors, Allegheny Energy and Anker, to reduce acid mine drainage (AMD) and prevent subsidence by filling the north lobe of the Omega Mine. The Omega Mine Injection Program had four goals: 1) To fill the voids in the north lobe of the Omega Mine to reduce contact of water and air with acid forming material with a secondary requirement that the grout have some alkaline leaching potential to help treat AMD; 2) a grout mix which would set to sufficient strength to prevent mine subsidence; 3 ) use of a mixture of fly ash and FBC materials to demonstrate the synergistic attributes of the combined materials; and 4) a grout mix that would flow without separation and develop reasonable strength and dimensional 
stability. These goals were met with the exception that the grout have some alkaline leaching to buffer the AMD.

For the grout mix design, an extensive laboratory testing program was conducted to evaluate both fly ash and FBC ash or mixtures of the two for injection into an abandoned deep mine to reduce AMD. The test program indicated that a blend of the two candidate materials provided an acceptable grout mix. The FBC ash had the potential to provide strength to the grout while the fly ash enhanced the fluidity of the grout. The addition of two percent cement provided dimensional stability to the hardened grout. It was recommended that a grout blend of $49 \% \mathrm{FBC}$ ash and $49 \%$ fly ash plus $2 \%$ cement with enough water added to produce a grout having a flow cone value of 60 seconds be used. This mix demonstrated the synergistic attributes of combined fly ash and FBC ash, would flow long distances without separation and develop reasonable strength and dimensional stability. These characteristics provided confidence that the almost $47,185 \mathrm{~cm}(61,716 \mathrm{cy})$ of CCB grout injected would fill 10.4 ha (26 acres) of the mine and encapsulate acid forming materials. The total cost for drilling and injecting the grout was $\$ 1,946,592$ or $\$ 24.60$ per cy. The cost of using CCB grout for mine filling is competitive with typical mine grouting using a fly ash-cement grout, if suitable materials are available within a reasonable haul distance from the mine. Four core borings drilled approximately one year after grouting showed good roof contact by the CCB grout. Testing of four grout core samples recovered from the mine a minimum of 9-10 months after injection showed a permeability range of $6.2 \times 10^{-7}$ to $8.9 \times 10^{-8} \mathrm{~cm} / \mathrm{sec}$. The hardened grout is relatively impervious and with its dimensional stability should encapsulate acid forming materials and greatly reduce future formation of AMD. Also, the strength, ability to fill the mine and dimensional stability exhibited by the FBC-fly ash grout indicate it is an excellent material for subsidence control (Broschart, 2001).

\section{9-EC-E24: Use of Clean Coal Technology Products in the Construction of Low Permeability Liners Principal Investigator: William Wolfe, Ohio State University}

The objective of this research was to establish long-term field-verified time-dependent relationships for the performance of liners constructed from stabilized FGD byproducts generated in Ohio. The project objective was accomplished with a coordinated program of testing and analyzing small-scale laboratory specimens under controlled conditions, mediumscale wetland experiments, and monitoring of a full-scale FGD-lined pond facility. It was shown that lime and fly ash enriched stabilized FGD materials can be compacted in the laboratory using standard soil testing procedures to obtain long-term permeability coefficients that are in the $10_{-8}$ to $10-9 \mathrm{~cm} / \mathrm{sec}$ range, which is lower than the $1 \times 10-7 \mathrm{~cm} / \mathrm{sec}$ value typically recommended by USEPA for constructing liners for waste containment facilities.

Researchers concluded that long-term actual permeability coefficients in the range of $10-7 \mathrm{~cm} / \mathrm{sec}$ $(3 \times 10-9 \mathrm{ft} / \mathrm{sec})$ can be obtained in the field by compacting lime and fly ash enriched stabilized FGD materials. Leachate from the FGD material met Ohio's non-toxic criteria for coal combustion byproducts, and for most potential contaminants the national primary and secondary drinking water standards were also met. The low permeability non-toxic FGD material investigated in this study posed very minimal risks, if any, for groundwater contamination. There 
were no significant differences in phosphorus retention between clay and FGD-lined basins during the high-phosphorus pulsing period. Plant productivity was lower in FGD-lined wetland basins than in clay-lined basins. The FGD-lined basins had a greater richness of plant species than did the clay-lined basins that had higher water levels. The clay-lined basins showed greater total plant productivity but with fewer plant species.

Although the specific uses included liners for surface impoundments, the results presented in this study are also useful in other applications, especially in the design of daily covers and liners for landfills, seepage cutoff walls and trenches, and for nutrient retention and pollution mitigation wetlands. The results obtained from this study are being incorporated into a revised draft ASTM standard guide for the use of FGD materials in the construction of liners and encapsulations (Wolfe et al., 2005).

\section{0-CBRC-E15: Siege of Acre \\ Principal Investigator: Paul Petzrick, Maryland Department of Natural Resources}

This project was a field scale experiment to determine the degree to which acid production is reduced by covering the sub-aerial mine pavement and related mine debris with a hydraulically placed grout compounded from mine water and locally available power plant coal combustion byproducts. The experimental site consisted of three 16-foot wide mine tunnels interconnected by several crosscuts developed in the normal manner of up dip room and pillar mining. The three tunnels extend 750 feet up hill, up dip, above the mine pool with overburden varying from 175 feet near the edge of the mine pool to 140 feet near the high wall. Project tasks included: 1) Drilling to locate the lower end of the tunnels and to establish water quality monitoring of water flowing on the mine floor; 2) drilling to locate the upper end of the tunnels to fully establish the mine geometry for the experimental site; and 3) initial design of the grout suitable for covering the exposed mine pavement and most of the debris normally left in such mines.

Drilling and down-hole camera observations at the upper end of the tunnels helped verify the exact orientation and geometry of the tunnels proposed at the experimental site. A grout recipe was selected to provide grout that will spread and flow long distances through the debris on the mine floor where slopes vary from 15-18\%. In July 2002 drilling was resumed at the lower end of the tunnels to obtain cores from the pavement in the two side tunnels and to drill through a previously installed well point. The removal of cores from the side tunnels left behind the desired sumps to allow for efficient water quality monitoring. While drilling through the well point in the center tunnel it dropped an additional 2.5 feet into a previously constructed sump and became positioned to monitor any mine water flowing near the center of that tunnel. The completion of these three project tasks provided an excellent basis for continuing pre-grout monitoring and subsequent grout injection and post-injection monitoring (Petzrick, et al., 2002).

\section{0-CBRC-E37: Effects of Large-scale CCB Applications on Groundwater: Case Studies Principal Investigator: Louis McDonald, West Virginia University}

Project objectives were to: 1) identify cases where CCBs had been placed in mine environments;

2) summarize their effects on subsequent water quality, and 3) use the Mine Water Leaching Procedure (MWLP) to characterize metal release from specific CCB-AMD combinations. Three 
sources of CCBs (FBC, FGD and Class F fly ash) and six sources of AMD were used. All were collected in northern West Virginia.

Although most authors considered their use of CCBs in mine environments a success, only one long-term study could be found, and in no study was water quality followed to CCB alkalinity exhaustion. Also, some elements known to be of concern during the initial phases of CCB dissolution (B, Mo, Se, As) and others identified in this study ( $\mathrm{Sb}, \mathrm{Cr}, \mathrm{Pb}, \mathrm{T}, \mathrm{Be}, \mathrm{Cd}$ ) were not measured in some studies.

Results indicate that, as expected, at alkalinity exhaustion CCBs can release metals to solution. This suggests that careful planning and monitoring are necessary to prevent alkalinity exhaustion. When leachates were very alkaline (in contact with distilled deionized water), elements such as $\mathrm{B}, \mathrm{Mn}, \mathrm{Zn}$ and $\mathrm{Pb}$ were present in leachates, sometimes in excess of drinking water standards. Further study of the geochemical controls on metal availability when CCBs are in contact with circum-neutral water is needed. It is suggested that CCBs not be placed in close proximity to primary drinking water supplies without first characterizing the geologic material the leachate will come in contact with. Because metals release depends on the specific CCB AMD combination, this work suggests that $\mathrm{CCBs}$ should be tested for their potential to release metals in site specific conditions. When CCBs are to be placed in AMD, metal leaching behavior should be tested in waters comparable to what is expected at the site, rather than simple acid containing solutions. Iron concentrations in AMD appear to play a role in metal source - sink behavior. Additional study is warranted into the specific mechanisms by which metals are retained or released during the AMD leaching process. When CCBs are not likely to come into contact with AMD, characterization of metal leaching behavior, particularly for $\mathrm{B}, \mathrm{Mn}, \mathrm{Zn}$ and $\mathrm{Pb}$ is still indicated. Given the relationship between CCB source and metals leaching, leaching characterization should be repeated whenever the CCB source changes (McDonald and Simmons, 2004).

\section{2-CBRC-E06: Prediction of the Effects of Placing CCBs in Contact with Mine Spoil Principal Investigator: Rick Herd, West Virginia University}

Studies of the Mine Water Leaching Procedure (MWLP) using acidic mine water and a coal combustion byproduct determined that many metals are controlled in solution by solubility, or solubility-like processes. Gypsum and barite were found to be supersaturated in the extracting solutions. The results of an extraction do not depend, within limits, on the volume of extractant, although the total mass extracted is a function of the volume.

Addition of mine spoil, as exemplified by sandstone or shale, did not substantially change the extraction behavior of the constituents. The solution $\mathrm{pH}$ of the first extraction was lower in the presence of mine spoil. Certain constituents were leached to a greater degree in the first cycle in the presence of spoil, but the total amount extracted (mass) over multiple cycles were usually the same.

Studies of the reproducibility of the method indicate that improvement in standardizing the method is needed (Ziemkiewicz et al., 2006). 
Director's Assessment: In the Herd study, the leachability of elements from mine spoil and CCBs was evaluated. Improved testing methods, the Mine Water Leaching Procedure, is considered to be a significant improvement over simpler leaching protocols, thus better able to address the concerns of the National Academy of Sciences panel convened to evaluate procedures for the evaluation of environmental risks in mine waste storage.

In general, this group of investigations all address various aspects of mine placement of CCBs for the control of acid mine drainage. While certain findings translate to many situations, the geology of each site will dictate variables to be considered. For example, the dipping strata at the Siege of Acre site in western Maryland adds a complication not found at some other Allegheny Plateau mine sites. Each application may consume a large amount of CCBs, but the rate of utilization will not be constant, dependent instead on the availability of funding for individual reclamation projects.

\section{Large-Volume CCB Utilization}

\section{0-CBRC-E41: Environmental Effects of Large-Volume FGD Fill Principal Investigator: Phillip E. Glogowski, GAI Consultants}

For this project, a large-volume of CCBs was placed at the Rostraver Airport Runway Safety Area. Much of the information obtained during pre-, active-, and post-construction was to determine whether or not the large-volume beneficial use of CCBs had the potential to create an environmental impact in the area of the project. Background samples for both air quality and water quality were collected prior to the placement of Low-Permeability Cementitious (LPC) material in the fill area. Air quality samples, collected using dustfall buckets placed in close proximity to the fill area, did not exceed the Pennsylvania Department of Environmental Protection dustfall standards established prior to the beginning of the project. Water quality samples collected during the project were compared to background levels of samples collected before LPC material placement. The background monitoring data showed that exceedances of secondary drinking water standards were observed at several locations prior to construction. The water quality for springs and wells during the project remained within the established background levels. The placement of the LPC material in the fill was also monitored. Based on monitoring performed by GAI, the placement of LPC material complied with standards for compaction established prior to the start of placement activities.

A unique experiment involving honeybees was proposed and implemented during the last year of the project as an additional way to assess the impact of LPC material in the area. The components involved in the production of honey were tested to determine if the LPC material impacted their quality. The four media tested were honey, wax, pollen, and the honeybees themselves. The media were tested for metals that have been identified as the most likely to be taken up by the bees and transferred through the pollen to the bees in the hives, the honey, and the wax. The results of the testing for the fill site hives showed similar constituent levels to those tested at the background hives.

Project results demonstrate that the placement of LPC material at the project site has not had an impact to the area surrounding the Rostraver Airport site (Glogowski et al., 2004). 
Director's Assessment: This project dealt with large-volume CCB utilization in the extension of an airport runway. While such projects may vary in number and need for $\mathrm{CCBs}$, it does serve as an example of civil engineering applications as an outlet for CCBs. Such utilization can go relatively unnoticed because the transaction may be a contribution rather than a sale of the material. Nevertheless, it has the potential to be an important component in the goal to reach at least $50 \%$ utilization of CCBs.

\section{Cement and Concrete Applications}

\section{9-EC-E04: Economical Treatment of High Carbon Fly Ash to Produce a Low Foam Index Product(s) with Carbon Content Retained Principal Investigator: Robert LaCount, Waynesburg College}

The overall objective of this research effort was to develop a method that will decrease the interaction between fly ash and the surfactants used to entrain air in concrete. The amount of surfactant required to entrain a given amount of air should decrease after treatment and thus increase the quantity of fly ash suitable for use in concrete products. Researchers identified a successful thermal treatment of fly ash that decreases the amount of surfactant required to entrain a given amount of air when this fly ash is used to replace a portion of the Portland cement in concrete. All tasks in this project were successfully completed.

A total of 6 fly ash samples of differing carbon content were thermally treated using both anoxic and oxidative conditions through two temperatures $\left(500^{\circ} \mathrm{C}\right.$ and $\left.800^{\circ} \mathrm{C}\right)$. To optimize conditions a fly ash was: 1) thermally treated with various temperature-programming rates up to $500^{\circ} \mathrm{C}$;

2) thermally treated to $500^{\circ} \mathrm{C}$ using a $30^{\circ} \mathrm{C}$ min-1 temperature-programming rate followed by maintaining the temperature at $500^{\circ} \mathrm{C}$ for different time periods; and 3) treated at various temperature-programming rates followed by maintaining the sample at temperature so that the total heat time was equal to that of thermal treatment to $500^{\circ} \mathrm{C}$ using a $3^{\circ} \mathrm{C}$ min- 1 temperature program rate.

Little difference was observed among the foam index values of the thermally treated products produced by variation in the temperature-programming rate but, the foam index values for all of the thermally treated fly ash samples were significantly less than that of the untreated fly ash. Thus the parameters chosen for this study consisted of a flow rate of $100 \mathrm{~cm}^{3} \mathrm{~min}-1$ and a temperature-programming rate of 3 degrees $\mathrm{C}$ min-1 up to the treatment temperature. A batch scale thermal reactor for treatment of larger quantities of fly ash was also constructed. The reactor was designed to permit thermal treatment of $400-500 \mathrm{~g}$ of fly ash. It was used to treat 6 different fly ash samples to produce representative samples of beneficiated fly ash in quantities suitable for the preparation of concrete test samples.

The batch scale fly ash samples were used to produce concrete test samples. These concrete test samples were tested for compressibility and for air entrainment. The results were compared with those from the corresponding concrete samples prepared using the same fly ash prior to thermal treatment. There was little or no difference in strength performance as a function of the thermal beneficiation process. These tests show that the thermally treated fly ashes may be utilized to 
produce concrete with compressibility test results comparable to untreated fly ash (LaCount and Kern, 2005).

\section{9-EC-E06: Effects of Ammonia Adsorption on Fly Ash Due to Installation of SCR Technology Principal Investigator: Gary Brendel, GAI Consultants}

This project investigated potential impacts associated with the utilization of selective catalytic reduction (SCR) systems at coal-fired power plants. The investigation included: 1) an extensive review of information and data from published and unpublished sources; 2) discussions with vendors and operations of SCR/SNCR systems; 3) a laboratory investigation of ammonia release using ash samples from power plants burning central Appalachian high-volatile bituminous coals; and 4) an evaluation of potential air and water quality impacts based on computer modeling of several hypothetical scenarios.

Major findings associated with this project involve ammonia adsorption and release, thermal analysis, process implications for air preheater, CEMS, catalyst, ESP, FGD, and ash handling and use, air quality impacts, and water quality impacts.

Findings related to ammonia adsorption and release include: 1) most of the ammonia present on fly ash is highly water soluble, and is completely dissolved into solution within several hours; 2) $\mathrm{pH}$ exerts the dominant influence on ammonia speciation in solutions of fly ash and water; 3) the effect of temperature on ammonia species in solution was much less pronounced than $\mathrm{pH}$, although it did exert a strong influence on the rate of ammonia loss from solution; 4) SCR/SNCR fly ash that produces a high $\mathrm{pH}$ in aqueous solution can potentially produce ammonia odors when wetted and ammonia odors from fly ashes that produce a low $\mathrm{pH}$ solution will be negligible; and 5) $\mathrm{NH}_{4}{ }^{+}$ion is stable in fly ash/water mixtures at low $\mathrm{pH}$ and is not out-gassed; however, conversion of at least a portion of it to $\mathrm{NO}_{3}{ }^{2-}$ and $\mathrm{NO}_{2}{ }^{2-}$ is likely in the natural environment because of the presence of nitrifying bacteria.

Regarding thermal analysis, thermogravimetric analysis-mass spectrometry (TG-MS) can be used to detect ammonia release from fly ash upon heating by monitoring the ratio of atomic mass unit (amu) 17/18. Evolution of high temperature ammonia is typically associated with amu 44 release, which probably represents $\mathrm{CO}_{2}$ evolution, suggesting that the ammonia may be bound by unburned carbon in the ash. When heated in an oxidizing atmosphere, high temperature ammonia appeared to be susceptible to $\mathrm{NO}_{\mathrm{x}}$ conversion, usually in association with amu 44 release, suggesting a possible catalytic role of the carbon in the ammonia-to- $\mathrm{NO}_{\mathrm{x}}$ conversion.

Air preheater process implications showed early SCR installations experienced significant air preheater plugging and corrosion resulting from formation and deposition of ammonium bisulfate. These problems can be resolved by proper system configuration and by limiting ammonia slip to less than $2 \mathrm{ppm}$, although some industry experts advocate even lower levels. CEMS process implications were that operators at several U.S. installations have had difficulty in maintaining CEMS at the operating conditions before the SCR (hot, dirty, etc.). Stack $\mathrm{NO}_{\mathrm{x}}$ measurements used to determine ammonia injection levels are not an effective means to optimize performance. Catalyst process implications showed catalyst deactivation can result from arsenic 
poisoning, ammonia salt deposition, alkaline metal poisoning, calcium sulfate masking, and fly ash plugging. Catalyst masking by calcium sulfate has become a major issue with Powder River Basin coal due to the concentration and form of calcium it contains. Limestone addition has been used to limit arsenic poisoning for coal burning facilities with low available calcium. Units with high carbon fly ash may have a potential for fire as the unit is brought down from normal operation. Electrostatic precipitator (ESP), FGD process implications were that the addition of SCR has had minimal impact on ESP performance at operating systems. Operators of FGD systems do not currently experience odor problems, although this can become a concern if the pH rises above approximately 9 and ammonia slip levels are elevated. In ash handling and use process implications, well-designed SCR installations have efficient ammonia distribution and $\mathrm{NO}_{\mathrm{x}}$ removal systems. This results in low ammonia slip (0-2 ppmv) and yields a corresponding ammonia on ash concentration at the lower range of those studied $(\sim 50-100 \mathrm{ppm})$. Operators of new SCR systems have not had to change ash handling systems. Odor has not become a problem at landfills or impoundments. Fly ash uses involving the addition of alkaline material, such as concrete, have been impacted by ammonia odors. Although ammonia does not affect the performance of concrete, the aversion to ammonia odor can limit ash sales.

Air quality impacts included stack releases of ammonia with expected minimal impact. Ammonia release to the air from ash ponds, landfills and storage piles appears to be driven almost solely by the $\mathrm{pH}$ of the aqueous solution. In general, no odors or significant releases occur at $\mathrm{pH}$ 7-8 or lower.

Water quality impacts show moisture to be the controlling factor in the rate and amount of ammonia that will desorb from fly ash. In cases where the ash is placed in ponds most or all of the ammonia will desorb into the pond water. Leachate and/or runoff at ash landfills will contain increased concentrations of ammonia. If and when these salts are contacted with water, they will most likely be dissolved and the resulting aqueous concentration of nitrogen-containing compounds will increase in the waters associated with the ash.

A mass balance model applied to three eastern power plants burning central Appalachian highvolatile coal and producing a relatively low-pH ash determined the following: 1) the predicted increase in ammonia as $\mathrm{N}$ concentrations in surface water due to installation of SCR systems may be of concern depending on site specific factors such as the assimilative capacity of receiving surface waters and regulatory permitting procedures; 2) the predicted increase in ammonia as $\mathrm{N}$ and nitrate as $\mathrm{N}$ concentrations in landfill leachate and surface water runoff will translate to increased concentrations and increased loading of nitrogen-containing compounds at treatment ponds; and 3) predicted concentrations of nitrate as $\mathrm{N}$ in groundwater, which is hydraulically connected with disposal sites that will receive ash from SCR units, may exceed the current USEPA drinking water standard of $10 \mathrm{mg} / \mathrm{L}$ whenever the ammonia concentration on the ash approaches $200 \mathrm{mg} / \mathrm{kg}$ (Brendel, et al, 2000).

\section{9-EC-E13: Odor and HAP Control in Waste Treatment Processes Using Coal Combustion Ash Principal Investigator: K.C. Das, University of Georgia}


The overall goal of the work performed in this project was to evaluate the use of coal ash for the reduction of dimenthyl disulfide (DMDS) and dimenthyl sulfide (DMS) emissions from aerobic biodegradation. Controlled incubation studies $\left(120 \mathrm{~h}\right.$ at $\left.37^{\circ} \mathrm{C}\right)$ using a mixture of $32 \%$ biosolids and $68 \%$ wood shavings (dry basis) amended with ash (biosolids blend:ash = 1:0.3) were conducted to evaluate the influence of ash on odor emissions and biological activity of the mix. Three coal fly ashes (high carbon, medium carbon, and low carbon), wood ash, and activated carbon were evaluated against a no-ash control. Results showed that peak emission rates of DMDS and DMS in the no-ash control were 41.9 and $1.89 \mu \mathrm{g} / \mathrm{kg} / \mathrm{min}$, respectively, while 120-h cumulative emissions were 189.95 and $11.39 \mathrm{mg} / \mathrm{kg}$, respectively. Amendments reduced DMDS emission rate in all treatments and percent reduction were highest in activated carbon and wood fly ash representing percent reductions of 90 and 63\%, respectively. For the three coal fly ashes, percent reduction ranged from 18 to $24 \%$.

Alternatively, researchers theorized that coal fly ash given its high metal content and the presence of carbon could act as an inexpensive catalytic oxidizer of reduced sulfur compounds for "odor" removal. Initial results indicate that coal fly ash can catalyze the oxidization of $\mathrm{H}_{2} \mathrm{~S}$ and ethanethiol, but not dimethyl sulfide and dimethyl disulfide at room temperature. In batch reactor systems, initial concentrations of $100-500 \mathrm{ppmv}_{2} \mathrm{~S}$ or ethanethiol were reduced to $0-2$ ppmv within 1-2 min and 6-8 min, respectively. This was contrary to control systems without ash in which concentrations remained constant (Das and Kastner, 2002).

\section{9-EC-E16: Ammonia Removal from Fly Ash in a Bubbling Fluidized Bed Principal Investigator: Robert Levy, Lehigh University}

Project researchers developed a process to remove ammonia from dry fly ash. Laboratory experiments on three different fly ashes showed ammonia can be removed from the ash by heating it in a bubbling fluidized bed with the assistance of acoustics to promote active bubbling. The bed in the experiments was a laboratory-scale batch bed. The results of the experiments showed that typically $90-95 \%$ ammonium removal was achieved with ash temperatures in the range of 700-750 degrees $\mathrm{F}$. The ammonium compounds in the ash decomposed to release gasphase ammonia which was carried from bed with the fluidizing air. Design calculations were also performed on a continuously operating system for commercial-scale applications.

Design calculations were performed on an inclined fluidized bed for steady continuous operation. In this design, dry ash was fed to the bed at one end and was heated as the ash flowed along the surface of the distributor. Ammonia-free ash was removed at the far end of the bed. Design calculations were performed for a system processing 25 tons of ash per hour. It was assumed the ash was heated using electrical resistance heaters immersed in the bed. At $\$ 0.04 / \mathrm{kWh}$ for electricity, the energy costs for ash heating ranged from $\$ 2.14$ to $\$ 3.05 /$ ton, depending on inlet temperature.

These results demonstrate the potential for using a heated fluidized bed to remove ammonia from fly ash. Researchers plan to build a small laboratory scale facility for demonstrating continuous processing of the ash in an inclined fluidized bed (Levy, 2001).

00-CBRC-E24: Laboratory and Field Demonstrations of the Control of Ettringite Swelling 


\section{Principal Investigator: Barry Scheetz, Pennsylvania State University}

The overall objective of this project was to develop the fundamental thermodynamic understanding for the stability of ettringite in "real world" ash systems and to demonstrate that, in practice, the sometimes deleterious swelling associated with the formation of ettringite can be controlled.

The preliminary work that led up to this project was, in part, prorogated on an understanding that the introduction of alkali to a FBC grout would raise the $\mathrm{pH}$ of the pore fluids to a level above which ettringite would not be thermodynamically stable. Findings support the observations that the solubility of gypsum, a principal component of ash, is suppressed in terms of the calcium concentration but the concentrations of sulfate in solution approached 1050 mmolar. Both alkalis, sodium and potassium, were present in the pore fluids at 2000 and 195 mmolar, respectively. What was observed in the analyses of the fluids was that the $\mathrm{pH}$ gradually approached the limit of $\mathrm{pH}$ of pore fluids which should exceed 12.5 stability limits for ettringite.

Scanning electron microscopy (SEM) characterization of the ash composites confirmed the x-ray diffraction and differential scanning calorimetry studies that indicated the presence of ettringite. The SEM data however revealed that what ettringite formed did so as a low density form with many of the individual needles growing into the void space without gaining purchase on the main structure of the composite. Although SEM and XRD conclusively showed the existence of ettringite, measured expansion data for the test specimens showed either zero or negative expansion throughout the test interval of six months. This behavior points to the formation of a low density ettringite that does not exert enough expansive force to cause any deleterious effects on FBC ash grouts. The data also suggested a pessimum in the concentration of alkali responsible for the retardation of expansion. This type of behavior is not uncommon in Portland cement chemistry but was not anticipated for this chemical system.

A field demonstration pad was placed at the Pennsylvania State University's Agriculture Progress fields using as-received FBC ash. The performance of this pad was, as expected, very poor. The formation of ettringite was evident resulting in cracking and spalling of the pad.

The technological approach to minimizing the swelling of consolidated FBC ash as a result of ettringite formation appears to have been successful. There are, however, several economic issues that result from the attempt to implement the technology. Work to date has shown that swelling can be eliminated by the addition of sodium hydroxide to the mix water for making a fly ash grout from FBC ashes. In field applications, the form in which the sodium hydroxide is purchased will have a strong influence on how readily the solid dissolves. This research effort found that the addition of $2 \%$ to $5 \%$ by mass of a "flake" form was adequate in controlling the expansion.

Director's Assessment: All of these projects relate to various cement and concrete applications. Traditionally, this industry has been a large consumer of CCBs, particularly fly ash. High fly ash carbon is detrimental to utilization. LaCount addressed that problem by means of a scheme for fly ash beneficiation, effectively lowering the carbon content to an acceptable level. Ammonia levels in fly ash passing through selective catalytic reduction (NOx control) systems are both an 
aesthetic and potential health concern. Both the Brendel and Levy projects addressed aspects of this problem. Overall, this industry represents a high volume user of CCBs and any research addressed at ammonia, swelling, or other problems has the potential to be beneficial in preserving the $\mathrm{CCB}$ market share.

\section{Midwestern Region}

Director: Y. Paul Chugh, Southern Illinois University-Carbondale

\section{Technology and Product Development Projects}

99-EC-M01: Development of Structural Materials from Sulfate-Rich FGD Scrubber Sludge

Principal Investigator: Vivak Malhotra, Southern Illinois University, Carbondale

The main goal of this project was to develop technology which converts flue gas desulfurization (FGD) sulfate-rich scrubber sludge into value-added decorative materials. Specifically, researchers were able to establish technology for fabricating cost-effective marketable materials such as countertops and decorative tiles from the sludge. In addition, researchers explored the feasibility of forming siding material from the sludge. At the end of the project 64 countertop pieces and 64 tiles of various colors were generated.

In pursuit of this goal, researchers conducted Fourier transform infrared (FTIR) and differential scanning calorimetry (DSC) measurements of the binders and co-processed binders to identify curing behavior. Using 6"x6" and 4" $\mathrm{x} 4$ " high pressure and high temperature hardened stainless steel dies, procedures were developed to fabricate countertop and decorative tile materials. The composites, fabricated from sulfate-rich scrubber sludge, were subjected to mechanical tests using a three-point bending machine and a dynamic mechanical analyzer (DMA). Comparisons were made between the materials' mechanical performance and commercially obtained countertops.

Researchers successfully established the procedures for developing countertop and tile composites from scrubber sludge by mounting materials on commercial boards. More than 64 pieces of countertop material were fabricated in at least 11 different colors having different patterns. In addition, more than 100 tiles in six different colors were fabricated. Procedures were developed by which the fabrication waste, up to 30 weight $\%$, could be recycled in the manufacturing of countertops and decorative tiles. Experimental results indicated that the fabricated countertops had mechanical strength which was comparable to high-end commercial countertop materials and contained substantially larger inorganic content than the commercial products. Moisture sensitivity tests suggested that the fabricated materials were not adversely impacted by water and did not disintegrate on submerging the product in water for at least two months. Countertop polishing techniques were also established (Malhotra and Chugh, 2004).

Director's Assessment: The technology was sound and products developed were fascinating to the power plant professionals. However, industry cooperation and involvement of an entity interested in commercialization were minimal. Funding should be explored for product development studies. After the initial investment, funding should be based on active involvement of industrial cooperators who understand the market and commercialization. 


\section{9-EC-M06: Development and Demonstration of High Carbon CCPs and FGD Byproducts in Permeable Roadway Base Construction Principal Investigator: Tarun Naik, University of Wisconsin}

This investigation was conducted to develop and demonstrate permeable base course materials using coal combustion products (CCPs) for highways, roadways, and airfield pavements. Three types of CCPs (two high-carbon, high-sulfate flue-gas desulfurization (FGD) by-products and a variable-carbon fly ash) were evaluated for no-fines or low-fines concrete as a permeable base material.

A total of 56 mixtures were proportioned and manufactured in the laboratory in this research. Mixture proportions for the base course materials were developed using a two-step experimental optimization process. The first step involved developing mixture proportions for permeable base course materials containing no CCPs. A total of 26 mixtures were produced in the first step. The optimum mixtures developed from the first step of the experimental process were used as candidate mixture proportions for the second step of the optimization process. The second step of the mixture optimization included various combinations of the three CCPs for developing mixtures for base course materials. Specimens from each mixture were made using rollercompacted concrete (RCC) technology in accordance with ASTM C 1435. Three different series of ten base course mixtures were developed and tested based on the structure of the base course: dense-graded, intermediate-graded, and open-graded. Each mixture was evaluated for both strength and durability properties. The strength properties that were evaluated consisted of compressive strength (ASTM C 39), flexural strength (ASTM C 78), and splitting tensile strength (ASTM C 496). Durability properties consisted of drying shrinkage (ASTM C 157), resistance to sulfate exposure (modified ASTM C 1012), and resistance to rapid freezing and thawing (modified ASTM C 666). Based on the mixture proportions established in the laboratory, four prototype open graded base course mixtures containing one source of CCP were manufactured at a commercial ready-mixed concrete plant.

A full-scale base course mixture was produced for a construction demonstration, which was held in conjunction with a technology transfer educational workshop conducted in Green Bay, Wisconsin. The base course mixture was open-graded to maximize drainage capability. The base course mixture was made by replacing approximately $50 \%$ of the cement with one of the sources of CCP evaluated for this project. Adequate compressive and flexural strength were achieved from the mixture used for the demonstration (Naik and Kraus, 2002).

Director's Assessment: This was a successful cooperative research and demonstration project with most stakeholders involved in the project.

\section{9-EC-M07: Industry-Government-University Cooperative Research Program for Development of CCP-Based Transmission Poles Principal Investigator: Y. Paul Chugh, Southern Illinois University-Carbondale}

The goal was to establish technical and economic feasibility to produce CCBs-based composite utility poles to replace wooden poles. Industrial cooperation was provided by Ashland 
Chemicals, Inc. (polymer expertise) and Trinity Industries (pole manufacturer and marketer), Paducah, Kentucky. Major customers such as Ameren CIPS, Kentucky Utilities, Springfield City Light and Power, Detroit Edison, and Cinergy were involved.

CCBs-filled polymer composite materials suitable for engineered utility poles were developed. These materials may contain about $18 \%$ high loss on ignition (LOI), as-received FBC fly ash. For fly ash less than 75 microns, up to $30 \%$ fly ash may be used. A cylindrical fiber reinforced utility pole design with very stiff outer shell and without ultra-lightweight inner core material was proposed. Each $35 \mathrm{ft}$. pole may use about 40 to $50 \mathrm{lb}$. of CCBs based on 10\% fly ash loading level. The commercial production was demonstrated in a facility in Pennsylvania to produce 200 -feet of about 5-inch diameter and 3/16 inch wall thickness pipe containing 5\% and 10\% FBC fly ash.

Engineering performance studies were performed on the fabricated model pole, including ultraviolet degradation, water absorption, strength-deformation properties in tension, compression, and flexure, and full-size cantilever testing. Commercial production of CCBs-based utility poles is technically, environmentally, and economically feasible with an estimated payback period of about 4 years (Chugh and Ma, 2006).

Director's Assessment: Researchers had good industrial cooperation that provided financial support to the project. Trinity Industries declined investing into a pultrusion line. Upon a market review of the project, Ashland Chemicals decided not to match the capital investment with Trinity Industries.

\section{0-CBRC-M04: Crushed Aggregates from Class C Fly Ash Principal Investigator: Anil Misra, University of Missouri}

In this project, researchers evaluated class $\mathrm{C}$ fly ash aggregates produced by: 1) extruding laboratory cured mixtures of water, class $\mathrm{C}$ fly ash, fibers and sand, 2) crushing laboratory cured mixtures of water and class $\mathrm{C}$ fly ash, and 3) crushing reclaimed hydrated ponded class $\mathrm{C}$ fly ash. A variety of tests were performed to characterize the physical and engineering properties of these aggregates, including particle shape, surface texture, moisture absorption capacity, specific gravity, density, soundness, and durability. The engineering properties of these aggregates for application as pavement base course material, as backfill material and as embankment materials were evaluated by investigating their compaction behavior, and California Bearing ratio (CBR).

Based upon the results of this research, researchers found that aggregates produced by exploiting class $\mathrm{C}$ fly ash self cementing property have characteristics that are best suited for applications such as road bases, lightweight embankment fills or lightweight granular backfills behind retaining walls. Therefore, ponded class $\mathrm{C}$ fly ashes could yield a rich source of crushed aggregates that may be used for these construction applications (Misra, 2005).

Director's Assessment: The potential for commercialization of this technology is small in the Midwest since natural aggregate industries are very strong.

00-CBRC-M05: Long Term Excavatability of Flowable Fill Containing Coal Combustion Byproducts 


\section{Principal Investigator: L.K. Crouch, Tennessee Technological University}

Twenty-three different excavatability flowable fill (EFF) mixtures were placed in trenches simulating utility cuts. All EFF mixtures were tested for flow, unit weight, gravimetric air content, and suitability for load application. Nine EFF mixtures were used to assess the impact of Portland cement content and ASTM C 618 Class F fly ash content. Portland cement contents of 30, 45, and 60 pounds-per-cubic-yard and ASTM C 618 Class F fly ash contents of 300, 370, and 440 pounds-per-cubic-yard were used to evaluate the impact of component proportions. Proportions for the EFF mixtures were chosen using Kentucky Transportation Cabinet and Tennessee Ready Mixed Concrete Association (TRMCA) recommendations as well as a previous Tennessee Technological University research mixture. Six EFF mixtures were used to assess the impact of Portland cement content and high unburned carbon fly ash content. Portland cement contents of 45 and 60 pounds-per-cubic-yard and high unburned carbon fly ash contents of 370,440 , and 510 pounds-per-cubic-yard were used to evaluate the impact of component proportions. The influence of aggregate type on EFF mixtures was evaluated by using five different aggregate types in the EFF mixture recommended by TRMCA (45 pounds-per-cubicyard Portland cement and 370 pounds-per-cubic-yard ASTM C 618 Class F fly ash). In addition three comparison EFF mixtures were used in the study: 1) Tennessee Department of Transportation and 2) air-entrained EFF mixtures (Crouch and Dotson, 2002).

Director's Assessment: This project had all the stakeholders involved. However, the CBRC Steering Committee recommended that since flowable fill is a mature technology, funding for this work should be provided by industry.

\section{0-CBRC-M11: Development of CCB Fill Materials for Use as Mechanically Stabilized Marine Structures \\ Principal Investigator: Kelly Rusch, Louisiana State University}

This research project investigated the technical and economic feasibility of stabilizing waste FGD sludge for use as fill material in the construction of mechanically stabilized marine structures, including embankments, retaining walls and dikes. The development of such material addresses two important issues. First, the inventory of waste FGD sludge would be reduced via the development of a marketable product. Second, the development of lightweight briquettes that could compete economically with conventional structural fill material would provide agencies involved in coastal restoration efforts an alternative to commonly utilized limestone.

FGD sludge was stabilized using class C fly ash and Portland type II cement. Blocks of ten different composite combinations were fabricated and screened to select five ingredients for further testing. The selected stabilized FGD briquettes were subjected to dynamic leaching, specific gravity, compaction, porosity, surface hardness and field submergence tests. The dynamic leaching showed that FGD:Class $\mathrm{C}$ fly ash:Portland type II cement briquettes in ratios of 64\%:35\%:1\%, 63\%:35\%:2\%, and 69\%:30\%:1\% have low effective sulfur (sulfate and sulfite) diffusion coefficients and lower values for 30 year effective diffusion depths $(18-50 \mathrm{~mm})$. The geotechnical tests conducted (specific gravity, compaction and sieve analysis) showed that all stabilized briquettes behave similarly. The field saltwater submergence experiment showed that these three stabilized FGD briquettes can survive in the field for more than four months. The 
economic analysis showed that these briquettes can be manufactured at large-scale at the cost of under $\$ 13 /$ ton. These results imply the feasibility of using stabilized FGD briquettes as conventional structural fill material in coastal protection projects (Rusch et al. 2002).

Director's Assessment: The technology was sound and products developed were fascinating to the power plant professionals. However, industry cooperation and involvement of an entity interested in commercialization were minimal. The economics of commercialization were not seriously considered in this project. Funding should be explored for product development studies. After the initial investment, funding should be based on active involvement of industrial cooperators who understand the market and commercialization.

\section{0-CBRC-M14: High Performance Masonry Units from 100\% Fly Ash-Synergistic Approach Principal Investigator: Hwai-Chung Wu, Wayne State University}

In this project, an innovative process of recycling fly ash for making high performance masonry units was investigated, and all the relevant factors were critically examined. Because of the continuously evolving new steps involved in the development process, results are divided into two parts: Part I and Part II. In Part I, hydrothermal reaction and mechanical pressing were conducted separately. After the starting material, mixture of fly ash, water and a small amount of chemical activator filled in a mould, a pressure of $20 \mathrm{MPa}$ was applied to the samples through a MTS machine. A special fixture was devised to retain the pressure by the use of several fasteners. Then the mould was removed from the MTS and put in an oven, heated at a designated temperature for several hours, during which time hydrothermal reaction developed and solidified the samples. During the period of heating, however, the pressures on the samples dropped when the samples consolidated. Some attempts were made to restore the pressure to 20 MPa by pressing the mould again with the MTS machine and then putting it back in the oven immediately. This approach only rendered partial success. A carbonation process was employed in this phase of the study. The key controlling factors for strength development of the fly ash samples were found to be activator content, heating temperature, heating time duration and pressure. In addition, other factors such as bearing type, cooling rate, and sample age also affected the splitting tensile strength of the samples.

In Part II, hydrothermal reaction and mechanical pressing occurred at the same time by using a split tube furnace that was mounted on the MTS machine. The compacting pressure could be guaranteed. Other than process improvement, two types of short fiber were used to enhance the ductility of the samples. The following conclusions were reached: 1) Class $\mathrm{C}$ and Class $\mathrm{F}$ ash showed different properties under the identical hydrothermal hot-pressing conditions. Generally speaking, Class $\mathrm{C}$ was much more active than Class $\mathrm{F}$ leading to better performance; 2) For Class $\mathrm{C} 2$ fly ash without $\mathrm{NaOH}$ as an activator, a splitting tensile strength of about $1.1 \mathrm{MPa}$ could be developed with a processing temperature ranging from 130 degrees $\mathrm{C}$ to 350 degrees $\mathrm{C}$; 3) $\mathrm{NaOH}$ was an effective activator for Class $\mathrm{C} 2$ fly ash. When a $10 \mathrm{M} \mathrm{NaOH}$ solution was employed, a very high splitting tensile strength of $11.0 \mathrm{MPa}$ could be reached under the following hydrothermal hot-pressing conditions: 200 degrees $\mathrm{C}$ heating temperature, 5.5 hours (or less) heating duration and $20 \mathrm{MPa}$ pressure. The properties of Class C2 samples increased with increasing $\mathrm{NaOH}$ contents and heating temperatures; 4) The addition of fibers could increase the ductility of Class $\mathrm{C} 2$ and Class F samples significantly. For the two types of fiber 
(PVA and Kevlar) investigated, the former could resist $\mathrm{NaOH}$ but would decompose at a higher temperature exceeding 200 degrees $\mathrm{C}$, while the latter could not survive in a $\mathrm{NaOH}$ environment at all; 5) In terms of composite performance, workability and cost, there was an optimum fiber volume fraction and an optimum heating duration for Class $\mathrm{C} 2$ samples with a $\mathrm{NaOH}$ activator. For PVA fiber, the optimum fiber content was found to be $1.0 \%$ and the optimum heating duration 1.0 hour under the hydrothermal hot-pressing conditions of 150 degrees $\mathrm{C}$ heating temperature, $20 \mathrm{MPa}$ pressure and $10 \mathrm{M} \mathrm{NaOH}$ activator.

The fly ash samples developed from this project show extremely positive short-term performance as building materials. Other issues, however, need to be studied in the future, especially the long-term durability, microstructure and chemical analysis (Wu and Sun, 2003).

Director's Assessment: Based on discussions with a professional from EPRI, this project was good conceptually. However, industrial involvement was minimal and it was not pursued beyond the initial CBRC funded project. The principal investigator pursued other areas of research and this concept was not pursued further.

\section{2-CBRC-M12: Manufacturing Fired Bricks with Class F Fly Ash from Illinois Basin Coals Principal Investigator: Melissa Chou, Illinois State Geological Survey}

The purpose of this project was to determine if Class F fly ash produced by one of the power generation stations of the Cinergy PSI is a viable raw material for brick production at a nearby brick plant. This power generation station is located in Indiana near the Illinois border, and burns Illinois Basin coals from both Illinois and Indiana.

A technical feasibility assessment was conducted for this process, which uses fly ash as a substitute for part of the clay and shale used in making conventional bricks. Commercial-scale production demonstrations, which included extrusion and firing evaluation, have produced a total of about 4,000 commercial-size paving bricks and 8,000 commercial-size three-hole building bricks for evaluation. The paving bricks contained $20 \%$ by volume fly ash, and the building bricks contained $20 \%, 30 \%$, or $40 \%$ by volume (about $37 \%$ by weight) fly ash. These final products have met or exceeded ASTM standard specifications for pedestrian and lightweight traffic paving bricks and for building bricks of a severe weather grade. An economic evaluation indicated that it would be economically feasible for the brick plant to use fly ash as a raw material in commercial brick production. Also, the environmental feasibility study showed that, similar to the regular commercial brick, the fly ash containing bricks are environmentally safe construction products.

This project was successfully completed, and the results indicated that the fly ash tested is a viable raw material for brick production at the nearby brick plant. The amount of fly ash that can be consumed will depend on the brick plant's production rate and the amount of ash that can be successfully incorporated into the brick body. If bricks with $40 \mathrm{wt} \%$ of ash can be produced, and if a brick plant produces sixteen million bricks per year at five pounds per brick, about 14,000 tons of fly ash could be consumed by that plant each year (Chou et al, 2006). 
Director's Assessment: This was a very good project with active involvement of industrial cooperators and with high commercialization potential. Technology implementation at the brick plant has hit many road blocks in the last few years and it is unlikely that the technology will be commercialized soon in Illinois. The investigators did a very good job of developing the technology and it is likely another company in the USA or abroad may have an interest.

\section{5-CBRC-M09: Cold In-Place Recycling of Asphalt Pavements Using Self-Cementing Fly Ash: Analysis of Pavement Performance and Structure Number Principal Investigator: Anil Misra, University of Missouri}

Full-Depth Cold In-Place Recycling (CPR) with self-cementing fly ash has been shown to be an effective method of converting conglomerate pavement sections into durable roads. CPR demonstration projects have been performed in several states, where it has been shown to produce longer road life at a major savings. This technology provides several economic and environmental benefits. The process recycles deteriorated asphalt pavement and self-cementing fly ash, reduces energy consumption, diesel emissions, land disposal requirements, virgin resource utilization, and increases road longevity. In addition to providing environmental benefits and long-lasting pavements, it has been reported that this technology could result in savings of up to $33 \%$ over conventional techniques.

A demonstration of this process on approximately 2.5 miles of roadway consisting of two different segments was conducted in August 2004. As a result, model construction specifications and a pre-construction testing program were developed. In addition, the construction procedures and the monitoring methods were documented and evaluated. Subsequently, the falling weight deflectometer (FWD) tests were conducted at different locations on these roads after 1.5-years of project completion. The deflection bowls measured in the FWD tests were analyzed to back calculate the resilient moduli of the road base. These moduli were utilized to estimate the structural layer coefficient which is a measure of the relative ability of a unit thickness of a material to function as a structural component of the pavement and may be used to calculate the structure number needed for the design of layer thicknesses. The conservatively recommended layer coefficient values, which ranged from 0.18 to 0.20 , were considerably higher than the AASHTO design requirement of 0.14 for the layer coefficient of flexible pavement granular base. The high layer coefficients for recycled asphalt base (RAB) base course may allow for thinner asphalt wear surfaces, thereby reducing construction costs (Misra, 2008).

Director's Assessment: This project was a cooperative project with a small amount of funding from CBRC. Based on discussions with Kansas City Power and Light, this was a successful project and will have long-term applications in the region. Such cooperative demonstrations should be done in every state to develop confidence for commercial application throughout the USA.

\section{5-CBRC-M 16: In Situ Stabilization of Gravel Roads with CCPs Principal Investigator: Tuncer Edil, University of Wisconsin}

The focus of this project was to develop a new large-volume application for self-cementing CCPs for in situ stabilization of gravel roads. The study assessed the engineering properties of 
two recycled materials and a natural aggregate. Laboratory experiments involved road surface gravel (RSG), a recycled pavement material (RPM), and a natural crushed aggregate (Class 5 base). California Bearing Ratio (CBR), resilient modulus (Mr), and unconfined compressive strength (UCS) were determined. The recycled materials were blended with two fly ash contents (10\% and 15\%) and had three curing times (7, 28, and 56 days). A Class $\mathrm{C}$ fly ash with $0.7 \%$ (LOI) was used. Resilient modulus and unconfined compression strength tests were also conducted to assess the impact of freeze-thaw cycling.

Unstabilized, three materials had CBR less than typically desired for base course (CBR $\geq 50$ ). CBRs of RSG and RPM with fly ash were 3 to 11 times the unstabilized material alone. The CBR and UCS for RSG and RPM increased with increasing fly ash content and curing time. After five freeze-thaw cycles, the UCS of RSG and RPM mixed with fly ash was still higher (5 and $18 \%$ ) than the UCS of material not subjected to freeze-thaw cycling. The SRM of RSG and RPM blended with fly ash increased with fly ash content and curing time, with the rate of increase being largest between 7 and 28 days of curing.

Fly ash reduced plastic strains of RSG and RPM during resilient modulus testing. Freeze-thaw cycling had a small effect on the summary resilient modulus (SRM) of Class 5 base, RSG, or RPM with or without fly ash, with no consistent effect for materials mixed with fly ash. Environmental assessment and field performance were undertaken on a segment of gravel county road (CR 53) that was stabilized with fly ash prior to paving in 2005. The results indicate a very successful application of the technology (Camargo, et al., 2008).

Director's Assessment: This is an excellent technology and should be extensively used in future. It has already been attempted in Missouri, Kansas, Wisconsin, and Minnesota. Additional demonstrations should be considered. This technology has the potential to use large-volumes of CCBs.

\section{5-CBRC-M20: New Technology Based Approach to Advance Higher Volume Fly Ash Concrete with Acceptable Performance Principal Investigator: Karthik Obla, National Ready Mixed Concrete Association}

A major obstacle that limits the widespread use of High-Volume Fly Ash (HVFA) concrete is its lower early-age strength as documented in research studies conducted in the laboratory with standard cured strength specimens. The objective of this study was to demonstrate, using maturity-based techniques, that the actual in-place strength of HVFA concrete in a structure is higher than that indicated by strength measured on field-cured cylinders. This is due to the higher in-place temperature resulting from the slower dissipation of heat of hydration due to the greater mass of structural members. The in-place strength of concrete in the structure can be determined by monitoring its temperature history over time, calculating the maturity, and by estimating the in-place strength from the pre-calibrated strength-maturity relationship. The maturity concept assumes hydraulic cement concrete of the same maturity will have similar strengths, regardless of the combination of time and temperature yielding the maturity. Maturity concepts are well established for Portland cement concretes but they are not so established for HVFA concrete mixtures containing chemical admixtures. The Arrhenius and Nurse-Saul maturity functions are commonly used to establish the maturity index. The Arrhenius maturity 
function is considered more accurate and was used in this study. The Arrhenius maturity function requires the use of mixture-specific activation energy to improve predictions of strength.

The activation energy quantifies the temperature sensitivity of the concrete mixture. An initial task was to determine the activation energy of each of the concrete mixtures using the procedure outlined in ASTM C1074. Various fly ashes (Class C and Class F fly ash meeting the standard ASTM C618) with multiple dosages ( $20 \%$ to $50 \%$ by mass of cementitious materials) were used in this study. Activation energies of these mixtures were determined. Some unexpected trends of strength based on curing temperature were observed for these fly ash mixtures. The fly ash mixtures cured at elevated temperatures demonstrated higher long-term strengths than anticipated in comparison to the strength of specimens cured at lower temperatures.

The next step was to develop strength-maturity relationships in the laboratory for four of the concrete mixtures. Additionally, pullout load versus compressive strength correlations were developed. To validate the strength predictions based on maturity, four concrete blocks and slabs were prepared in the field during the period of October to December, when the ambient temperature ranged from 15.5 degrees $C$ (60deg F) to 7.5 degrees $C$ ( 45 degrees F). The in-place compressive strength of the concrete blocks and slabs were predicted based on the following approaches: 1) match-cured cylinders; 2) pullout testing using the pullout versus compressive strength relationship previously developed; 3) maturity based on the activation energy and strength-maturity relationship previously measured; and 4) field-cured cylinders (Obla, 2008).

Director's Assessment: This was a cooperative study among a concrete users group and university researchers and it demonstrated that higher volume fly ash concrete can be used with confidence in certain situations. Field demonstrations of this technology in several regions should be the next step. The Midwest Regional Director visited the principal investigator to review his work and was impressed with the work completed and the next steps toward commercialization.

\section{5-CBRC-M23 Manufacturing Building Products with Fly Ash and Advanced Coal Combustion Byproducts Principal Investigator: Melissa Chou, Illinois State Geological Survey}

Due to more stringent NOx and $\mathrm{SO}_{2}$ standards, the production of FGD (flue gas desulfurization) byproducts, as well as fly ash and bottom ash, will continue to increase. The utilization of bottom ash or FGD byproducts (sulfite-rich and sulfate-rich materials) instead of, or in combination with, fly ash was investigated for the production of large quantities of high-quality fired construction bricks. Various combinations of fly ash, bottom ash, FGD sulfite-rich material, and FGD sulfate-rich material were used as a partial substitute for the shale to mix with clay. These commercial-size fired bricks showed good physical appearance, with no scum, lime pops, cracks, black hearts, or red hearts. The majority of the fired bricks produced met the ASTM classification for a severe weathering grade. The remainders were acceptable for moderate- or negligible-weathering grade. Bricks containing FGD sulfite-rich material were whiter in color, lower in compressive strength, and greater in water absorption capacity than regular fired bricks containing no CCBs. The fired bricks containing fly ash/bottom ash blends were comparable with the regular fired bricks without $\mathrm{CCBs}$ in color. In particular, the addition of bottom ash to 
the brick composition increased the redness of the brick color, improved the brick's compressive strength, and decreased its water absorption capacity.

All the fired bricks containing CCBs produced from the bench-scale tests are considered environmentally safe construction products. The fly ash and bottom ash from the specific source for this project can be recommended for use in making fired bricks. However, the use of FGD byproducts as an ingredient in fired bricks is not recommended because their high sulfur concentration may pose issues of secondary emissions during brick firing. The FGD byproducts may be more suited for conditioning soil or for making sulfur fertilizer, in addition to wallboard application (Chou et al., 2008).

Director's Assessment: This was a cooperative project with all stakeholders (brick manufacturer, CCBs supplier, and investor) involved. Based on discussions with a stakeholder, the developed technology was considered technically sound and economically viable. Since western coal is expected to be the primary fuel for Illinois power plants, the availability of F-ash needed for the process is not assured. The principal investigator is planning to license the technology to another country. Overall, it was an excellent project with tremendous potential.

\section{Environmental Issues Projects}

\section{9-EC-M04: Boron Transport from CCP Utilization and Disposal Sites Principal Investigator: Bradley Paul, Southern Illinois University-Carbondale}

The primary objective of this project was to characterize the ability of naturally occurring geologic materials to adsorb boron from ground and surface waters. CCBs potentially can release enough boron to allow significant plumes contamination to develop in the groundwater if only dispersion and dilution phenomena exist. The adsorption on the host rocks and soils can greatly reduce the potential for any kind of contamination to spread through the environment.

Most of the common soil and degraded rock materials found around management sites in the Midwest are capable of adsorbing boron. A predominantly silica sand material was an exception to this rule. The amount of boron adsorbed is sufficient to significantly alter the potential for boron plumes to develop in the field. The $\mathrm{pH}$ in most cases has a pronounced effect on the amount of boron adsorbed. Particle size and composition play a key role in determining the amount of boron adsorbed. Very fine clay materials adsorb much more boron than very coarse material. Dissolved solids did not (over the range and conditions tested) have any consistent tendency for reducing the amount of boron a material could adsorb (Paul, 2002).

\section{1-CBRC-M21: The Impact of Adsorption on the Mobility of Arsenic and Selenium Leached from Coal Combustion Products Principal Investigator: Bradley Paul, Southern Illinois University, Carbondale}

Coal combustion products (CCPs) make suitable fills for use in a variety of settings including as road sub-bases and fills, or as backfills in open pit operations replacing what has been removed. In many instances environmental concerns arise that these materials might leach toxic ultra trace elements such as arsenic (As) and selenium (Se) into groundwater supplies with deleterious effects. Many test procedures have been developed to characterize whether various elements 
may leach from coal combustion products, but site characteristics have been heavily ignored. Specifically, the question of whether elements once leached from coal combustion products would actually remain in solution has not been addressed. Obviously, an element once leached from a CCP would not be a water contaminant if it were not in the water. The objective of this research was to determine whether soils and degraded rocks common to the road cut and mine environments in which CCPs might be placed would allow arsenic and selenium to remain in the water if they did leach. This would provide an environmental risk assessment check that is seldom used in today's permitting reviews. The over-all conclusion of this study is that materials commonly found around Midwestern sites where coal combustion products are placed as loose fills will usually adsorb enough As and Se to prevent formation of harmful plumes of any noteworthy area extent (Paul and Chen, 2002).

Director's Assessment: These were good projects and the results were debated extensively among the professionals. Unfortunately, there was no consensus on the results achieved and the regulatory agencies are holding back on using the data for permitting purposes.

\section{9-EC-M05: Soil Stabilization and Drying by Use of Fly Ash Principal Investigator: Tuncer Edil, University of Wisconsin}

This study was conducted to evaluate the potential for leaching of metals from fly ash stabilized subgrade soils used in highway construction. Four different tasks were undertaken: 1) water leach testing (WLT); 2) laboratory column testing; 3) field lysimeter testing; and 4) numerical modeling. Testing was conducted on soil-fly ash mixtures that were prepared with three locally available fly ashes and four subgrade soils representing a range of subgrade soil conditions that might be encountered in Wisconsin.

The WLT showed that concentrations of metals in the leachate from soil-fly ash mixtures tend to be lower (1.5 to 2.5 times) than those from fly ash alone. The concentration increased nonlinearly with increasing fly ash content, and could not be estimated from a simple dilution calculation. The partitioning of metals between the solid and liquid phases was non-linear because the $\mathrm{pH}$ of the leachate increased non-linearly with increasing fly ash content.

Column leaching tests conducted in the laboratory showed that the $\mathrm{pH}$ of the effluent and initial effluent concentration from soil-fly ash mixtures increased with increasing fly ash content. The initial effluent concentration depended primarily on the type of fly ash, and the retardation factor depended primarily on the type of soil that was used to prepare the soil-fly ash mixture. The partition coefficient increased slightly for soils having higher CEC. The release pattern for metals from the soil-fly ash mixtures appeared to be adsorption-controlled. The $\mathrm{pH}$ of the pore fluid was persistent for at least 30 pore volumes of flow, which corresponded to at least 30-yrs of flow in the field.

Lysimeters installed at the field sites showed that the average annual water flux through the stabilized soil layer to be approximately $4-6 \%$ of the average annual precipitation, and was comparable to that from a control section constructed without fly ash. Concentrations of most of the metals of concern were higher in leachate collected from the fly ash stabilized pavement section than the control pavement section, and decreased slightly over time. Concentrations of 
metals in the field leachate agreed well with concentrations in the effluent from the column leaching tests conducted in the laboratory, which suggests that transport parameters obtained from the column leaching tests could be used to predict field conditions.

A numerical model was developed to simulate typical field scenarios where subgrade is stabilized with fly ash. Simulations conducted using transport parameters obtained from the column tests showed that the maximum concentration decreases by about 5 times within the first meter below a fly ash stabilized layer, and then decreases more gradually at deeper depths. The maximum concentration at a given depth is independent of the retardation factor, and decreases with increasing dispersion coefficient and decreasing thickness of the stabilized layer. The time to reach the maximum concentration at a particular depth is independent of the thickness of the stabilized layer, and increases as the dispersion coefficient decreases and the retardation factor increases.

Design charts based on the results of numerical simulations can be used to quantify the maximum relative concentration at a particular depth and the time required to achieve the maximum concentration. The only required parameter is the initial effluent concentration, which depends primarily on the type of fly ash and can be estimated from a water leach test. To determine the time required to achieve the maximum concentration at a given depth, the Darcy flux and the retardation factor are required. The retardation factor depends primarily on the type of soil being stabilized, but does not vary significantly for fine-grained soils. Thus, quick and reasonable predictions can be made using a conservative estimate of the retardation factor and Darcy flux (Bin-Shafique, et al., 2003).

Director's Assessment: Based on input from two Wisconsin electric utilities professionals, this project was a major success and has helped utilize CCBs for highway applications.

\section{0-CBRC-M09: Environmental Performance Evaluation of Filling and Reclaiming a Surface Coal Mine with Coal Combustion Byproducts Principal Investigator: Ishwar Murarka, Ish Inc.}

The project objectives were to: 1) develop environmental chemistry knowledge on the interaction of coal combustion byproducts (CCBs) and water in mined land; 2) establish neutralization value and document formation of chemical precipitates; 3) obtain field-scale hydrologic and water quality data; and 4) conduct in-depth analysis for metals chemistry in pore water from cores obtained from laboratory experiments. About 24 months of hydrologic, geochemical, and water quality data were collected and analyzed for chemical, mineralogical, and hydrologic parameters. The data was analyzed using appropriate statistical, graphical, and modeling techniques.

The study site, located near Terre Haute, Indiana, is a surface coal mine final pit. From 1988 to 2003, Cinergy filled the former mine pit with approximately 1.6 million tons of fly ash. A fivefoot soil cover and vegetation were placed on top of the ash material to maintain the land as a wildlife refuge. The Indiana Department of Natural Resources permitted the disposal of coal ash in the mine pit and required monitoring of groundwater and surface water at a number of locations. Researchers have monitored 44 chemical parameters on a quarterly basis since 1988 and continued this monitoring through 2006. Researchers installed 16 additional monitoring 
wells and obtained eight rounds of groundwater quality data to develop a field-scale evaluation of leaching, attenuation, and migration of the ash constituents. The final groundwater sampling event was completed in February 2005.

The researchers used all Cinergy compliance monitoring data and the CBRC research monitoring data for time-series and other statistical analyses. Laboratory studies on batch and column leaching experiments were performed to better understand generation and sustaining of leaching for the target inorganic constituents. Laboratory column experiments were also performed to dynamically evaluate leaching and attenuation of arsenic and boron for the coal ash and the spoil materials from the site. Finally, the project team collected and analyzed groundwater and surface water samples for isotopic ratios of boron, sulfur, and strontium to better identify sources of the constituents in groundwater and surface water at the site.

The monitoring data indicates that the alkaline coal ash leachate has been effective in neutralizing the AMD water that was present at the site particularly as evidenced by the mine seep water sampling results. The coal ash leachate neutralized the acidic $\mathrm{pH}$, increased alkalinity, essentially eliminated acidity, and significantly decreased manganese, iron, and sulfate concentrations in the AMD water. However, the coal ash leachate did increase significantly boron concentrations in the mine seep water as well as in groundwater at the site. Limited amount of arsenic migration was noted only in the close vicinity of the ash fill area. There were no indications of any other trace metals migration via the mine seep.

The groundwater quality data similarly shows that coal ash leachate has not resulted in the leaching and migration of most of the trace metals contained in ash. Boron, arsenic, calcium and sulfate are leached significantly from the coal ash in different amounts. However, because of the presence of sulfate in groundwater in the spoil material, it is not feasible to discern the migration of sulfate contained in the coal ash leachate from the sulfate contributed by the mine spoil material. The compliance monitoring data and data from the research efforts do show that boron in the coal ash leachate has migrated out of the coal mine pit into the groundwater in the minespoil material. There is more than a magnitude order of decrease in boron concentration within 150-200 feet down-gradient of the ash fill (Murarka, 2008).

Director's Assessment: This was an excellent project and has provided very good, long-term data to support management of CCBs in mine settings. More studies such as this need to be done to support continued management of $\mathrm{CCBs}$ in mining areas.

\section{1-CBRC-M12: The Effect of Mercury Controls on Wallboard Manufacture Principal Investigator: Sandra Meischen, Tennessee Valley Authority}

Two methods were investigated to indirectly identify the mercury form in flue gas desulphurization (FGD) gypsum. These methods rely on the widely different vapor pressures and solubility of mercury compounds postulated to be in the FGD gypsum. Solid materials studied included: 1) mercury-amended calcium sulfate; 2) laboratory-prepared FGD material isolated from a simulated flue gas in a small wet-FGD system; and 3) site-collected FGD. 
Comparison of the leaching profiles of the mercury-amended calcium sulfate, laboratoryprepared FGD and site-collected FGD samples proves that mercury-amended calcium sulfate cannot be used as a surrogate for FGD material. Nearly all the mercury was leached from the mercury-amended samples; a result dissimilar to the lab-prepared or site-collected FGD samples. Likewise, the thermodecomposition profiles of the mercury-amended samples were complex and dissimilar to the lab-prepared and site-collected samples. Of significance, the thermodecomposition profiles after 8 weeks provided clear evidence that the mercury complex in the gypsum had changed in three of the samples. The profiles for mercuric oxide, mercuric sulfate and mercuric chloride amended gypsum were similar to each other and roughly comparable to laboratory-prepared and site-collected FGD gypsum. The mercuric sulfide profile did not change, was not comparable to laboratory-prepared and site-collected FGD gypsum and, consequently, mercuric sulfide was not a primary component of the FGD gypsum. Additional tests were conducted to determine if different oxidized forms of mercury in a flue gas would affect the mercury form in the gypsum as determined by thermodecomposition profile. There was no difference in the profiles and both were similar to the site-collected FGD. The conclusion is that the form of mercury in FGD gypsum is probably not a distinct mercury compound but tightly associated with the calcium sulfate matrix. The mercury-gypsum interaction is such that mercury leaching and thermal decomposition is limited compared to a discrete mercury compound in gypsum. The mercury-gypsum interaction can cause other mercury compounds to undergo rearrangement in the gypsum solid phase.

To produce the laboratory-prepared FGD gypsum, parametric tests were designed such that a range of mercury concentrations could be produced, from 0.7 to $4.6 \mathrm{pm} \mathrm{Hg}$. All mercury in the simulated flue gas was converted to the oxidized form prior to contact with laboratory-scale FGD unit. The mercury concentration of the solids isolated ranged from $0.1 \mathrm{ppm}$ to $0.3 \mathrm{ppm}$. Any elemental mercury measured as evolving from each experiment did not account for the discrepancy in the solids. The equipment and test design were scrutinized for appropriate changes. Although the laboratory-prepared FGD material did not contain the mercury concentrations anticipated, they were in the range of field FGD gypsum. Further thermal tests on lab and field FGD gypsum demonstrated that mercury begins to evolve from FGD material at 380 to 390 degrees F. The mercury evolution rate increased with an increase in mercury concentration in FGD gypsum and decreased with an increase in weight of a wallboard sample. The conclusion is that if necessary, the wallboard drying temperature could be lowered to mitigate mercury evolution. Considering the large sheets of papered wallboard and that the exposed surface area is the cut edges only, mercury evolution may not be a significant problem. To assess this hypothesis and possibly establish a predictive method, mercury content and evolution around a large sheet of papered wallboard should be monitored during drying to determine the ratio of evolution to exposed gypsum surface area with mercury initial mercury content.

Ramped temperature thermodecomposition profiles were also used to get a rough idea of the mercury concentration in the solids. For quick determination of mercury concentrations in FGD or other solids, a high temperature thermodecomposition method should be developed with an appropriate QA/QC procedure as an analytical method for mercury (Meischen, 2004). 
Director's Assessment: This was a good timely project. Since this project, USDOE-NETL has undertaken much more detailed studies at several wallboard manufacturing facilities. Since this project was done by TVA, there was a perceived conflict of interest.

\section{1-CBRC-M23: Quantifying CCBs for Agricultural Land Application Principal Investigator: David Hassett, University of North Dakota}

Agriculture application is potentially one of the largest unrealized coal combustion byproduct (CCB) utilization options in the United States. Many rural power plants that cannot market CCBs to distant markets may find local farmers to be repeat customers. A case study in Illinois provided the opportunity to study the appropriateness of the use of a mixed CCB from a rural power plant as an agricultural soil amendment. Local farmers expressed interest in using the material because they understood that it could be a source of calcium and sulfur. While field application had been tried in limited locations by one farmer with success, the utility producing the mixed CCB stream felt that a more rigorous investigation was required. CCB use regulations in Illinois include agricultural application of CCBs as an option approved by the Illinois Environmental Protection Agency (IEPA). The utility producer initiated an effort to evaluate the mixed CCB stream of interest to local farmers to understand if the material was allowable for agricultural land application under Illinois regulatory requirements.

The goal of the effort was to determine the environmental appropriateness of the use of a specific mixed stream of CCBs for agricultural land applications and to develop a draft methodology for generically qualifying CCBs for agricultural land application. The project evaluated a mixed stream of CCBs (bottom ash, fly ash and sulfite-rich flue gas desulfurization [FGD] material) recovered from wet storage for agricultural land application.

The data indicate that both untreated and field-treated soils exhibit similar concentrations of most of the trace elements tested. The concentrations in the as-managed mixed CCB stream were frequently similar to those found in the untreated soils. Some elements, most notably boron, beryllium, mercury, nickel, and zinc were more concentrated in the as-managed mixed CCB stream as compared with the untreated soil. However, concentrations of these elements in the field-treated soil, three years after the as-managed mixed CCB application, were not elevated above the concentrations noted in the untreated soil.

The following conclusions were drawn from this study: 1) CCBs can provide benefits when used to amend agricultural soils, but caution must be exercised to ensure environmental protection, crop and soil appropriateness, and human health; 2) FGD gypsum has benefits equivalent to natural gypsum and can be applied for the same purposes and at the same rates; (Studies under way on the use of FGD gypsum should provide good information to aid in marketing FGD gypsum for agricultural applications, and the criteria for use should be the same for natural and FGD gypsum); and 3) total concentrations of inorganic constituents in CCBs are not the best indicator on which to base decisions regarding the suitability of CCBs for use in agricultural land applications (Hassett and Heebink, 2007).

Director's Assessment: The principal investigator is a world-class researcher and he did an extremely good job in the project. The project findings, however, were not implemented because 
of environmental concerns. The agricultural applications of CCBs need further investigation to demonstrate that they do not pose long-term environmental concerns.

\section{Western Region}

Director: Debra Pflughoeft-Hassett, University of North Dakota

\section{Mine Placement of CCBs}

\section{9-EC-W01: Varra Coal Ash Burial Project-Phase I \\ 00-CBRC-W02: Varra Coal Ash Burial Project-Phase II Principal Investigator: Joby Adams, CGRS, Inc.}

The Varra Coal Ash Burial Project was a field scale study to evaluate the feasibility of largescale reclamation using coal ash. The project was conducted by obtaining required permits in combination with performing bench scale leaching tests and a small scale ash burial and water quality monitoring program. The field scale study consisted of placing 400 tons of two types of coal ash in an unlined saturated trench. The lack of information regarding the use of coal ash in wet systems and the uncertainty of which regulatory agency had statutory oversight created a lengthy and costly permitting process. This project was the first successfully permitted project of its kind in Colorado and represents a case study where CCBs were successfully used in a wet environment. This project successfully promoted the use of CCBs to local and state governmental agencies for nontraditional uses.

Blended ashes were used. The initial premise was that as long as the mass loading of elements from the ash was small relative to the volume of water bypassing the ash deposit, it may be possible to safely deposit ashes of any composition in saturated environments. The project successfully demonstrated the use of blended ashes in nontraditional uses.

This project also addressed the issue of possible water quality impacts resulting from mine land reclamation. The results showed negligible water quality impacts over a limited areal extent. No drinking water standards were exceeded at the point of compliance (50 feet downgradient of the trench) and only minimal affects were documented within 25 feet downgradient of the trench. Changes to local hydrology were as expected. Most encouraging of all were the dramatic elemental concentration reductions within the ash deposit over a short duration. Data obtained indicate that elements or ions of concern will be reduced within ash deposits at this location (Adams and Warner, 2002).

\section{9-EC-W04: The Use of CCBs for In Situ Treatment of Acid Mine Drainage Principal Investigator: Geoff Canty, CC Environmental}

In 1994, a demonstration project was undertaken to investigate the effectiveness of using CCBs for the in situ treatment of acidic mine water. Actual injection of alkaline material was conducted in 1997 with initial positive results. However, the amount of alkalinity added to the system was limited and resulted in short duration treatment. In 1999, further investigation was performed to determine the effectiveness of alkaline injection technology (AIT). In December 2001, 2500 tons 
of fluidized bed combustion (FBC) ash were injected into the wells used in the 1997 injection project.

Post injection monitoring continued for 24 months. During this period the mine chemistry had gone through a series of chemical changes that manifested as stages or treatment phases. The mine system appeared to be in the midst of reestablishing equilibrium with the partial pressure of mine headspace. Alkalinity and $\mathrm{pH}$ appeared to be gradually increasing during this transition. As of December 2003, the pH and alkalinity were roughly 7.3 and $65 \mathrm{ppm}$, respectively. Metal concentrations were significantly lower than pre-injection levels, but iron and manganese concentrations appeared to be gradually increasing (roughly $30 \mathrm{ppm}$ and $1.25 \mathrm{ppm}$, respectively). Aluminum, nickel, and zinc were less than pre-injection concentrations and did not appear to be increasing (roughly $<\mathrm{PQL}, 0.02 \mathrm{ppm}$, and $0.1 \mathrm{ppm}$, respectively). Arsenic and boron were not identified in concentrations that were of concern for protecting freshwater aquatic communities; however, selenium was well above the CCC and MCL.

Overall, this project was successful at achieving water quality improvement goals and providing valuable insight and information about the chemistry of this technology. In addition, there were obvious improvements observed in the receiving environment-benthic habitat recovery and the return of fish species. Researchers believe additional monitoring is needed to determine the duration of the treatment and to evaluate the applicability of the treatment technology (Canty and Everett, 2004).

\section{5-CBRC-W03: Evaluation of CCBs for In Situ Treatment of Acid Mine Drainage Principal Investigator: Geoff Canty, CC Environmental}

The purpose of this work was to study the long-term effectiveness of Alkaline Injection Technology (AIT). This in situ technology uses alkaline coal combustion byproducts (CCBs) to provide alkalinity, increase $\mathrm{pH}$, and precipitate metals to remove them from the mine water. As the mine water reaches the ground surface, the quality of acidic mine drainage (AMD) is improved. Because this method of treating AMD does not rely on active physical and chemical processes such as combined neutralization and precipitation, the cost of treatment is greatly reduced. Fewer chemical inputs, equipment, personnel and funds are required by AIT. Furthermore, AIT can be, in many cases, combined with other passive treatment technologies such as treatment wetlands, sequential alkaline producing systems (SAPS), anoxic limestone drains, and many combinations of these systems.

Two AIT projects were undertaken to evaluate AIT in an abandoned coal mine located in southeast Oklahoma, near the town of Red Oak. The mine is located in the Interior Province, Western Region Coal Field, in the Howe-Wilburton Coal District. This down-dip slope operation undermined approximately 46.5 acres. In 1997, the first AIT project imparted a limited amount of alkalinity to the system. While this project had positive results, they were relatively short-lived. In December 2001, the second AIT project injected approximately 2500 tons of fluidized bed combustion (FBC) ash using the same injection wells. The second project was more successful. As of June 2007, the second AIT project was still exhibiting success. This project examined the long-term AIT treatment of the seep for a period of 13 months. 
Water quality during the treatment phase (following the 2001 injection) before the 2006-07 monitoring project averaged $\mathrm{pH}$ and alkalinity of 8.35 and $87.9 \mathrm{ppm}$ as $\mathrm{CaCO}_{3}$, respectively, and iron, manganese, and aluminum concentrations of $14.3 \mathrm{ppm}, 2.5 \mathrm{ppm}$, and $4.8 \mathrm{ppm}$, respectively. The 2001 AIT demonstration can be described in three phases.

As of June 2007, the mine water was in Phase $2 b$ of treatment. Phase $2 b$ is distinguished by slightly decreasing $\mathrm{pH}$ and increasing alkalinity. Alkalinity increased from a low in August 2002 of $30 \mathrm{ppm}$ as $\mathrm{CaCO}_{3}$ after the injection to approximately $227 \mathrm{ppm}$ in June 2007. As bicarbonate became the more important species, there was an observed increase in alkalinity. Alkalinity continued to gradually increase from August of 2002 at a rate of $0.12 \mathrm{ppm}$ as $\mathrm{CaCO}_{3}$ per day. The $\mathrm{pH}$ decrease observed during Phase $2 \mathrm{~b}$ has been approximately 0.0004 units per day from 7.2 to 6.6 .

During Phase 2, the concentrations of iron and manganese were expected to reach a threshold as $\mathrm{pH}$ continued to decrease. As of June 2007, iron and manganese were approaching background levels (before 1997 injection) with concentrations of $116 \mathrm{ppm}$ and $5.2 \mathrm{ppm}$, respectively. Both iron and manganese are influenced by the carbonate system. In contrast, aluminum concentrations were well below background levels. Aluminum forms a hydroxide solid within this $\mathrm{pH}$ range and is not influenced by the carbonate ligand. Aluminum levels are not likely to increase until the $\mathrm{pH}$ returns to pre-injection levels (i.e., $<5$ ) at some time in the future. As of June 2007, the concentration of aluminum was $0.045 \mathrm{ppm}$, compared to pre-injection levels of $7.8 \mathrm{ppm}$. Aqueous carbon dioxide and carbonic acid species $\left(\mathrm{H}_{2} \mathrm{CO}_{3}{ }^{*}\right)$ concentrations have yet to reach pre-injection levels of $3.8 \mathrm{mM}$. In June 2007, $\left[\mathrm{H}_{2} \mathrm{CO}_{3}{ }^{*}\right]$ was $2.7 \mathrm{mM}$. Because $\mathrm{H}_{2} \mathrm{CO}_{3}{ }^{*}$ is still increasing to pre-injection levels, it is unknown how much longer Phase $2 \mathrm{~b}$ will continue. Consequently, the duration and beginning of Phase 3, wherein an equilibrium between injected alkalinity and the partial pressure of carbon dioxide in the headspace will be reached, is unknown.

This treatment technology has been successful in treating AMD as of June 2007. The mine water at the discharge contained considerable alkalinity and circumneutral $\mathrm{pH}$. AIT has been successful at removing metals from mine water and is treated further by the passive treatment cells downstream from the seep. The receiving stream of this mine water was much less negatively impacted than before the injection. This improvement was shown by the significant enhancement of the macro-invertebrate community, aquatic habitat and riparian vegetation.

Nickel, zinc, and arsenic were also monitored in this report to ensure this treatment strategy did not increase the concentrations of toxic metals that are sometimes found in CCBs. This monitoring period exhibited a significant decrease in nickel and zinc in the mine water from preinjection levels ( $94 \%$ and $95 \%$ decrease, respectively).

AIT improves water quality by increasing alkalinity and reducing metal loading. Using these technologies in combination can greatly increase their effectiveness. AIT can be used to pretreat mine water entering other AMD passive treatment cells. Consequently, treatment cell efficiency is improved. While this monitoring project has shown the success of this technology to date, the longevity could be further assessed (Winfrey, et al., 2008). 
Director's Assessment: These projects focused on issues related to mine placement of CCPs, which continues to be important as the Federal government drafts rules for use of CCPs in mine placement and states subsequently reevaluate their regulations of this high-volume use of CCPs.

\section{9-EC-W05: Promote Increased Use of Coal Combustion Products to State Regulators and Government Agencies Principal Investigator: Ishwar Murarka, Ish Inc.}

For this project, information was gleaned from literature on chemical and physical characteristics of CCBs produced in the United States along with some information on mine spoil material. Background information on coal mines and available data on water quality characteristics of mine areas was gathered. A summary list was compiled of mine sites where CCBs have been utilized for filling the mined land and/or for abatement of acid mine drainage conditions.

Beneficial use of CCBs for coal mine reclamation occurs in varying degrees across the United States. Injection of CCBs into deep mines has been performed to provide structural support for subsidence abatement, and placement of CCBs in surface mines has been utilized to reclaim mined land to original grade and to mitigate AMD. Such practices have been employed at both active and abandoned coal mines.

Several surface and deep mines in the midwestern and western United States that have utilized CCBs for reclamation were identified for this report. Types of CCBs placed at these mines include fly ash, bottom ash, and FGD materials. Thirteen mines were selected based on availability of site-specific data required to perform a reasonable evaluation of the benefits and impacts of CCB placement on groundwater quality. These case studies represent a large range of $\mathrm{CCB}$ uses from filling of mine pits to using $\mathrm{CCB}$ grout mix to minimizing/eliminating acid mine drainage. A brief summary of each case study is presented in the final report (Murarka and Erickson, 2006).

\section{Concrete Production/Performance}

\section{5-CBRC-W04: Using Class C Fly Ash to Mitigate Alkali-Silica Reactions in Concrete Principal Investigator: Bruce Dockter, University of North Dakota}

CBRC funded year 1 of this 3 year study. In this study, ASTM standard methods are to be applied to fly ash samples and cast specimens produced using varying levels of Class $\mathrm{C}$ fly ashes. In addition to empirical tests, researchers will evaluate specimens using advanced electron microscopy techniques to look at the mineralogy of the ash and the aggregates and, especially, the reaction products. Researchers anticipate that results will confirm limited unpublished work that indicates the efficacy of using higher percentages of Class $\mathrm{C}$ fly ash to mitigate ASR when using moderately reactive aggregates.

A very comprehensive and diverse group of industry sponsors was successfully assembled for this project. They include Boral Material Technologies Inc., Western Region Ash Group, Holcim (U.S.) Inc., Lafarge North America Inc., WE Energies, Nebraska Ash Company, Ash Grove Resources, and Mineral Resource Technologies Inc. Between all of these companies, 14 
types of fly ash will be tested using two cement sources. As of June, 2008, all members were in the process of sending in samples.

There were mainly three ASTM methods for evaluating expansion because of alkali-silica reactivity. The first is ASTM C1260, "Potential Alkali Reactivity of Aggregates (Mortar-Bar Method)," and is probably the most widely used test method. Another commonly used test method is ASTM C1293, "Determination of Length Change of Concrete Due to Alkali-Silica Reaction." A third and more recent specification, ASTM C1567, "Determining the Potential Alkali-Silica Reactivity of Combinations of Cementitious Materials and Aggregate (Accelerated Mortar-Bar Method)," addresses ASR mitigation using supplementary cementitious materials such as fly ash.

For the laboratory effort, it was decided to use ASTM C1567 for the bulk of the testing. Some of the samples tested under this method will also be evaluated using the concrete method ASTM C1293. All laboratory testing will be performed in future years 2 and 3 of the project.

The year 1 CBRC-funded activities were achieved as proposed. At the time of the original proposal, there were only three industry sponsors; now there are seven. An evaluation of existing literature on the topic of ASR has helped in focusing the needed laboratory effort for the next two years of this research effort. Much of the laboratory work will be conducted using the standard test method ASTM C1567. A selected ash sample from each sponsor will also be evaluated using the concrete prism method ASTM C1293. The EBSD will also be a useful tool to evaluate fly ash mineralogy and ASR mitigation.

The proposed mix proportions and test matrix will include the following replacement levels:

- Class C fly ash: $30 \%, 40 \%$, and $50 \%$

- Class F fly ash: $20 \%$ and $35 \%$

- Class C/F blends: 20\% and 30\% (Dockter, 2008).

\section{5-CBRC-W08: Evaluation of the Durability and Commercial Potential of $\mathbf{1 0 0 \%}$ Fly Ash Concrete Principal Investigator: Jerry Stephens, Montana State University}

Building upon previous research conducted at Montana State University on concretes in which $100 \%$ of the binder is Class $\mathrm{C}$ fly ash from the Corette power plant in Billings, Montana, the specific objectives of this project were threefold: 1) to identify additional fly ashes that could be used in $100 \%$ fly ash concretes; 2 ) to develop fly ash concrete mixtures with entrained air (which is a proven mechanism to improve freeze-thaw resistance in traditional concretes); and 3) to determine the durability of these concretes under various environments.

Three fly ashes similar in composition and production to the Corette fly ash were screened as potential binders in 100\% fly ash concrete, namely, fly ashes from the Port Neal (Sioux City, Iowa), Dave Johnston (Glenrock, Wyoming), and Council Bluffs (Council Bluffs, Iowa) power plants. Based on laboratory trial mixtures, concretes made with the Port Neal and Dave Johnston fly ashes had properties similar to those obtained using the Corette ash (e.g., 28-day compressive strength approaching 4,000 psi), and the Dave Johnston ash was selected for further 
consideration in addition to the Corette ash. Entrained air appeared to be readily induced in the Corette concrete using a commercial admixture. This entrained air had little effect on the workability of the fresh concrete, while it noticeably decreased the strength of the hardened concrete.

From a durability perspective, the freeze-thaw resistance of the Corette fly ash concrete (determined following ASTM C666) is promising, while there may be concerns about the performance of the Dave Johnston concrete (these test are on-going). Relative to ASR, both the Corette and the Dave Johnston concretes exhibited very little reactivity when tested following the test method described in ASTM C1260. The sulfate resistance test (ASMT C1012 is of relatively long duration, and no meaningful results have yet been obtained although these tests are on-going. Relative to hydrogen sulfide/microbial related deterioration of fly ash concrete, no significant corrosion was seen in samples exposed for approximately 2-1/2 months to a sulfur enriched, wastewater-based microbial environment.

The results of this project have substantially increased the body of knowledge on $100 \%$ fly ash concretes. While the basic strength and other engineering properties of concretes made using just Class C fly ash from the Corette power plant in Billings, Montana, as the binder (without any Portland cement) have been known for some time, little definitive information has been available on: 1) whether other similar fly ashes exhibit the same degree of cementing action as the Corette fly ash and can be used as the binder in fly ash concretes, and 2) whether these concretes offer acceptable durability for their intended application (e.g., construction of buildings, bridges, pavements, wastewater structures, etc.). Prior to this test program, the durability of fly ash concretes could only be speculated on based on knowledge of, and past experience with, Portland cement concretes (Stephens, 2008).

Director's Assessment: These projects focused on concrete production or performance using regionally available high-calcium fly ash. Work in the area of concrete is needed in order to maintain and expand the market for fly ash in concrete and to provide improved concrete for infrastructure projects in transportation, which is also an on-going challenge in the United States.

\section{Mercury Control}

\section{0-CBRC-W04: Pilot Testing of Fly Ash Derived Sorbents for Mercury Control in Coal Fired Flue Gas \\ Principal Investigator: James Butz, ADA Technologies, Inc.}

Research into the removal of vapor-phase mercury from coal-fired flue gas streams has shown that certain native fly ash materials have an affinity for mercury, to the point where these fly ashes capture virtually all the mercury present at some generating facilities. Specific fly ashes from Colorado bituminous and Wyoming sub-bituminous coals have been measured to remove from $75-98 \%$ of the mercury in full scale generating units (Butz, et al., 2000). Investigations of the properties of these fly ashes have revealed that most of the mercury was present in the smallest size fraction. Researchers at ADA Technologies, Inc. investigated the feasibility of employing these fly ash materials as mercury sorbents. The planned testing was performed on a slipstream from a full-scale generating unit at Xcel Energy's Comanche station in Pueblo, 
Colorado. The testing was performed in a pilot plant built and installed to evaluate the use of activated carbon for the removal of mercury from a slipstream from the Comanche station. The sorbent being tested was injected upstream of the baghouse at a location to provide a one-second residence time in the gas flow before entering the baghouse. Measurements of mercury content were taken upstream of the injection location and at the outlet of the baghouse.

Candidate fly ash materials were also obtained from three other Xcel generating facilities. Two were from plants burning a Colorado bituminous coal, and the third was from a site burning a Wyoming sub-bituminous (Powder River Basin) coal. The fly ash derived sorbents were created by grinding the materials to generate a sorbent with $90 \%$ of the mass in particles less than 20 micrometers in diameter.

Fly ash derived sorbents were injected into the pilot gas flow at two rates, $22 \mathrm{lb}$. per million actual cubic feet and $7.3 \mathrm{lb}$. per million actual cubic feet. All three fly ash materials showed significant incremental removal of fly ash, from $53 \%$ to $85 \%$ at the high injection rate and about $23 \%$ at the low rate.

An economic analysis showed that the use of fly ash derived sorbents was projected to be costcompetitive with the injection of activated carbon for flue gas conditions and plant configuration of the host site. The major factor in considering the use of fly ash derived sorbents may be their effect on the salability of the collected native fly ash plus sorbent at plants where mercury control must be implemented. The use of fly ash derived sorbents for mercury control is anticipated to allow the continued sale of collected particulate material for use as a pozzolan additive (Butz and Broderick, 2002).

Director's Assessment: Other opportunities for regional materials in products and applications were also performed in the Western Region, including the use of fly ash as a sorbent for mercury emission controls. It is anticipated that these projects will contribute to the CCP industry knowledge base as CCPs change and as regulations and regional needs change and develop.

\section{CCB Literature Database}

\section{1-CBRC-W01: Development of a Database of CCB Publications Principal Investigator: Tera Berland Buckley, University of North Dakota}

At the time this project was proposed, there was not a system in place that allowed for universal information sharing within the coal combustion byproduct (CCB) industry. By providing a forum to support technology transfer between producers, regulators, and end users, the FIRST SEARCH database plays a key role in removing barriers at the national, state, and local levels. The FIRST SEARCH database provides those with a vested interest in CCBs with a web-based information-sharing tool that allows them to stay abreast of research and, in turn, bridge the gap between research and commercialization.

Developed by the University of North Dakota Energy \& Environmental Research Center, the FIRST SEARCH database contains abstracts and full paper instructions to over 600 publications from more than 40 publishers, making the FIRST SEARCH database the first place to go for 
CCB information. The FIRST SEARCH database is accessible at www.undeerc.org/carrc/firstsearch (Buckley, 2003).

Director's Assessment: This project developed a database of technical documents that allows the user to search for literature related to CCPs in an online format with links to a large number of documents. That database has been maintained and expanded by the contractor and is still available at this time.

\section{$\underline{\text { Regulatory Practices for CCBs }}$}

02-CBRC-W12: Engineering and Environmental Specifications of State Agencies for Utilization and Disposal of Coal Combustion Products Principal Investigator: Bruce Dockter, University of North Dakota

Two separate documents, or reports, were produced: Volume 1 - DOT Specifications and Engineering and Environmental Specifications of State Agencies for Utilization and Disposal of Coal Combustion Products and Volume 2 - Environmental Regulations. The objectives of both volumes 1 are 2 is twofold. The first was to present a state-by-state comparison of U.S. Department of Transportation (DOT) specifications governing the use of coal combustion products. Because of a lack of resources, namely, time and funding, most transportation and materials engineers cannot fully research all of the current technologies of coal ash utilization. This compilation allows these professionals to become familiar with other department practices and to identify areas where specifications need to be developed within their own transportation offices. Engineering practices are slow to change for many reasons. To facilitate changes, a systematic approach must be taken. The results from this effort will help familiarize DOT engineers and officials with coal ash use applications and will help the coal ash industry develop a plan to work with these departments and individuals in expanding their knowledge and familiarity while expanding coal ash markets.

The second goal was to establish a comparison of state environmental laws and regulations as they pertain to utilization and/or disposal. As a result of the interpretation of the Bevill Amendment, utilization and disposal are not regulated at the federal level. These issues have been left to the states. Many states have enacted laws, adopted regulations, or both governing the utilization and disposal of CCBs. These laws and regulations vary widely. A particular utilization authorized in one state may not be authorized in the adjoining state. The objectives of these reports were to present a survey of the state laws and regulations authorizing beneficial reuse of CCBs (Dockter and Jagiella, 2005).

Director's Assessment: This project assembled information on state regulations related to CCPs which facilitates an understanding of practices by state entities and opportunities in each state for increased CCP utilization.

99-CBRC-W02: Fiber-Fly ash Based Wall-panel Development Principal Investigator: John Hunt, AeRock, LLC 
The overall objective was to bring together existing and emerging technologies, integrating them in such a way that the process: 1) used fly ash as the main component for the product's raw material input and 2) produced a superior siding or construction panel that is about less than half the weight of conventional panels and siding. Other objectives for the panel are that it should have high strength, superior fire performance, be capable of retaining screws, have good flexural strength, be capable of use as a structural component, be water resistant, and have good thermal insulation properties. Since the start of the work, the scope of the project expanded to include whole wall, floor and roof sections.

This research resulted in the successful creation of several full-thickness prototype panels. These panels marked the beginning of a complete building system. The panels have a high R-value, are resistant to fire, rot and pests and are highly durable yet lighter in weight than concrete. The panels were designed as a structural insulated panel (SIP). The SIP system allows for improved thermal performance, reduced infiltration and greater moisture control over conventional methods. With the completion of this initial panel, AeRock moved towards producing a full size AeRock panel. The goal is to produce panels that are extremely tough as well as having high strength. AeRock has been able to vary properties of panels for different applications through control of the materials preparation and process parameters. The process is economical and ready for commercial deployment (Hunt, 2001).

\section{0-CBRC-W10: Evaluation of the Fly Ash Admixtures for Final Cover and Composite Liner Applications Principal Investigator: James Carlson, Sunflower Electric Power Corporation}

This study examined the laboratory characteristics of fly ash and native soil materials with the goal of demonstrating their potential use in landfill, lagoon liner, and final vegetative cover applications. In the initial phase, the geotechnical and engineering qualities of several mixtures were studied and the performance of the more ideal blends documented. Following evaluation of the geotechnical and engineering aspects, the fly ash/soil blends were subjected to leaching and the chemical characteristics of the leachate were determined through laboratory analyses. Concurrent with the leachate analyses, a chemical evaluation of in situ soils and a screening of suitable plants were performed. During this phase, plant samples which had established themselves on the landfill were collected and identified.

The 25/75 and 30/70 fly ash/soil mixtures displayed engineering characteristics which indicated good potential for use in landfill and animal lagoon liner applications. Leachate chemical analyses did not reveal the presence of mercury or arsenic above laboratory detection limits. The presence of selenium, chromium, sulfate, chloride, alkalinity and boron at various concentrations were, however, observed in some leachate samples. It is believed that the chemical concentrations of the leachate can effectively be managed in arid regions by placement of ash in increased thicknesses, as operationally practicable.

Modeling of leachate percolation was performed using the ash mixtures and the conditions found at the site. In the context of the modeling and the recommended operational changes, percolation rates were found to be at or below those of clay lined landfills in more humid areas. In the 
context of this study, the leachate chemical constituents in a landfill setting were viewed as nonsubstantial (Carlson et al. 2001).

\section{2-CBRC-W09: Power Plant Combustion Byproducts For Improved Crop Productivity of Agricultural Soils Principal Investigator: Mick O’Neill, New Mexico State University}

Two coal combustion power plants in the Four Corners region of north western New Mexico, San Juan County, consume approximately 14.5 million metric tons of coal on an annual basis for the generation of electricity. In addition, these power plants generate substantial coal combustion byproducts (CCBs) in the form of 3.8 million metric tons of ash and 0.39 million metric tons of flue gas desulfurization (FGD) materials. Near the two power plants is the Navajo Agricultural Products Industry (NAPI), a large commercial farm currently operating over 600 automatic center pivot irrigation systems on 31,000 ha of farmland. The calcareous soils are generally sandy to sandy loam with limited water-holding capacity, low inherent nutrient status, and elevated $\mathrm{pH}$. CCBs may increase water-holding capacity and contribute to the pool of micronutrients available for plant uptake. However, salinity may pose negative consequences if excessive loading of soluble salts on soil occurs.

This project was designed to: 1) evaluate plant growth response cultivated in CCB-amended soil; 2) characterize potentially beneficial or harmful constituents of CCBs in plant, soil, and water samples; and 3) examine potential benefits of soil physical properties by measuring waterholding capacity and saturated hydraulic conductivity of CCB-amended soils. This study was a collaborative project with New Mexico State University, NAPI, and the Arizona Public Service (APS) Four Corners Power Plant.

Objectives were to test an indicator plant for growth responses and elemental uptake in two greenhouse studies, examine leachate and soil for elemental constituents, $\mathrm{pH}$, and salinity in packed soil columns, and examine potential changes in water retention and transmission properties of CCP amended soils.

Analysis of the CCPs showed that the fly ash material had the highest $\mathrm{pH}$ (12.41) and EC (6.65 $\mathrm{mS} / \mathrm{cm}$ ). Sodium adsorption values were highest for the bottom ash, though well within normal levels. Phosphorous, Fe, $\mathrm{Ca}$, and $\mathrm{Ba}$ were highest in the fly ash. Magnesium, $\mathrm{Ca}, \mathrm{Na}, \mathrm{S}, \mathrm{As}, \mathrm{B}$, $\mathrm{Cr}$, Sr, and $\mathrm{Si}$ were high in the scrubber slurry material. Zinc was highest in bottom ash.

The greenhouse studies were initiated in the fall and spring of 2004 and 2005, respectively. In the 2004 Greenhouse study, the hybrid poplar clone OP-367 had higher leaf greenness values than NM-6. For OP-367, the highest scrubber slurry rate applied to soil produced the highest SPAD values followed by the bottom ash and fly ash treatments. This trend was not observed in the clone NM-6 possibly due to B toxicity. The scrubber slurry raised salinity but lowered SAR values of amended soil. The lowered SAR values were attributed to the high amounts of exchangeable $\mathrm{Ca}$ and $\mathrm{Mg}$. Increased salinity with the scrubber slurry did not factor into decreased growth for either poplar clone. The $\mathrm{pH}$ increased in fly ash treated soil to 8.7, though this did not immediately impact biomass production, especially for the clone OP-367. Nutrition generally improved in hybrid poplar leaves: $\mathrm{S}, \mathrm{Mg}, \mathrm{Ca}, \mathrm{Na}, \mathrm{Fe}$, and $\mathrm{Mn}$ were highest under 
scrubber slurry plus supplemental $\mathrm{N}$ amending; leaf $\mathrm{P}$ and Fe increased in fly ash plus $\mathrm{N}$ amended soils; Copper and Zn improved under bottom ash plus $\mathrm{N}$ amending.

In the 2005 Greenhouse Study, only the hybrid poplar clone OP-367 and fly ash were investigated. Chlorosis evaluations showed that the fly ash at the highest rate plus supplemental $\mathrm{N}$ improved leaf greenness over the control. Biomass improved for most measured parameters under fly ash cultivation, although the highest fly ash rate was less productive than lower rates. Leaf $\mathrm{P}, \mathrm{Mg}, \mathrm{Ca}$, and $\mathrm{Na}$, as did micronutrient status, all increased in fly ash plus $\mathrm{N}$ amended soil. Boron also increased in leaves of poplars but were below toxicity limits

The following metals were analyzed in plant tissues and soils from acid digests: $\mathrm{Cr}, \mathrm{As}, \mathrm{Ag}, \mathrm{Se}$, $\mathrm{Pb}, \mathrm{Cd}$, and $\mathrm{Ba}$. Of these, only $\mathrm{Ba}$ was detected in leaves and stems. Leaf $\mathrm{Ba}$ was highest under fly ash amending followed by bottom ash. Scrubber slurry did not increase Ba. Barium accumulation differed between the two poplar clones: Ba tended to accumulate more equally in stems and leaves for the clone NM-6 while preferentially accumulated in stems rather than leaves in OP-367. Lead, Cr, and Cd did not increase in soils in either study and were well below USEPA toxic level standards.

The initial ECs were high for all treatments including the control, but fell to values below salt tolerance levels on the next irrigation. Consistent with the Greenhouse Studies, the scrubber slurry treatments had the highest ECs, eventually decreasing to the same levels as the control after 18 irrigations. $\mathrm{pH}$ levels dropped in all treatments at the onset before rising to static levels that ranged from 8.18 (BA 44.5) to 8.36 (FA 44.5) at the study's termination. The pH drop was attributed to soluble salt leaching. The fly ash leachate was generally the most alkaline. Water soluble $\mathrm{Al}, \mathrm{Be}, \mathrm{Bi}, \mathrm{Cd}, \mathrm{Cr}, \mathrm{Pb}, \mathrm{Mo}, \mathrm{Se}, \mathrm{Tl}, \mathrm{V}$, and $\mathrm{Zn}$ were below minimum detection limits. For most measured elements, the highest values were found in the first leachate followed often by rapid declines. Nitrate levels were lower in CCPs than the control and fell below drinking water regulations on the second irrigation. Potassium, $\mathrm{Mg}, \mathrm{Ca}$, and $\mathrm{Na}$ levels were slightly higher in the scrubber slurry amendments. Leachate S was highest in the scrubber slurry which was consistent with the Greenhouse Studies. The detection of Fe and $\mathrm{Mn}$ in leachate likely coincided with reducing environments formed within the columns as the soil became saturated. Boron was highest in the scrubber slurry followed by the fly ash treatment leachate, but moved rapidly from columns after subsequent irrigations. Ni levels were below EPA water quality regulatory levels.

Arsenic generally increased in the leachate of CCP amended soil and was highest at the first collection, even for the control columns, before falling to $<0.05 \mathrm{mg} / \mathrm{L} 12$ weeks into the study. These levels were above the newest EPA drinking water standards (even for the control) and require more investigation.

Leachate Ba also increased above EPA drinking water standards (depending on interpretation) in the initial leachate (even for the control). The Ba content rapidly lowered below regulatory limits after subsequent irrigations. Soil Ba was highest for the fly ash amendments but movement was largely confined to the upper portion of the soil profile where CCP loading had occurred.

No differences were observed between most soil retention and transmission properties but trends emerged. At $30 \mathrm{~cm}$ of suction, the FA 22.75 retained more water than the control, the SS 44.5 
and FA 22.75 treatments retained the most water at $60 \mathrm{~cm}$ of suction, at $300 \mathrm{~cm}$ suction, SS 44.5 and BA 22.75 retained more water than the control, at $1,000 \mathrm{~cm}$ of suction, the BA 22.75 treatment retained the most water compared to the control, at $3,500 \mathrm{~cm}$ of suction, the FA 44.5 and SS 44.5 treatments both retained more water than the control and at 5,000 cm suction, the CCP treatments were the same as the control. The $15,000 \mathrm{~cm}$ suction was the only theta to show any significant difference; all, CCP treatments had the same moisture content but retained more moisture compared to the control.

Decreasing drainable $\left(f_{a}\right)$ and effective porosity $\left(f_{e}\right)$ values indicate a decrease in faster draining macropores. The fly ash $22.75 \mathrm{mT} /$ ha and scrubber slurry treatments had the lowest drainable porosity values, while the two scrubber slurry treatments had two of the lowest effective porosity values. Saturated hydraulic conductivity values indicated that the finer particle size of the scrubber slurry and fly ash reduced water transmission rates through soil cores. A negative relationship between SAR values and AW was found. Sodium values were also negatively correlated with AW content while Ca was positively correlated with AW (O’Neill et al., 2006).

\section{Successes}

The American Coal Ash Association has tracked production and beneficial use levels of coal combustion products (byproducts) over time. Figures 3 and 4 depict CCP production and beneficial uses by type between $1966-2004$.

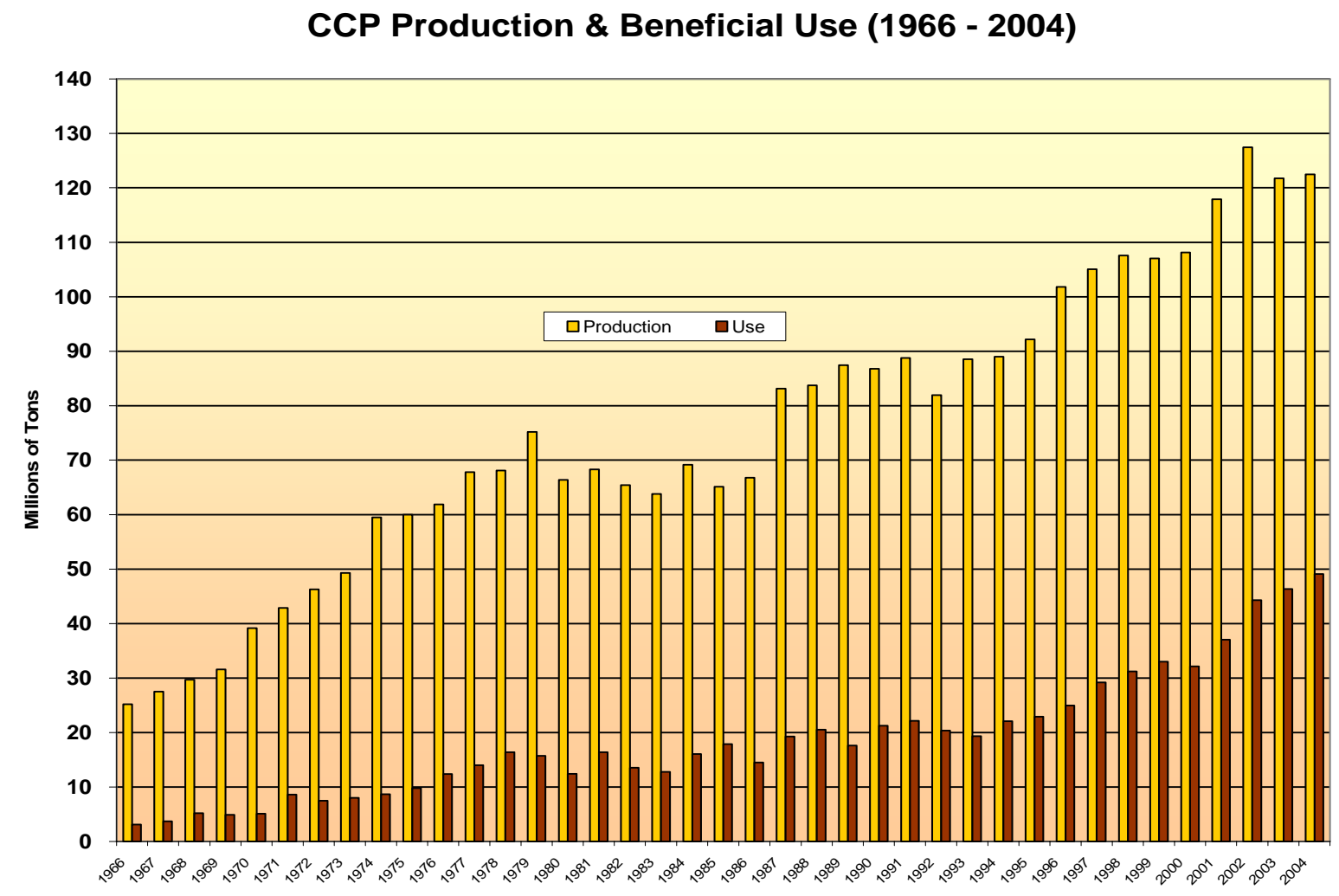


Figure 3. CCP Production and Beneficial Use Between 1966 - 2004 (ACAA, 2005)

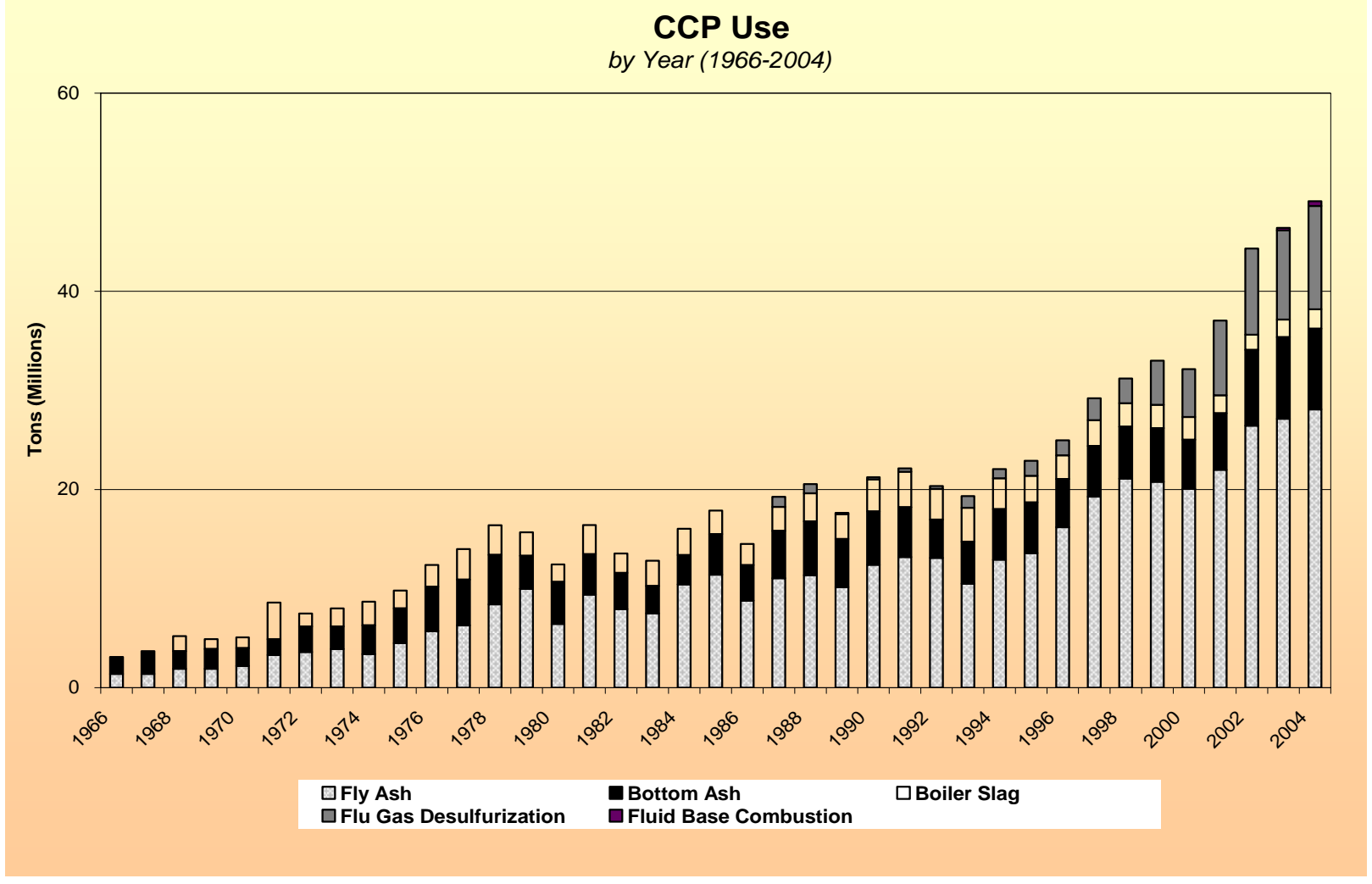

Figure 4. CCP Use by Type Between 1966 - 2004; (ACAA, 2005)

The authors believe that the CBRC program, through its research and educational outreach, has contributed to the increasing utilization of coal combustion byproducts between 1998 and present. Table 8 illustrates the usage of CCBs by type in 1998 versus 2008 .

Table 8. CCB Usage by ACAA Category 1998 and 2008

\begin{tabular}{|l|l|l|}
\hline \multicolumn{1}{|c|}{ ACAA Category } & \multicolumn{1}{|c|}{1998} & \multicolumn{1}{|c|}{2008} \\
\hline CCB production & $87,460,000$ short tons & $124,795,124$ short tons \\
\hline CCB beneficial use & $20 \%$ & $43 \%$ \\
\hline Fly ash & $58 \%$ & $45 \%$ \\
\hline Bottom ash & $28 \%$ & $45 \%$ \\
\hline Boiler slag & $14 \%$ & $83 \%$ \\
\hline FGD & $<1 \%$ & $79 \%$ \\
\hline FBC & $0 \%$ & $68 \%$ \\
\hline
\end{tabular}


The CBRC program also successfully leveraged significant amounts of matching funds to those provided by the USDOE-NETL as is depicted in Table 9.

Table 9. Federal (USDOE-NETL) and Matching Funds for CBRC Projects by ACAA CCB-Type Categories

\begin{tabular}{|c|c|c|c|c|c|c|}
\hline $\begin{array}{c}\text { ACAA } \\
\text { Category }\end{array}$ & $\begin{array}{l}\text { No. CBRC } \\
\text { Projects }\end{array}$ & $\begin{array}{l}\text { USDOE- } \\
\text { NETL \$ }\end{array}$ & $\begin{array}{c}\text { Matching } \\
\text { Cost-Share } \\
\$\end{array}$ & $\begin{array}{l}\text { Total \$ } \\
\text { Value }\end{array}$ & $\begin{array}{c}\text { \% USDOE- } \\
\text { NETL }\end{array}$ & $\begin{array}{c}\% \\
\text { Matching } \\
\text { Cost-Share }\end{array}$ \\
\hline Concrete & 6 & 459,938 & 421,938 & 881,876 & 21.56 & 5.39 \\
\hline Flowable fill & 1 & 38,933 & 16,203 & 55,136 & 1.82 & 0.20 \\
\hline Structural fill & 4 & 238,114 & $5,348,664$ & $5,586,778$ & 11.16 & 68.29 \\
\hline $\begin{array}{l}\text { Road } \\
\text { Base/Pavement }\end{array}$ & 3 & 137,626 & 472,663 & 618,289 & 6.45 & 6.03 \\
\hline $\begin{array}{l}\text { Soil } \\
\text { Modification }\end{array}$ & 1 & 101,310 & 36,651 & 137,961 & 4.75 & 0.47 \\
\hline $\begin{array}{l}\text { Mining } \\
\text { Application }\end{array}$ & 10 & 604,760 & $1,046,823$ & $1,651,583$ & 28.35 & 13.36 \\
\hline Wallboard & 2 & 108,033 & 67,930 & 175,963 & 5.06 & 0.87 \\
\hline Agriculture & 5 & 368,192 & 319,880 & 688,072 & 17.26 & 4.08 \\
\hline Aggregate & 1 & 76,563 & 101,988 & 178,551 & 3.59 & 1.30 \\
\hline Totals & 33 & $2,133,469$ & $7,832,740$ & $9,966,209$ & 100.00 & 100.00 \\
\hline
\end{tabular}

The program has been instrumental in paving the way for additional follow-on research and utilization efforts. The following information was reported from CBRC-funded researchers in response to a 2007 survey issued by the National Center:

- Several CBRC follow-on projects were funded by the Ohio Coal Development Office (OCDO). One researcher reported receiving nearly \$1M from OCDO to conduct CCB research in partnership with AEP and EPRI. OCDO also partnered with Ohio State University and the Ohio Minelands Partnership to continue monitoring at an abandoned mine site.

- USEPA and a new EPRI/CBRC project were funded to develop the technology and gather information related to enhanced use of FGD products in agriculture.

- As part of a team of scientists and engineers involved in CCB utilization, materials properties, and testing, much of CBRC researchers' efforts have included incorporating past and present research associated with $\mathrm{CBRC}$ projects with future research efforts.

- Follow-on funding was received from the Oklahoma Abandoned Mine Land Program to reclaim a strip mine pit; funding was also received from the Oklahoma Conservation Commission to support the use of FBC ash and FGD for soil $\mathrm{pH}$ adjustment. 
- The Rural Roads Research Board, Minnesota sponsored follow-on research into the stabilization of city streets and gravel roads with fly ash.

- The Wisconsin Department of Transportation sponsored follow-on research into the longterm behavior of fly ash stabilized soft sub-grade.

- The Wisconsin Department of Natural Resources and Alliant Energy sponsored followon research to develop a leaching model for assessing groundwater impacts of CCBs used in highways.

- CBRC researchers have worked with local and state agencies to modernize materials specifications.

- CBRC researchers have presented on several occasions to state departments of transportation on CBRC research activities.

- CBRC researchers at Ohio State University have been involved in technology transfer with their University Extension program.

- $\quad$ BRC researchers have conducted reviews on state regulations, standards, and practices related to the use of CCBs with the primary goal of reviewing factors related to the use of CCBs to develop recommendations that may result in an increase in the use of CCBs in an environmentally-sound manner. Follow-on funding was provided by EPA, ACAA, and Headwaters Resources.

- Many presentations and publications resulted from CBRC research efforts.

- Involvement in planning, designing, and carrying out technical and marketing research and technology transfer related to CCBs is continuing into the future.

- Researchers report continuing partnerships with the American Coal Ash Association, MCAA, C2P2, Utilities Solid Waste Activities Group, and the Coal Ash Resources Research Consortium which includes members from Alliant Energy, Ameren, Great River Energy, Indianapolis Power \& Light, Lafarge North America, Otter Tail Power Company, Tennessee Valley Authority, and Xcel Energy.

- There seems to be a growing acceptance of using FGD gypsum in agriculture by farmers, regulators, and academic researchers.

- The North Dakota State Department of Transportation recently increased the allowable amount of fly ash used as a partial cement replacement in concrete from $15-20 \%$ to $30 \%$ for road base.

- CBRC research has led to the awareness within the brick manufacturing industry in Illinois and Indiana that Class F fly ash material is a suitable raw material for their commercial products. Furthermore, they are interested to know whether an addition of bottom ash to the raw mix material can improve the firing procedure for high quality brick production.

- Collaboration has increased between industry, IPA, and universities.

- Wisconsin never used fly ash prior to 2000 in road projects. In 2007, there were six projects done for the Wisconsin DOT and several city and private projects. All Class C fly ash in 2006 was used in Wisconsin. Wisconsin now accepts fly ash stabilization of sub-grades. The Wisconsin DOT is conducting an implementation project to incorporate the fly ash specifications into their books.

- Minnesota is developing use of fly ash in rural roads reconstruction.

- Many report developing courses and workshops on CCBs. 
- One researcher worked with Cooperative Power Association of North Dakota to replace $70 \%$ of cement with fly ash for concrete placement. The construction site was located at the Coal Creek Power Station near Underwood, North Dakota.

- One reported seeing an abandoned mine strip pit reclaimed with FBC ash.

- Oklahoma Department of Mines permits the placement of FBC ash in strips. This is becoming very common.

- At least one company in Oklahoma markets FBC as a soil amendment.

- Some local farmers have used FGD gypsum for soil conditioning to improve crop production.

- The Illinois Clean Coal Institute supported a CCB construction project.

- CCBs were used in renovations to Ohio State University stadium, the FGD gypsum plant near Cincinnati, Ohio, and structures in Chisago county, Minnesota, City of Wasecan, Minnesota, and City of Cross Plaines, Wisconsin.

- As a result of CBRC-funded research conducted, one researcher was titled Senior Researcher in 2005.

- The Environmental Engineering Research Center, University of North Dakota, received the C2P2 First Place Award for Research, April 13, 2005 at the World of Coal Ash Conference for outstanding research on CCBs and for outstanding public outreach.

- Colonial Brick Company in Indiana received an Outstanding Cooperator Award sponsored by the ISGS for its significant cooperation with the ISGS on the CBRC-funded brick research projects.

In addition, specific outcomes and outputs have been identified as follows.

\section{Outcomes}

The Midwestern Region CBRC program was a huge success based on executive summary and director's assessment for each Midwestern project funded. The following comments summarize major outcomes.

- Technology for making fired bricks using CCBs has been developed and demonstrated. Although its commercial implementation in Illinois will not occur in the near future, the technology is being licensed for brick manufacturing in areas where F-fly ash is available for this process. Some progress has also been made toward extending this technology for use with FGD byproducts such as FBC ash and sulfite-rich FGD byproducts.

- Technically sound and environmentally safe management of CCBs in base and sub-base applications and full-depth stabilization of recycled materials for highway applications was demonstrated in several CBRC-funded projects as well as other projects funded through other sources.

- Long-term monitoring of CCBs managed in a surface mine was completed. There is general agreement among regulatory agencies that this was much needed information and it will allow permitting of CCBs management in mining areas in the Midwest.

- Technology for high-volume use of fly ash in some cement-concrete applications has been developed. The technology should be demonstrated on large-scale in several regions of USA.

- Technology for utility poles containing up to $10 \% \mathrm{CCBs}$ was demonstrated in the field. The technology came very close to being commercialized. 
- Commercially-viable construction products were developed using sulfate-rich FGD byproducts.

- Almost all funded projects had active industry involvement. Some also had active regulatory agency involvement. This should be strengthened even further in future projects.

- Although not funded by CBRC, some of the knowledge gained led to development and demonstration of high-strength feedlot and road sub-base construction materials. Similarly, technology for underground paste backfilling of coal processing waste in conjunction with CCBs was demonstrated at a mine.

- A large demonstration project using ponded fly ash for road sub-base was completed. This has made use of fly ash much more acceptable by the Department of Transportation and regulatory agencies.

- The use of FBC fly ash in low grade concrete applications was demonstrated in the field at SIU for a photo-voltaic project.

- Use of a poor-quality $\mathrm{C}$-ash for acid mine drainage is being pursued for reclamation at a mine in the Midwest.

\section{Outputs}

The following summarize comments from Regional Directors on outputs.

- The CBRC developed expertise in the area of CCBs throughout the region by funding projects in different states. That allowed local area power plants and regulatory agencies to work with those individuals and enhance their expertise even further. In addition, most projects led to graduation of one or more MS or PhD level students. They continue to provide significant technology and information transfer to industry and regulatory agencies. In the Midwestern Director's opinion that achievement alone was worth the money spent in this program.

- Except for 2-3 projects, all projects involved university faculty and researchers and graduate students. Although exact numbers in each category are not available at this time, it is estimated that at least 20 students received their MS or PhD degrees through CBRC funds. Similarly, it is estimated that at least 10-12 faculty members were trained in research and development activities through CBRC funds.

- Although exact numbers for reports, journal articles, and publications in proceedings is not available at this time. However, it is estimated that at least 100 archival value publications resulted from CBRC funded studies in the Midwestern region.

- Technology and information transfer is also achieved through oral presentation at conferences and in small groups. In the Midwestern Director's opinion, this is very important part of the success of the CBRC program but cannot be fully documented. Many of the Eastern Region projects resulted in reports, conference presentations and publications, student theses and dissertations, and refereed publications. Many of the publications came after the submission of the final project report, so the number reported is likely low. It is likely the case that CBRC was not acknowledged on all publications. This is unfortunate, but it is impossible to monitor all of the output and we must rely on the honesty of the investigator and colleagues to give credit where deserved. 
Although some categories can never be measured exactly, such as presentations made, papers generated, researchers involved with CBRC projects, Table 10 reflects estimates the authors are comfortable making.

Table 10. Estimated Program Stats at a Glance

\begin{tabular}{|l|r|}
\hline \multicolumn{1}{|c|}{ Category } & Number \\
\hline Projects funded by USDOE-NETL & 52 \\
\hline States with CBRC-funded projects & 18 \\
\hline Researchers involved with CBRC projects & $\sim 100+$ \\
\hline Students trained & $\sim 50+$ \\
\hline Papers generated & $\sim 100+$ \\
\hline Presentations given & $\sim 40+$ \\
\hline Final reports completed and available to the public & 50 \\
\hline Quarterly newsletters (Ashlines) published & 27 \\
\hline RFP's developed and released & 5 \\
\hline Proposals received in response to RFPs & 316 \\
\hline
\end{tabular}

\section{Lessons Learned}

Throughout the ten year lifespan of the CBRC program, the national steering committee and managers worked together with the USDOE-NETL COR to determine ways to improve the operations of the program. The following serves as a compilation of lessons learned throughout the course of the program.

- It is more efficient to request pre-proposals prior to full proposals. This eliminates time and effort on both the part of the applicants and reviewers. The selection of projects through the pre-proposal route did serve to eliminate many marginal ideas from further consideration, saving considerable time.

- In the final evaluation, not everyone evaluated every proposal. Given differing interests and differing review styles, some proposals may not have been treated on an equal basis with others. While time consuming, a review system in which all reviewers comment on all proposals would serve to more fairly assess the merits of all proposals. In addition, proposal reviews should be conducted by identified experts in the field in addition to the steering committee members. This allows for a broader arena of expertise.

- It is more efficient to place pre- and full-proposals on a secure web site for reviewers' access than distributing paper copies. Likewise, it is more efficient to handle reviewers' evaluations electronically than by hard copy.

- It was necessary for the Steering Committee members to meet in person for the final selection of which proposed projects to recommend for funding.

- Many of the projects met the objective of large-volume, sustained use of coal combustion byproducts. Because many were funded for one year, many did not get to a point where the effort could be sustained or commercialized. 
- Policing the willingness of investigators to acknowledge the source of funding is difficult. The Eastern Regional Director observed an example in a review copy of a manuscript where CBRC funding should have been acknowledged. It is unknown if the oversight was corrected in the final version of the manuscript. The same research team did not acknowledge $\mathrm{CBRC}$ in a press release about their project. While it is understood that $\mathrm{CBRC}$ was not the major funding source, the program did provide funding and should have been mentioned. This is just one example, but it may have been more widespread. Unfortunately, particularly with projects with multiple sources of funding, the smaller sources may be overlooked, leading to a "take the money and run" attitude.

- The quarterly newsletter, Ashlines, had more impact in paper format than in electronic format. It would probably be a good idea to produce at least one paper copy of the newsletter each year for distribution.

- Overall, the CBRC has been an excellent research program to support the national need for environmentally-safe and economically-viable approaches for management of CCBs. The research program was broad-based and involved characterization, cement-concrete applications, products development and demonstration for potential commercialization, and large-volume management in mines and structural fills, with associated environmental issues.

- The concept of three regional centers was extremely good. It provided significant input on regional issues and permitted effective oversight to projects in each region. The organizational structure was efficient and effective with all stakeholders involved. Regional centers should, however, be considered for more control in the technical and fiscal oversight areas. That would help in improving both the technical quality of research as well as the quality of technical reports. However, it proved more expedient to eliminate the middle step (regional centers) in subcontract initiation and issue subcontracts directly from the awardee (WVU-national center) to the sub-recipients (researchers).

- With respect to the duration of the funding, the dollars available, and the consequent limit in the number of projects, a funding model without the regional centers would have allowed that overhead to be paced back into the projects. While all of the regional centers did provide guidance to the projects and eased the management load at the top level, perhaps 5-6 project years were expended on the regional management.

- By having the National Center serve as central hub for the program, there was consistency in procedures, communication, and confusion was reduced.

- The CBRC developed expertise in the area of CCBs throughout the regions by funding projects in different states. That allowed local area power plants and regulatory agencies to work with leading professionals and enhance their expertise even further. In addition, most projects led to graduation of one or more M.S. or Ph.D. level students. They continue to provide significant technology and information transfer to industry and regulatory agencies. In the opinion of the Midwestern Regional Director, that achievement alone was worth the money spent in this program. 
- Funded projects during the first five (5) years had several products, technology development, and demonstration-related aspects. During the last five years, most of the funded projects emphasized technologies and environmental issues related to largevolume management. This was appropriate based on results of products and technology development studies.

- Although cost-sharing was a requirement; most of it was in-kind support. There was little financial commitment from participating organizations. This is an area that needs further improvement even though CBRC did a very good job of requiring and documenting matching support.

- The research program was too broad for the amount of allocated funds. The program could have focused on only two areas: cement-concrete applications and large-volume management in mines and structural fills.

- Stronger industry involvement is the key to success of a highly applied CBRC research program with requirements to demonstrate near-term benefits. This needs to be strengthened even more in the future.

\section{Program Outreach and Promotion}

Promoting the CBRC program through outreach and product dissemination occurred in a number of ways throughout the lifespan of the program. Major avenues for program promotion are described below.

\section{Ashlines}

Between 2000 and 2006, a quarterly newsletter, Ashlines, was developed and released free of charge to a subscription base of approximately 600. Initially, for the first two years, paper copies were distributed. Then at the request of the DOE-NETL COR, paper copies were no longer produced. Rather, electronic copies were placed on the CBRC web page in a downloadable format and notices were sent to the subscription list via list serve. All copies of Ashlines can be found in Appendix F or on line at:

http://wvwri.nrcce.wvu.edu/programs/cbrc/publications/ashlines.html.

\section{Web site}

A web page dedicated to the CBRC program was housed on the National Center's home web site at: http://wvwri.nrcce.wvu.edu/programs/cbrc. Information on the program, upcoming events, project abstracts, project final reports, contact information on the researchers, directors, national steering committee members, and helpful links were placed on the site. The site was maintained by the National Center.

\section{Conferences, Meetings, and Workshops}


The CBRC program was actively promoted at conferences meetings, and workshops. National and Regional Center personnel often took the lead in organizing events, submitting abstracts on the program and projects, giving presentations on the program and research results, and developing papers for submission in conference proceedings. This was often done in conjunction with researchers.

For example, the Western Regional Director promoted CBRC projects to audiences at venues including the Western Region Ash Group meetings, Coal Ash Resources Research Consortium meetings, American Coal Ash Associate meetings, and the World of Coal Ash (WOCA) conference.

On October 5, 2004, a special CBRC session was held at the American Coal Ash Association meeting in Denver, Colorado. The agenda included the presentations from the following CBRC program managers and researchers:

- Welcome and Introductions by Paul Ziemkiewicz, Director, CBRC National Center

- The Role of CBRC in USDOE-NETL's Ash Portfolio by William Aljoe, COR, USDOENETL

- CBRC Program Accomplishments to Date by Tamara Vandivort, CBRC Consortium Manager

- The Use of Fly Ash as an Aggregate for Foundry Sand Mold and Core Production by Robert Purgert, Energy Industries of Ohio

- High Performance Masonry Units from 100\% Fly Ash: Synergistic Approach by HwaiChung Wu, Wayne State University

- Pilot Testing of Fly Ash-Derived Sorbents for Mercury Control in Coal-Fired Flue Gas by James Butz, ADA Technologies, Inc.

- Development of Structural Materials from Sulfate-Rich Wet Scrubber Sludge by Vivak Malhotra, Southern Illinois University

- Environmental Effects of Large-Volume FGD Fill by Phillip Glogowski, GAI Consultants, Inc.

- Beneficial Use of CCPs in Agronomic and Horticulture Applications by Warren Dick, Ohio State University

- Use of Clean Coal Technology Products in the Construction of Low Permeability Liners, William Wolfe, Ohio State University

- Development and Demonstration of High-Carbon CCPs and FGD By-products in Permeable Roadway Base Construction by Tarun Naik, University of Wisconsin

- Varra Coal Ash Burial Project by Joby Adams, Varra Companies

\section{Presentations and Papers}

Many presentations were made regarding the CBRC program and its research projects. The following is a partial listing of known presentations, papers, and publications. 
Baltrus, J.P. and R.B. LaCount. 2001. Measurement of Adsorption of Air-Entraining Admixture on Fly Ash In Concrete And Cement. Concrete and Cement Research 31(5):819-824.

Baltrus, J.P, R.B. LaCount, and D.G. Kern. 2001. Relationships Between Foam Index, AEA Adsorption And Unburned Carbon Content Of Coal-Combustion Fly Ash. ACS Division Fuel Chemistry Preprints 46(1):304-305.

Baltrus, J.P., R.B. LaCount, and D.G. Kern. 2001. The Role of Unburned Carbon in AEA Adsorption As Measured By Foam Index and UV-Vis Methods. Paper presented at the USDOE/NETL Conference on Unburned Carbon on Utility Fly Ash, May 15, Pittsburgh, PA.

Black, D.C. and P.F. Ziemkiewicz. 1998. Consortium for Research and Development in Coal Combustion By-Product Utilization. Paper presented at the Advanced Coal-Based Power and Environmental Systems 98 Conference, July 21-23, U.S. Department of Energy, Federal Energy Technology Center, Paper 2B.1.

Black, D.C. and P.F. Ziemkiewicz. 1998. Full Scale Injection of Coal Combustion By-Products into an Underground Mine to Control Acid Mine Drainage and Subsidence. Paper presented at the Advanced Coal-Based Power and Environmental Systems 98 Conference, July 21-23, U.S. Department of Energy, Federal Energy Technology Center, Paper 2B.2.

Butalia, T.S., W. E. Wolfe, and H. Walker. 2001. Long-Term Monitoring of an FGD-Lined Pond Facility. Paper presented at the 2001 International Ash Utilization Symposium, October 22-24, Lexington, KY.

Butalia, T.S. 2000. Use of Stabilized FGD Material for Liners and Encapsulations. Paper presented at the Educational Program for Managers of Coal Combustion Products, American Coal Ash Association, June 4-9, Morgantown, WV.

Butalia, T.S. and W. E. Wolfe. 2000. Performance Assessment of a Flue Gas Desulfurization Material at a Lined Pond Facility. Paper presented at the Use and Disposal of Coal Combustion By-Products at Coal Mines: A Technical Interactive Forum, April 11-12, United States Department of Interior, Office of Surface Mining, Morgantown, WV.

Butalia, T.S. and W.E. Wolfe. 1999. Evaluation of Permeability Characteristics of FGD Materials. FUEL 78:149-152.

Butalia, T.S. 1998. Use of CCPs as Liners and Feedlots. Paper presented at the Educational Program or Managers of Coal Combustion Products, American Coal Ash Association, June 8-11, Morgantown, WV. 
Butalia, T.S., S. Mafi, and W.E. Wolfe. 1998. Design and Construction of Full-Scale Demonstration Lagoon Using Coal Combustion By-Products. Solid Waste Technology and Management 25(3\&4):189-192.

Butalia, T.S., S. Mafi, W. E. Wolfe. 1997. Design of Full Scale Lagoon Using Clean Coal Technology By-Products. Paper presented at the Thirteenth International Conference on Solid Waste Technology and Management, November 16-19, Philadelphia, PA.

Butalia, T.S. and W.E. Wolfe. 1997. Re-Use of Clean Coal Technology By-Products in the Construction of Impervious Liners. Paper presented at the International Ash Utilization Symposium, October 22-22, Lexington, KY.

Canty, G. A. and J. Everett. 2004. The Use of Coal-Combustion By-Products for In Situ Treatment of Acid Mine Drainage. Paper presented at the Annual Meeting of the American Society for Surface Mining and Reclamation, Lexington, KY.

Chen, L., W. A. Dick, and S. Nelson. 2005. Flue Gas Desulfurization Products as Sulfur Sources for Alfalfa and Soybean. Agronomy 97:265-271.

Chen, L., Y.B. Lee, C. Ramsier, J. Bingham, B. Slater, and W. Dick. 2005. Increased Corp Yield and Economic Return and Improved Soil Quality Due to Land Application of FGDgypsum. Paper presented at the 2005 World of Coal Ash, April 11-15, Lexington, KY.

Chou, Melissa. 2007. Manufacturing Fired Bricks with Class F Fly Ash from Illinois Basin Coals. Paper presented at the $22^{\text {nd }}$ International Conference on Solid Waste Technology and Management, March 18-20, Philadelphia, PA.

Chou, Melissa. 2006. Manufacturing Fired Bricks with Class F Fly Ash from Illinois Basin Coals. Paper presented at the American Chemical Society Annual Meeting, September 10-14, San Francisco, CA.

Cockley, Kent. 2001. Rostraver Airport Safety Expansion Project. Paper presented at the 14th International Symposium on Management \& Use of Coal Combustion Products, January, San Antonio, TX.

Cross, J., and J. Stephens. 2005. An Alternative to Portland Cement Concrete. Paper presented at the Third International Conference on Construction Materials: Performance, Innovations and Structural Implications, August 22-24, Vancouver, BC.

Cross, J., J. Stephens, and J. Vollmer. 2005. Production of High Strength, 100\% Fly Ash Concrete Using Conventional Redimix Equipment, Paper presented at Concrete International, American Concrete Institute, Detroit, MI.

Crouch, L.K., H.J. Sauter, A.R. Copeland, C.T. Walker, J. Dotson, and D. Badoe. 2001. The Effects of Fly Ash and Portland Cement on Long Term Excavatability of Flowable Fill. 
Paper presented at the 2001 International Ash Utilization Symposium, October 22-24, Lexington, KY.

Dick, W.A., Y. Hao, R.C. Stehouwer, J.M. Bigham, W.E. Wolfe, D. Adriano, J.H. Beeghly, and R.J. Haefner. 2000. Beneficial Uses of Flue Gas Desulfurization By-Products: Examples and Case Studies of Land Application. Land Application of Agricultural, Industrial, and Municipal By-Products, Soil Science Society of America Book Series No. 6, Chapter 18, p. 505-536, Madison, WI.

Dick, W., J. Bigham, L. Forster, F. Hitzhusen, E. McCoy, R. Stehouwer, S. Traina, W. Wolfe, R. Haefner, G. Rowe, and J. Beeghly. 1998. Land Application Uses for Dry Flue Gas Desulfurization By-Products, Phase 3. Electric Power Research Institute, Report TR112916 (variously paginated), Palo Alto, CA.

Edil, T. B., C. Benson, M. Bin-Shafique, B. Tanya, W. Kim, and A. Senol. 2002. Field Evaluation of Construction Alternatives for Roadways Over Soft Subgrade. Journal of the Transportation Research Board 1786;36-48.

Fulton, Jennifer, Tamara Vandivort and Paul Ziemkiewicz. 2007. Combustion Byproducts Recycling Consortium. Paper presented at the Twenty-fourth Annual International Pittsburgh Coal Conference, September, Johannesburg, South Africa.

Gray, D.D., T.P. Reddy, D.C. Black, and P.F. Ziemkiewicz. 1998. Filling Abandoned Mines with Fluidized Bed Combustion Ash Grout. A.K. Howard and J.L. Hitch, Eds. The Design and Application of Controlled Low-Strength Materials (Flowable Fill), American Society for Testing and Materials Standard Technical Publication 1331 (ASTM STP 1331).

Hatipoglu, B., T. Edil, and C. Benson. 2008. Evaluation of Base Prepared from Road Surface Gravel Stabilized with Fly Ash. ASCE Geotechnical Special Publication 177;288-295.

Haefner, R.J. 2002. Water Quality and Geochemical Modeling of Water at an Abandoned Coal Mine Reclaimed with Coal-Combustion By-Products. U.S. Geological Survey WaterResources Investigations Report 02-4216.

Haefner, R.J. 2001. A Sulfur-Isotope Mixing Model to Trace Leachate from Pressurized Fluidized Bed Combustion Byproducts in an Abandoned-Coal-Mine Setting. FUEL 80:829-836.

Haefner, R.J. 1998. Environmental Traces for Coal Combustion Byproducts in an Abandoned Mine Setting. Paper presented at the Geological Society of America 32nd Annual Meeting North Central Section.

Haefner, R.J. 1998. Geochemistry and Ground-Water Flow Beneath an Abandoned Coal Mine Reclaimed with Pressurized Fluidized Bed Combustion By-Products. Unpublished Ph.D. Dissertation, The Ohio State University, Columbus, $\mathrm{OH}$. 
LaCount, R.B., J.P. Baltrus, T.L. Banfield, J.R. Diehl, K.A. Giles, D.G. Kern, T.A. Leyda, and P.J. Pique. 2001. Treatments for Lowering Foam Index in High-Carbon Fly Ashes for Concrete Applications. Paper presented at the $18^{\text {th }}$ Annual International Pittsburgh Coal Conference, December 3-7, Newcastle, New South Wales, Australia.

LaCount, R.B., J.P. Baltrus, T.L. Banfield, J.R. Diehl, E.A. Frommell, K.A. Giles, G.A. Irdi, D.G. Kern, T.A. Leyda, D.V. Martello, and J.P. Tamilia. 2001. Treatment of High Carbon Fly Ash to Produce a Low Foam Index Product with Carbon Content Retained. Paper presented at the $14^{\text {th }}$ International Symposium on Management and Use of Coal Combustion Products (CCP's), January 22-5,San Antonio, Texas, Volume I, EPRI, Palo Alto, California, 2001.1001158:15-1 to 15-13.

Li, L., C. H. Benson, T.B. Edil, B. Hatipoglu, and E. Tastan. 2007. Evaluation of Recycled Asphalt Pavement Material Stabilized with Fly Ash. ASCE Geotechnical Special Publication (CD-ROM). 169 p.

Malhotra, V.M. and A. A. Rameanianpour. 1994. Fly Ash in Concrete. MSL 94-45 (IR), CANMET, Canada Center for Minteral and Energy Technology, Natural Resources Canada, Ottawa, Ontario, Canada.

Misra, A., S. Upadhyaya, C. Horn, S. Kondagari, and F. Gustin. 2006. CBR and DCP Correlation for Class C Fly Ash-Stabilized Soil. Geotechnical Testing Journal 29(1): 3036.

Misra, A., S. Upadhyaya, F. Gustin, A. Roohanirad, and J.D. Stokes. 2005. Full-depth Cold Inplace Recycling of Asphalt Pavements Using Self-cementing Fly Ash. Paper presented at the World of Coal Ash, April 2005, Lexington, KY.

Misra, A., A. Roohanirad, A. Somboonyanon. 2003. Guidelines for Roadway Management System (RMS) for Local Government. Report to Midwest Transportation Consortium, Iowa State University.

Obla, K. H., R. L. Hill, M.D. Thomas, S. G. Shashiprakash, and O. Perebatova. 2003. Properties of Concrete Containing Ultra Fine Fly Asah. ACI Materials Journal; 100(5):426-433.

Senol, A., T. B. Edil, M. Bin-Shafique, H.A. Acosta, and C. H. Benson. 2006. Soft subgrades' stabilization by using various fly ashes. Resources Conservation and Recycling 46(4): 365-376.

Senol, A., M.Bin-Shafique, T. B. Edil, and C. Benson. 2003. Use of Class C Fly Ash for Stabilization of Soft Subgrade. ARI Bulletin of the Istanbul Technical University; 53(1):98-104. 
Stehouwer, R., W. Dick, J. Bigham, L. Forster, F. Hitzhusen, E. McCoy, S. Traina, W. Wolfe, R. Haefner, and G. Rowe. 1998. Land Application Uses for Dry Flue Gas Desulfurization By-Products, Phase 2. Electric Power Research Institute, Report TR-109652 (variously paginated), Palo Alto, CA.

Vandivort, T. F. and P. F. Ziemkiewicz. 2007. Potential Uses for Coal Combustion Byproducts for Sustainable Construction Materials. Paper presented at the Sustainable Construction Materials and Technologies Conference, June 11-13, 2007, Coventry, UK.

Vandivort, Tamara F. and Paul F. Ziemkiewicz. 2006. Environmental Concerns Related to the Use of Coal Combustion Byproducts in Mine Placement. Paper presented at the Twenty-third Annual International Pittsburgh Coal Conference, September 25-27, 2006, Pittsburgh, PA.

Vandivort, Tamara F. 2006. Combustion Byproducts Recycling Consortium. Presentation made at the American Coal Ash Association meeting, Denver, CO.

Vandivort, Tamara F. 2006. Combustion Byproducts Recycling Consortium. Presentation made to the U.S. Department of Energy-National Energy Technology Laboratory Training for Foreign Service Officers, July, Shippingport, PA.

Vandivort, Tamara F. 2005. Combustion Byproducts Recycling Consortium. Presentation made to the U.S. Department of Energy-National Energy Technology Laboratory Training for Foreign Service Officers, July, Shippingport, PA.

Vandivort, Tamara F. 2005. The United States' Combustion Byproducts Recycling Consortium. Paper presented at Pittsburgh Coal Conference, September, Pittsburgh, PA.

Vandivort, Tamara F. 2004. Combustion Byproducts Recycling Consortium. Presentation made to the Indiana Society for Mining and Reclamation, December 6, Jasper, IN.

Vandivort, Tamara F. 2003. Combustion Byproducts Recycling Consortium. Presentation made to the U.S. Department of Energy-National Energy Technology Laboratory Training for Foreign Service Officers, July 23, Shippingport, PA.

Vandivort, Tamara F. 2001. Combustion Byproducts Recycling Consortium. Presentation made at the WRAG (Western Region Ash Group) meeting, Denver, CO.

Vandivort, Tamara F. 2001. The United States' Combustion Byproducts Consortium Program. Paper presented at the Eighteenth Annual International Pittsburgh Coal Conference, December 3-7, Newcastle, Australia.

Wen, H., J. Warner, and T. Edil. 2008. Laboratory Comparison of Crushed Aggregate and Recycled Pavement Material with and Without High-Carbon Fly Ash. Paper presented at the $87^{\text {th }}$ Annual Meeting, Transportation Research Board, Washington, DC. 
Wen, H., J. Baugh, and T. Edil. 2007. Use of Cementitious High Carbon Fly Ash to Stabilize Recycled Pavement Materials as Pavement Base Material. Paper presented at the $86^{\text {th }}$ Annual Meeting, Transportation Research Board, Washington, DC.

Wolfe, W.E., T.S. Butalia, and C. Fortner. 2001. Permeability Monitoring at an FGD-Lined Pond Facility. Paper presented at the $14^{\text {th }}$ International Symposium on Management and Use of Coal Combustion Products, January 22-26, Electric Power Research Institute, Report \#1001158, Palo Alto, CA.

Wolfe, W.E., T.S. Butalia, E. Whitlatch, and W. Mitsch. 2000. Re-Use of Clean Coal Technology By-Products in the Construction of Low Permeability Liners. Technical Report, The Ohio State University, Columbus, $\mathrm{OH}$.

Wolfe, W.E., T.S. Butalia, and C. Fortner. 1999. Preliminary Performance Assessment of an FGD-Lined Lagoon Facility. Paper presented at the Thirteenth International Symposium on Use and Management of Coal Combustion Products (CCPs), January 11-15, Orlando, FL.

Wolfe, W.E. and T.S. Butalia. 1998. Use of FGD as an Impervious Liner. Paper presented at the Twenty-third International Conference on Coal Utilization and Fuel Systems, March 9-13, Clearwater, FL.

Wu, H.C. 2002. Sodification of Fly Ash by Hydrothermal Process. Paper presented at Geopolymer, Melbourne, Australia.

Ziemkiewicz, Paul F. 2007. Environmental Concerns Related to the Use of Coal Combustion Byproducts in Mine Placement. Paper presented at the 2007 World of Coal Ash Conference, Lexington, KY.

Ziemkiewicz, Paul F. 2007. Environmental Concerns Related to the Use of Coal Combustion Byproducts in Mine Placement. Paper presented at the 2007 Pittsburgh Coal Conference, September, Pittsburgh, PA.

Ziemkiewicz, Paul F. and Tamara F. Vandivort. 2005. The United States' Combustion Byproducts Recycling Consortium-Program Update. Paper presented at the Twentysecond Annual International Pittsburgh Coal Conference, September 12-15, 2005, Pittsburgh, PA.

Ziemkiewicz, Paul F. 2004. Combustion Byproducts Recycling Consortium. Presentation made at Pennsylvania State University, June, State College, PA.

Ziemkiewicz, Paul F. and Tamara F. Vandivort. 2004. The United States' Combustion Byproducts Consortium. Paper presented at the Twenty-first Annual International Pittsburgh Coal Conference, September 13-15, 2004. Osaka, Japan.

Ziemkiewicz, Paul F. and Tamara F. Vandivort. 2001. The United States’ Combustion 
Byproducts Consortium Program, Paper presented at the Eighteenth Annual International Pittsburgh Coal Conference, December 3-7, 2001, Newcastle, Australia.

Ziemkiewicz, P.F. and D.C. Black. 2000. Disposal and Use of Coal Combustion Products in Mined Environments. Paper presented at ICARD 2000, May 21-24, Denver, CO.

\section{Fact sheets}

Project fact sheets were developed on the 2002 projects. They were placed on the CBRC web page and disseminated at conferences and workshops.

A fact sheet was also developed on the CBRC program and was disseminated as part of a program promotional package.

\section{Program Promotional Package}

A promotional package was developed in 2007 that included a cover explanatory letter from the Director, Paul Ziemkiewicz, a fact sheet on the CBRC program, and a draft letter to Congress. This promotional package was distributed at ACAA meetings, to the CBRC list serve, and to the Steering Committee for additional distribution. The purpose was to alert the readers that cuts to USDOE-NETL's power plants program had resulted in funding cuts to the CBRC program; that no additional monies were expected to flow from USDOE-NETL to CBRC; and to write to their Congressional representative asking that monies be put back into the USDOE-NETL budget for the CBRC program.

\section{Conclusions}

Overall, through all of the variation on projects over the years, the Eastern Region projects met the goal of expanded utilization of CCBs. The largest scale applications are, in general, the nonspecialty applications. As an example, a single airport runway expansion in steep terrain in western Pennsylvania has the potential to use more CCBs than several years of foundry applications. Continued use of fly ash in the construction industry, expanded use of CCBs in mining and post-mining applications, and the expanded use of CCBs, FGD products in particular, in agricultural applications are necessary if $50 \%$ or greater utilization of CCBs can be reached and sustained.

The CBRC program funded projects in the Midwestern Region Center which can be divided into two major areas: 1) Technology and Product Development, and 2) Environmental and Regulatory Issues. About $65 \%$ of the Midwestern projects were related to product and technology development and demonstration.

The CBRC program in the Midwestern Region progressed well to meet most of the identified goals. All the problems have not been solved but significant progress was made. The long-term environmental data from Universal Mine in Indiana was a major achievement and it will help in future permitting of management in surface mines. Technology to make commercially viable bricks that incorporate $20 \%$ to $40 \%$ F-fly ash is noteworthy. Utilization of CCBs in technologies 
such as road sub-base and base and in situ stabilization of recycled materials are major achievements. The CBRC program has also enhanced available expertise in this topical area in most of the states within the region and that is paying big dividends.

\section{Future Implications}

The impacts of $\mathrm{CBRC}$ projects and activities are expected to have impacts on $\mathrm{CCB}$ utilization and regulation into the future.

The evolving nature of CCBs, both in response to air quality standards and to changes in the nature of the feed coal and the fuels blended with coal, implies that there is a continuing need for research in CCBs. We should never assume that the product quality and mix of one year will resemble the quality and mix of the future. If CCBs are to be efficiently recycled in an environmentally friendly manner, the research needs to keep pace with the evolution of the material.

The current coal transportation and utilization trends in the Midwest point in the direction that the Midwestern Region power plants will utilize more western coal and the Illinois Basin coals will be shipped to power plants in the east. So, Midwestern region utilities will have lot of C-fly ash while the eastern utilities will have lot of F-fly ash and FGD byproducts. Most of the bottom ash will have beneficial use applications. Based on expected trends, the following research needs are identified.

- Large-volume $\mathrm{C}$-ash based cement-concrete applications.

- Effect of mercury controls on quality of $\mathrm{C}$-ash produced and its implications on cementconcrete applications.

- Effect of higher loss-on-ignition on environmental properties of CCBs.

- Environmental performance of sulfite-rich and sulfate-rich FGD byproducts in largevolume structural fills in mining and non-mining settings.

- Long-term environmental performance of large-volume CCBs management in mining areas as well as in landfill settings.

- Controlled studies on adsorption of trace elements on host soils and rocks by several investigators.

- Geochemical modeling of large-volume CCBs management in different geologic environments.

- Effects of CCBs and FGD byproducts management for agricultural applications with emphasis on the long-term fate of mercury.

- Underground management of waste coal slurry with CCBs and FGD byproducts.

- Use of cementitious CCBs in landfill liner applications.

- Management of CCBs as part of the municipal waste in landfills.

- Development of CCBs-based cover materials for landfill applications.

The CBRC has been a role-model research program of the U.S. Department of Energy with strong cooperation among all stakeholders (industry, regulatory agencies, universities, 
government research organizations). It has served a very useful role to bring together professionals nationally and internationally to work on critical issues related to this subject. There is significant future need for this program to work on problems facing different regions.

The CBRC has recognized the changing nature of $\mathrm{CCBs}$ and has adapted accordingly. As air quality regulations have become more stringent, more scrubber sludge, high-carbon ash, and sorbents are produced. Markets for these new byproducts need to be found to ensure an increasingly high recycle rate for CCBs.

The passage in 2005 of the Clean Air Interstate Rule and the Clean Air Mercury Rule has resulted in new emission control devices being added to power plants to comply with these rules. This impacts the quality and quantity of CCBs produced. Adding new scrubbers to comply with regulations may increase FGD gypsum amounts by two to three times current production. Resultant CCB quality may also result in less usage by the concrete industry.

More research is needed to reach the goals set out by the CBRC. Research needed includes:

- Increase the overall CCB utilization rate from the current $43 \%$ to $50 \%$ or more

- Increase the current rate of flue gas desulfurization used

- Increase the number of uses considered allowable under state regulations, and

- Examine the environmental impact of byproduct use and disposal.

Additional research is also needed to determine:

- If CCBs affected by the new air emission scrubbers can be restored to a quality that would allow it to be used in concrete;

- If additional beneficial uses can be identified for CCBs that cannot meet the quality necessary for use in concrete production, and

- If CCBs produced from the new air emission scrubbers will be safe for use in building material products.

\section{References}

Adams, Joby L. and James W. Warner. 2002. Field Scale Study Results for the Beneficial Use of Coal Ash as Fill Material in Saturated Conditions_-Varra Coal Ash Burial Project, Weld County, Colorado. Final Report for Combustion Byproducts Recycling Consortium Project Nos. 99-EC-W01 and 00-CBRC-W02. 38 p.

American Coal Ash Association (ACAA). 2007. 2007 Coal Combustion Product (CCP) Production and Use Survey. American Coal Ash Association. Aurora, Colorado. 3 p.

Bin-Shafique, Md Sazaad, Craig H. Benson, and Tuncer B. Edil. 2003. Leaching of Heavy Metals from Fly Ash Stabilized Soils Used in Highway Pavements. Final Report for Combustion Byproducts Recycling Consortium Project No. 99-EC-M05. 221 p. 
Brendel, G.F., J. E. Bonetti, R. F. Rathbone, and R.N. Frey, Jr. 2000. Investigation of Ammonia Adsorption on Fly Ash Due to Installation of Selective Catalytic Reduction Systems. Final Report for Combustion Byproducts Recycling Consortium roject No. 99-EC-E06. $105 \mathrm{p}$.

Broschart, David. 2001. Omega Mine Injection Program. Final Report for Combustion Byproducts Recycling Consortium Project No. 99-EC-E17. 169 p.

Buckley, Tera Berland. 2003. Development of a Database of Coal Ash Publications. Final Report for Combustion Byproducts Recycling Consortium Project No. 01-CBRC-W01. $11 \mathrm{p}$.

Buggeln, Richard. 2007. Community-based social marketing: the tool to get target audiences to use coal combustion by-products. Final Report for Combustion Byproducts Recycling Consortium Project No. 05-CBRC-E19. 4 p.

Butalia, Tarunjit S., William E. Wolfe, Harold Walker, Wei Tu, Behrad Zand, Sung Hwan Kim, and Jason Cheng. Full Scale of Coal Combustion Product (CCP) Pavement Sections Subjected to Repeated Wheel Loads. Final Report for Combustion Byproducts Recycling Consortium Project No. 01-CBRC-E10. 398 p.

Butz, James and Thomas Broderick. 2002. Pilot Testing of Fly Ash-Derived Sorbents for Mercury Control in Coal Fired Flue Gas. Final Report for Combustion Byproducts Recycling Consortium Project No. 00-CBRC-W04. 30 p.

Canty, Geoff A. and Jess W. Everett. 2004. The Use of CCBs for In Situ Treatment of Acid Mine Drainage. Final Report for Combustion Byproducts Recycling Consortium Project No. 99-EC-W04. 33 p.

Carlson, James, Mohan V.S. Bonala, and Lakshmi N. Reddi. 2001. Evaluation of the Geotechnical, Hydraulic and Leaching Characteristics Fly Ash Admixtures for Final Cover and Composite Liner Applications. Final Report for Combustion Byproducts Recycling Consortium Project No. 00-CBRC-W10. 72 p.

Carmargo, Felipe F., Tuner B. Edil, Craig H. Benson, and Wilfung Martono. 2008. In Situ Stabilization of Gravel Roads with Fly Ash. Final Report for Combustion Byproducts Recycling Consortium Project No. 05-CBRC-M16. 150 p.

Chen, Liming and Warren Dick. 2002. Flue Gas Desulfurization By-Products Provide Sulfur and Trace Mineral Nutrition for Alfalfa and Soybean. Final Report for Combustion Byproducts Recycling Consortium Project No. 99-EC-E08. 33 p.

Chou, Mei-In Melissa, Sheng-Fu Joseph Chou, Vinod Patel, Michael D. Pickering, and Joseph W. Stucki. 2006. Manufacturing Fired Bricks with Class F Fly Ash from Illinois Basin Coals. Final Report for Combustion Byproducts Recycling Consortium Project No. 02CBRC-M12. $36 \mathrm{p}$.

Chou, Mei-In Melissa, Sheng-Fu Joseph Chou, Lu-Ming Chen, and Joseph W. Stucki. 2008. Manufacturing Building Products with Fly Ash and Advanced Coal Combustion 
Byproducts. Final Report for Combustion Byproducts Recycling Consortium Project No. 05-CBRC-M23. $39 \mathrm{p}$.

Chugh, Yoginder P. and Jinrong Ma. 2006. Development and Demonstration of Coal Combustion Byproducts-Filled Composite Materials for Utility Pole Fabrication. Final Report for Combustion Byproducts Recycling Consortium Project No. 99-EC-M07. 157 p.

Crouch, L. K. and Vernon J. Dotson. 2002. Long Term Excavatability of Flowable Fill Containing Coal Combustion Byproducts. Final Report for Combustion Byproducts Recycling Consortium Project No. 00-CBRC-M05. 12 p.

Das, K. C. and J. R. Kastner. 2002. Odor and HAP Control in Waste Treatment Processes Using Coal Combustion Ash. Final Report for Combustion Byproducts Recycling Consortium Project No. 99-EC-E13. 25 p.

Dick, Warren and David Kost. 2008. National Network of Research and Demonstration Sites for Agricultural and Other Land Application Uses of FGD Product. Final Report for Combustion Byproducts Recycling Consortium Project No. 05-CBRC-E08. 22 p.

Dockter, Bruce and Diana M. Jagiella. 2005. Engineering and Environmental Specifications of State Agencies for Utilization and Disposal of Coal Combustion Products: Volume 1 DOT Specifications. Final Report Volume 1 for Combustion Byproducts Recycling Consortium Project No. 02-CBRC-W12. 65 p.

Dockter, Bruce. 2005. Engineering and Environmental Specifications of State Agencies for Utilization and Disposal of Coal Combustion Products: Volume 2 - Environmental Regulations. Final Report Volume 2 for Combustion Byproducts Recycling Consortium Project No. 02-CBRC-W12. 65 p.

Glogowski, Phillip E., Kent C. Cockley, Anthony M. Digioia, Jr., and Robert J. Cimarolli. 2004. Rostraver Airport Runway Safety Area. Final Report for Combustion Byproducts Recycling Consortium Project No. 00-CBRC-E41. 106 p.

Haefner, Ralph J. 2002. Water Quality at an Abandoned Coal Mine Reclaimed with PFBC Byproducts. Final Report for Combustion Byproducts Recycling Consortium Project No. 99-EC-E15. $37 \mathrm{p}$.

Hassett, David and Loreal Heebink. 2007. Quantifying CCBs for Agricultural Land Application. Final Report for Combustion Byproducts Recycling Consortium Project No. 01-CBRCM23. $70 \mathrm{p}$.

Hunt, John. 2001. Fiber-fly-ash-based Wall-panel Development. Final Report for Combustion Byproducts Recycling Consortium Project No. 00-CBRC-W02. 8 p.

LaCount, Robert B. and Douglas G. Kern. 2005. Economical Treatment of High Carbon Fly Ash to Produce a Low Foam Index Product with Carbon Content Retained. Final Report for Combustion Byproducts Recycling Consortium Project No. 99-EC-E04. 28 p. 
Levy, Edward K. 2001. Ammonia Removal from Fly Ash in a Bubbling Fluidized Bed. Final Report for Combustion Byproducts Recycling Consortium Project No. 99-EC-E16. 16 p.

Li, Yuncong, Min Zhang, Peter Stofella, Zhenti He, and Herbert Bryan. 2002. Utilization of Fly Ash and Urban Yard Waste as Soil Amendments to Improve Soil Fertility. Final Report for Combustion Byproducts Recycling Consortium Project No. 99-EC-E11. 106 p.

Malhotra, Vivak and Y. P. Chugh. 2004. Industry-Government-University Cooperative Research Program for the Development of Structural Materials from Sulfate-Rich FGD Scrubber Sludge. Final Report for Combustion Byproducts Recycling Consortium Project No. 99-EC-M01. 65 p.

Maroto-Valer, M. Mercedes, John M. Andresen, Yinzhi Zhang, and Zhe Lu. 2004. Development of Fly Ash Derived Sorbents to Capture $\mathrm{CO}_{2}$ From Flue Gas of Power Plants. Final Report for Combustion Byproducts Recycling Consortium Project No. 01-CBRC-E09. 62 p.

McDonald, Louis M. and Jennifer Simmons. 2004. Effects of Large-scale CCB Applications on Groundwater-Case Studies. Final Report for Combustion Byproducts Recycling Consortium Project No. 00-CBRC-E37. 30 p.

Meischen, Sandra. 2004. The Effect of Mercury Controls on Wallboard Manufacture. Final Report for Combustion Byproducts Recycling Consortium Project No. 01-CBRC-M12. $20 \mathrm{p}$.

Misra, Anil. 2005. Crushed Aggregates from Class C Fly Ash. Final Report for Combustion Byproducts Recycling Consortium Project No. 00-CBRC-M04. 41 p.

Misra, Anil. 2008. Cold In-place Recycling of Asphalt Pavements Using Self-cementing Fly Ash: Analysis of Pavement Performance and Structure Number. Final Report for Combustion Byproducts Recycling Consortium Project No. 05-CBRC-M09. 16 p.

Murarka, Ishwar and Jim Erickson. 2006. Use of Coal Combustion Products in Mine-Filling Applications-A Review of Available Literature and Case Studies. Final Report for Combustion Byproducts Recycling Consortium Project No. 99-EC-W05. 115 p.

Murarka, Ishwar. 2008. Laboratory Studies and Field Scale Monitoring for Groundwater Quality of the Universal Mine Site Reclaimed by Filling with Coal Fly Ash from an Electric Power Plant. Final Report for Combustion Byproducts Recycling Consortium Project No. 00-CBRC-M09. 159 p.

O’Neill, Mick, Kevin Lombard, Blake Onkin, April Ulery, and Manoj Shukla. 2006. Power Plant Combustion Byproducts for Improved Crop Productivity of Agricultural Soils. Final Report for Combustion Byproducts Recycling Consortium Project No. 02-CBRCW09. $95 \mathrm{p}$. 
Paul, Bradley and Shuai Chen. 2002. Arsenic and Selenium Transport from Coal Combustion Products Utilization and Disposal Sites. Final Report for Combustion Byproducts Recycling Consortium Project No. 01-CBRC-M21. 18 p.

Paul, Bradley C. 2002. Boron Transport from Coal Combustion Product Utilization and Disposal Sites. Final Report for Combustion Byproducts Recycling Consortium Project No. 99-EC-M04. 11 p.

Petzrick, Paul, Heather Wattenbach, Brent Williams, Ray Hemmings, Ed Lyons. 2002. Siege of Acre. Final Report for Combustion Byproducts Recycling Consortium Project No. 00CBRC-E15. 119 p.

Pier, Paul A. 2008. Field Testing of Arsenic and Mercury Bioavailability Model from LandApplied Coal Combustion Byproducts. Final Report for Combustion Byproducts Recycling Consortium Project No. 05-CBRC-E18. 29 p.

Rusch, Kelly A., Roger K. Seals, and Tingzong Guo. 2002. Development of CCB Fill Materials for Use as Mechanically Stabilized Marine Structures. Final Report for Combustion Byproducts Recycling Consortium Project No. 00-CBRC-M11. 24 p.

Sobczak, Jerzy, Robert Purgert, Andrzej Balinski, and Pawel Darlak. 2005. Commercialization Demonstration for Production Foundry Molds Made from CCBs for High Volume Automotive Applications. Final Report for Combustion Byproducts Recycling Consortium Project No. 02-CBRC-E10. 44 p.

Wolfe, William E., Tarunjit S. Butalia, Harold Walker, and William Mitsch. 2005. Re-Use of Clean Coal Technology By-Products in the Construction of Low Permeability Liners. Final Report for Combustion Byproducts Recycling Consortium Project No. 99-EC-E24. $174 \mathrm{p}$.

Wu, Hwai-Chung and Peijaing Sun. 2003. High Performance Masonry Units from 100\% Fly Ash-Synergistic Approach. Final Report for Combustion Byproducts Recycling Consortium Project No. 00-CBRC-M14. 79 p.

Ziemkiewicz, Paul F., Richard Herd, and Raymond Lovitt. 2006. Observations on the Mine Water Leaching Procedure and the Effects of Placing CCBs in Contact with Mine Spoil. Final Report for Combustion Byproducts Recycling Consortium Project No. 02-CBRCE06. $61 \mathrm{p}$. 


\section{Appendices}

- Appendix A: Request for Pre-proposals 2005

- Appendix B: Invitation to submit full proposals 2005

- Appendix C: Roles \& Responsibilities

- Appendix D: Notice From USDOE-NETL Regarding Reduction in DOE's IEP Program Budget

- Appendix E. Project Final Reports

- Appendix F. Ashlines 